\title{
Using Lentivirus and CRISPR to Modify Cattle Embryonic Genes
}

Jevon Stuart Upton

A thesis submitted to Victoria University of Wellington in fulfilment of the requirements for the degree of Master of Cell and Molecular Bioscience

January 2019

Supervisor: Dr Peter Pfeffer

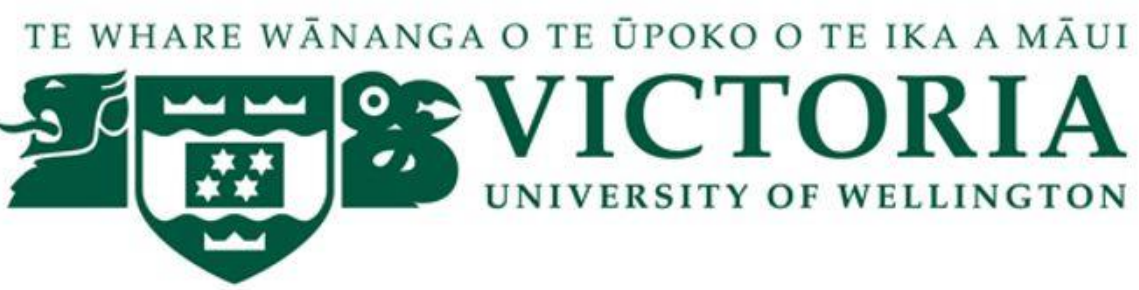




\section{Abstract}

Developing transgenic livestock has become popular in recent years after advances in the field of genetic editing. Cattle are one of the main exports in New Zealand and are a prime target for new genetic editing tools. Applications of genetic editing in cattle can extend to increases in production, and elimination of disease genes. Due to its ease of use, CRISPR/Cas9 has become one of the most popular methods of editing genes, hence this was employed in the research. Cattle embryos in culture are very sensitive to environmental changes and for this reason, a delivery vector is necessary to deliver the genetic material as traditional transfection methods cause high rates of embryo death. The zona pellucida, a glycoprotein coat surrounding the embryo, acts as a protective agent against viral vectors, and needed to be considered in the research.

This research aimed to create a novel, high titer lentivirus particle capable of transducing bovine embryos, and causing subsequent genetic modification by integration of CRISPR/Cas9 into the genome. Using fluorescent reporters, viral transduction was monitored. The research found that after optimizing transfection protocols, high-titer lentiviral particles can be produced and can infect bovine embryos. Zona pellucida removal experiments revealed over-digestion in early stage embryos, however, this was not observed in compact morulas. Removing the zona allowed for successful transduction of bovine embryos, resulting in transgenic cells expressing eGFP. While CRISPR/Cas9 experiments were in preliminary stages, these indicated eGFP knock-out in certain eGFP-HEK293T cells. Though challenges were encountered throughout the research process, solutions were explored, and it was shown that transgenic bovine embryos using lentiviral gene delivery can be produced. This indicates the high likelihood that CRISPR/Cas9 systems can be delivered this way, inducing targeted genetic modification. 


\section{Acknowledgements}

I would like to thank Peter Pfeffer, my supervisor throughout this research. Without Peters guidance and expertise none of this would have been possible. Peter allowed me to embark on a journey I will never forget, and for that I am eternally grateful.

Another person that I would like to thank is Kate Isaac. Without Kate, much of the bovine embryo culture would not have been possible. Kate also was a rock for me throughout my research, she was someone I could talk with about anything and everything, and we shared many great conversations. Thank you, Kate, you were essential to the success I achieved throughout my research.

I would also like to thank my wife Nicole. Nicole bore with me when times got tough and lab work was failing and celebrated with me when I had successes. Thank you, Nicole, I love you more than you could know.

Lastly, I would like to thank my parents. My parents have been there for me every step of the way throughout my life, I owe them everything. From financial to emotional, the support they have given me has made all of this possible. I love you guys so much, thank you for everything you have done for me. 


\section{List of figures}

Figure 1. Systematic diagram of bovine embryo development (Bazer, Spencer, Johnson,

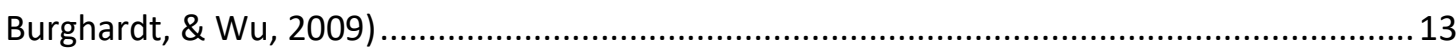

Figure 2. Cas9 mechanism of action. (The Cell Cuture Dish, 2016) ........................................19

Figure 3. a) DNA repair mechanisms that result from Cas9 cleavage-induced DSB. NHEJ leads to knock-out mutation, while HDR results in either gene replacement or knock-in mutation.

b) Cas9 mechanism that leads to DSB (Shan, Wang, Li, \& Gao, 2014)...................................21

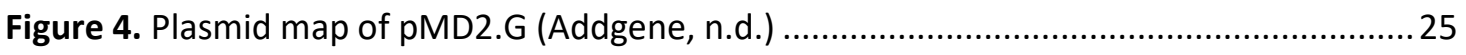

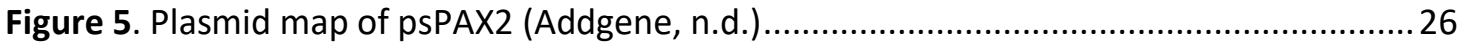

Figure 6. Plasmid map of pll3.7 (Rubinson, et al., 2003) .....................................................27

Figure 7. Plasmid map of pLENTI-CRISPR-mCHERRY (McComb, et al., 2016) ...........................28

Figure 8. Plasmid map of EGFP gRNA (Doench, et al., 2016) ...............................................29

Figure 9. Diagram depicting culture droplet layout of IVM plate .............................................41

Figure 10. Calcium phosphate transfection of HEK293T/17 cells with varying DNA concentrations added

Figure 11. Increased calcium phosphate crystal size/abundance after increasing $\mathrm{CaCl} 2$

concentration during transfection.

Figure 12. 24- and 48-hour post transfection comparisons of cells transfected with $20 \mathrm{ug}$ pll3.7 at varying concentrations of $\mathrm{CaCl} 2$

Figure 13. HEK293T/17 cells 24 hours post-transduction using pll3.7 lentivirus derived from producer cells transfected with varying $\mathrm{CaCl} 2$ concentrations

Figure 14. Time series monitoring brightfield and eGFP expression post-transduction of HEK293T/17 transduced with lentivirus containing pll3.7 over 10 days. 50

Figure 15. Bovine Fibroblast cells showing expression of eGFP following transduction with lentivirus containing pll3.7.

Figure 16. Cumulus-Oocyte complex cells showing positive eGFP expression following transduction with lentiviral particles containing pll3.7. 52

Figure 17. Bovine Cumulus-oocyte complexes transduced with higher concentration lentivirus $\left(\sim 10^{9} \mathrm{TU} / \mathrm{mL}\right)$ containing pll3.7 at time of fertilisation with bull sperm. .53

Figure 18. Bovine Cumulus-oocyte complexes transduced with lower concentration lentivirus $\left(\sim 10^{7} \mathrm{TU} / \mathrm{mL}\right.$ ) containing pll3.7 at time of fertilisation with bull sperm. .53

Figure 19. Pooled treatment of $0.2 \%$ protease on bovine embryos. .55 
Figure 20. 4-day monitoring of bovine embryos treated with $0.2 \% \mathrm{w} / \mathrm{v}$ protease for lengths of 1 minutes, 3 minutes and 5 minutes. 56

Figure 21. Groups of bovine compact morulas treated with varying exposure times to $0.2 \%$ protease.

Figure 22. Bovine blasts expressing eGFP following $0.2 \%$ protease digestion of zona and lentiviral transduction during morula stage.

Figure 23. eGFP and mCHERRY analysis of HEK293T cells over 4 days post transfection with PLENTI-CRISPR-mCHERRY and EGFP-sgRNA.

Figure 24. Close-up eGFP and mCHERRY analysis of HEK293T after transfection with pLENTICRISPR-mCHERRY and eGFP-sgRNA

Figure 25 HEK293T cells transfected with 20 ug pLENTI-CRISPR-mCHERRY, 16 ug psPAX2 and 6 ug PMD2.G using optimised calcium phosphate transfection method.

Figure 26. HEK293T/17 cells transduced with lentiviral particles containing pLENTI-CRISPRMCHERRY

Figure 27. diagram depicting the cleavage of DNA by BsmBI digestion (Berkley University of California, n.d.).

Figure 28. Agarose gel electrophoresis showing ligation of filler sequence back into pLENTICRISPR-mCHERRY.

Figure 29. A) Agarose gel of plasmid DNA isolated from ligation colonies 67 


\section{Contents}

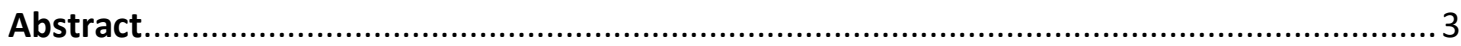

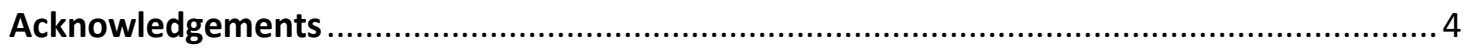

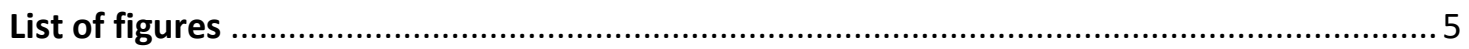

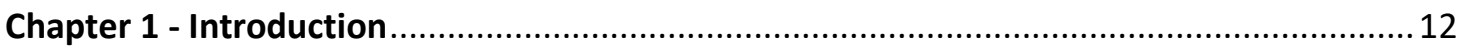

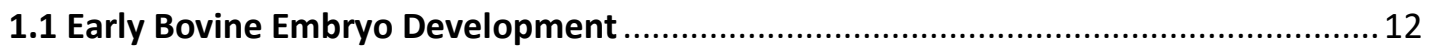

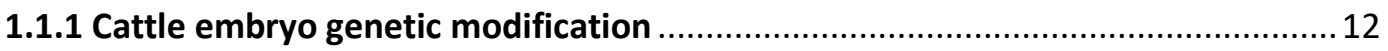

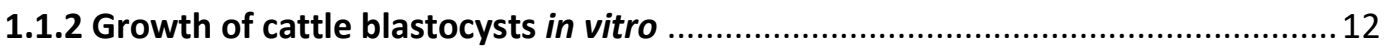

1.1.3 CRISPR-Cas9 Nuclease-mediated Genome modification in livestock...................13

1.1.4 Embryo modification using CRISPR-Cas9...................................................... 14

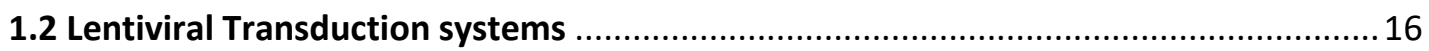

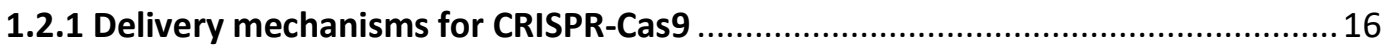

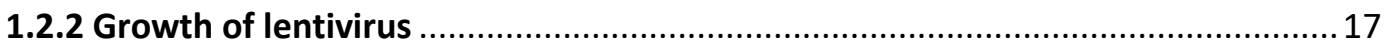

1.3 Biological function of CRISPR-Cas9 and use as a genetic editing tool .......................17

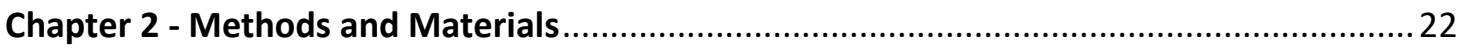

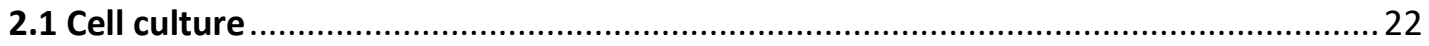

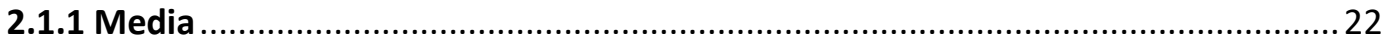

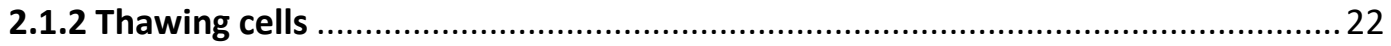

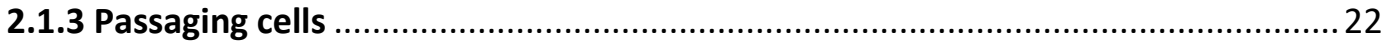

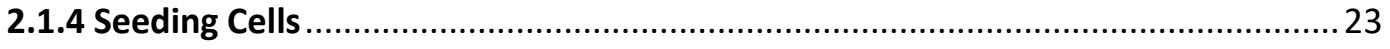

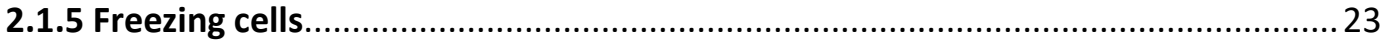

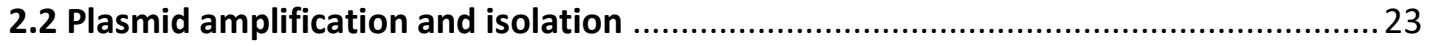

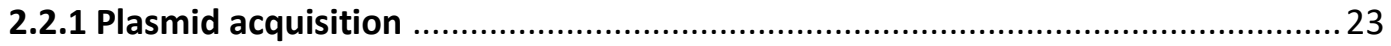

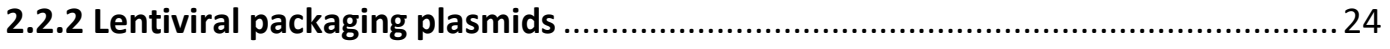

2.2.2.1 pMD2.G

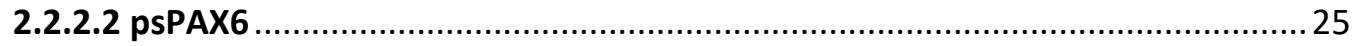




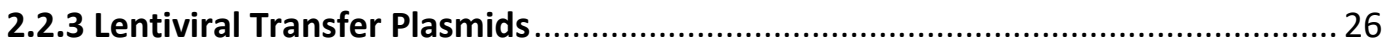

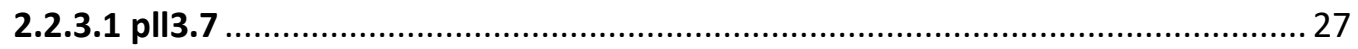

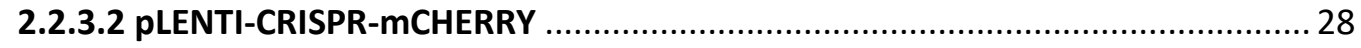

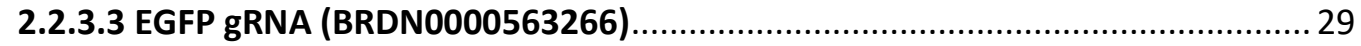

2.2.4 Bacterial Transformation by Heat Shock ......................................................... 30

2.2.5 Bacterial Transformation by Electroporation .................................................... 30

2.2.5.1 Preparing electrocompetent E. coli ............................................................. 30

2.2.5.2 Transforming electrocompetent E. coli .................................................. 31

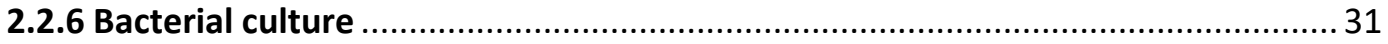

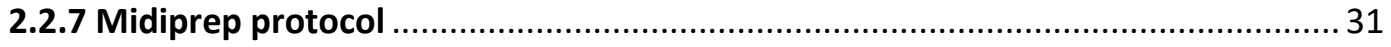

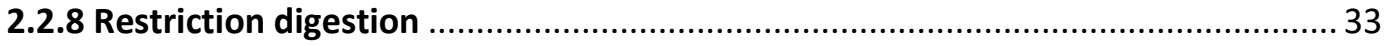

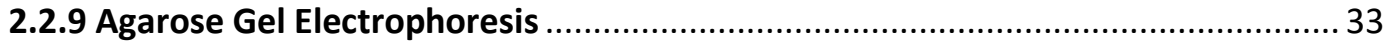

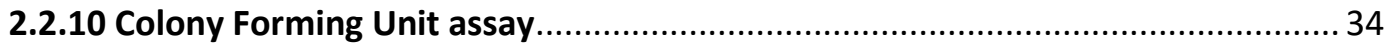

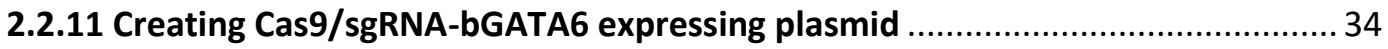

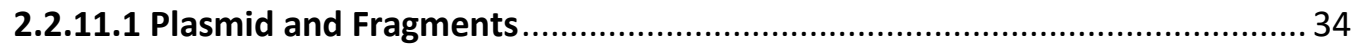

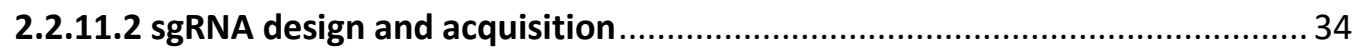

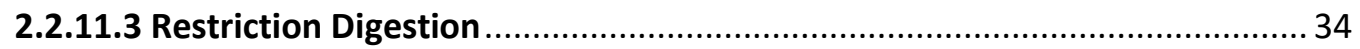

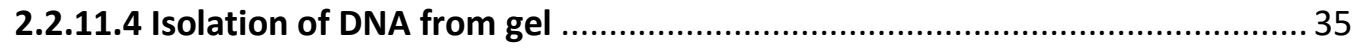

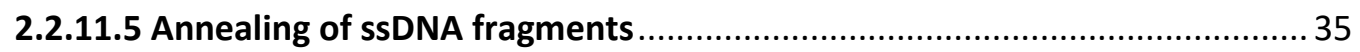

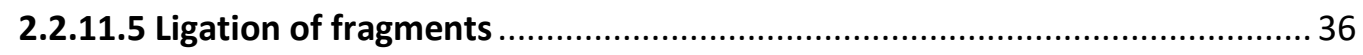

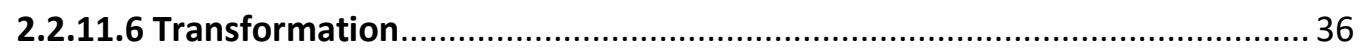

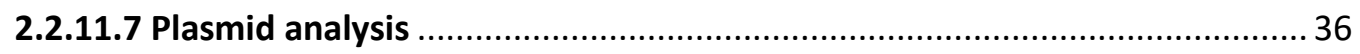

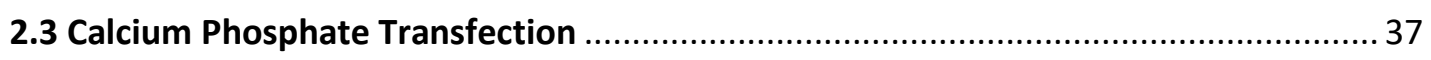

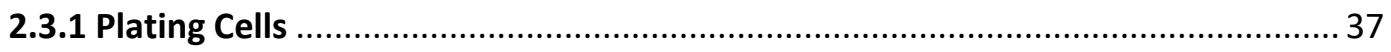

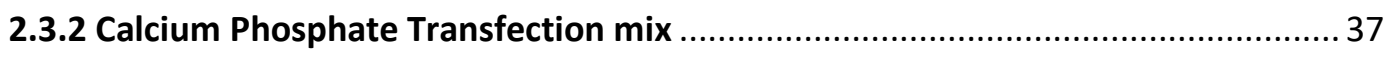

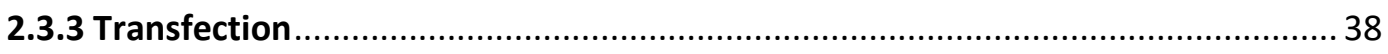




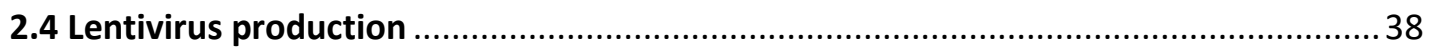

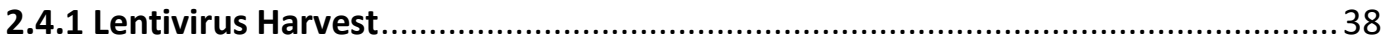

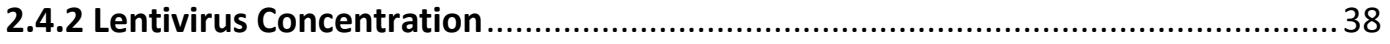

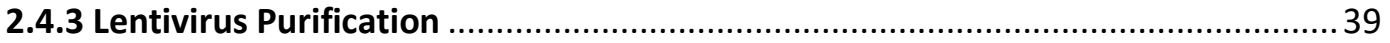

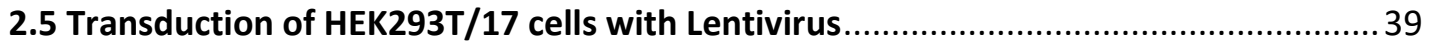

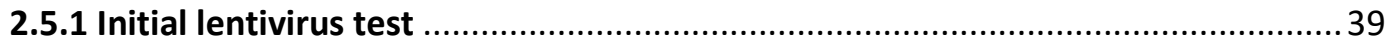

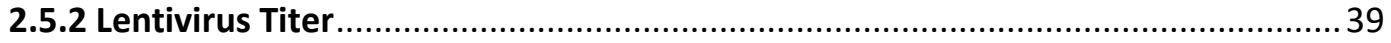

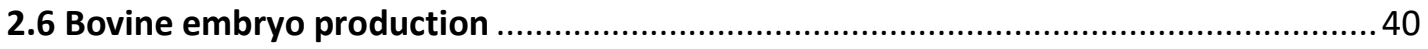

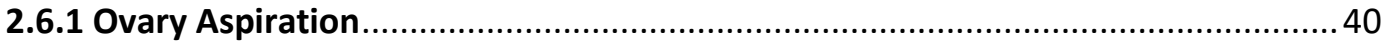

2.6.2 In Vitro Maturation of bovine oocytes ............................................................ 41

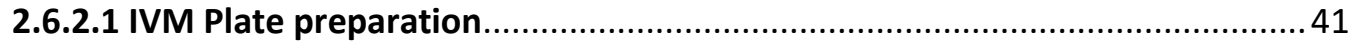

2.6.2.2 Oocyte transfer to IVM drops ................................................................ 41

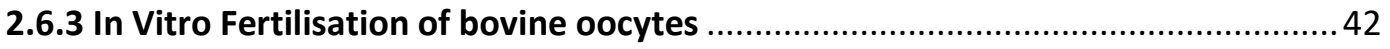

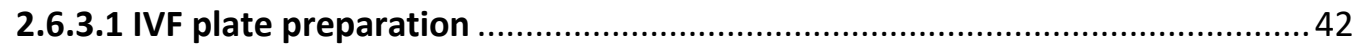

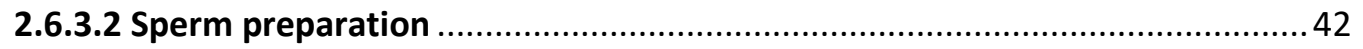

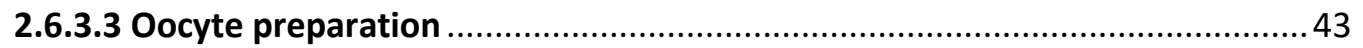

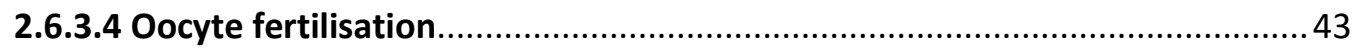

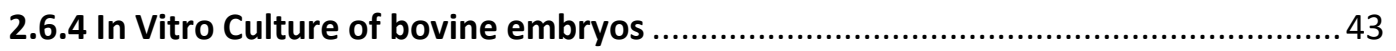

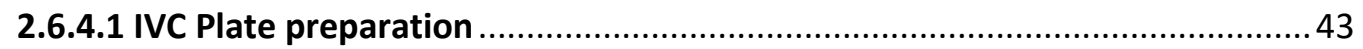

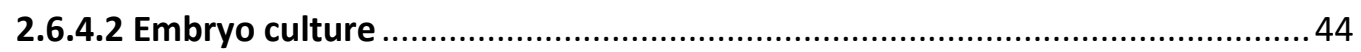

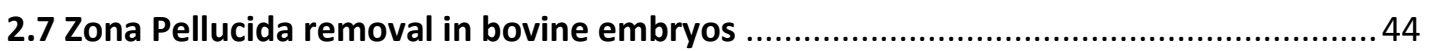

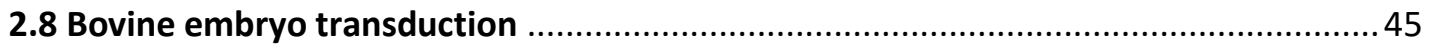

2.9 Monitoring eGFP excision by Cas9 activity in HEK293T cells .................................. 45

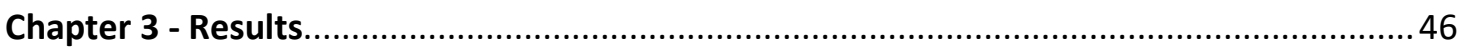

3.1 Results I: Optimisation of Calcium phosphate transfection ................................. 46

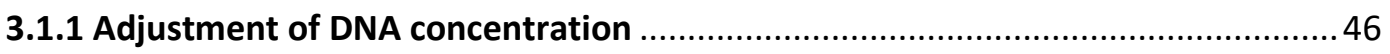


3.2 Results II: Production and Titer of GFP lentiviral particles .................................... 48

3.3 Results III: Creation of GFP expressing HEK293T/17 using lentivirus ....................... 49

3.4 Results IV: Transduction of Bovine cells associated with embryo culture using GFP

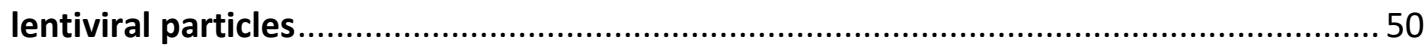

3.4.1 Transduction of Bovine fibroblast cells with eGFP lentivirus .............................. 50

3.4.2 Lentiviral transduction of Cumulus oocyte complex cells ................................. 51

3.4.3 Lentiviral transduction during fertilisation ................................................ 52

3.5 Results V: Removal of Zona pellucida from bovine embryos ................................ 53

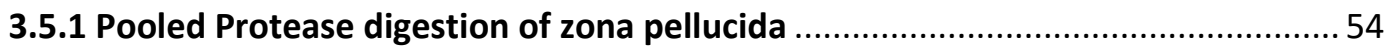

3.5.2 Timed protease digestion on early stage embryos ......................................... 55

3.5.3 Timed protease digestion on compact morulas ................................................... 56

3.5.4 Lentiviral Transduction of protease-treated embryos..................................... 58

3.6 Results VI: Co-transfection of GFP-HEK293T/17 with Cas9 and eGFP-sgRNA..............59

3.7 Results VII: Production of Lentiviral particles containing Cas9 expressing plasmid ... 62

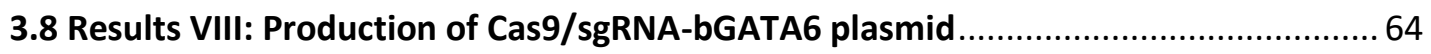

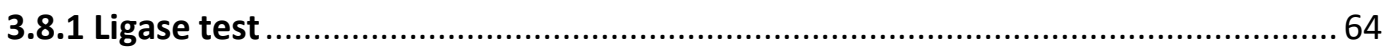

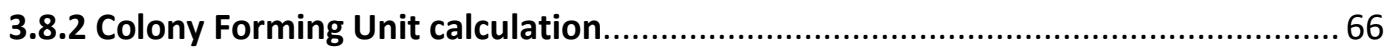

3.8.3 Agarose gel electrophoresis of prospect ligation success ...............................6 66

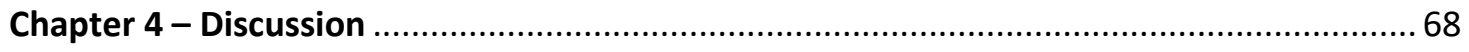

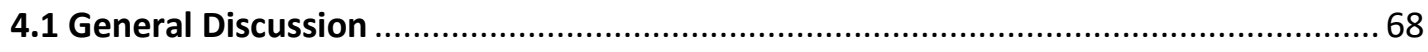

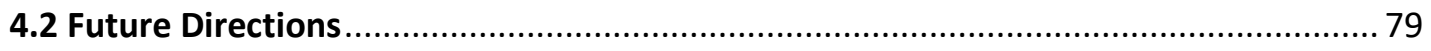

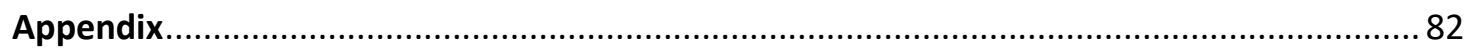


References 


\section{Chapter 1 - Introduction}

\subsection{Early Bovine Embryo Development}

\subsubsection{Cattle embryo genetic modification}

Cattle are one of New Zealand's main exports and sources of local protein, and this industry would likely benefit from research involving CRISPRCas9 systems for genetic modification on bovine models. Due to the success of recent genetic modification technologies, genome engineering is becoming more prevalent in mammalian models. (Wang, et al., 2013; Wu, et al., 2014). Testing these technologies in cattle is still an understudied field, therefore we propose to test CRISPR-Cas9 based systems on cattle embryos by lentiviral infection to determine the feasibility and efficiency of genetic modification, further contributing to current knowledge.

\subsubsection{Growth of cattle blastocysts in vitro}

Bovine in vitro embryo culture has become common due to quickly advancing reproductive technology. It has been shown that fertile cattle offspring can be produced by oocytes grown in vitro after fertilisation with bull sperm (Parrish, 2014). Livestock embryo growth in vitro has presented difficulties in the past, however, complex resolutions such as discrete medium changes have overcome these issues and have been available for over two decades (Petters, 1992). In vitro bovine embryo culture provides a ready supply of test material at a faster rate than is possible using in vivo-derived embryos. 
*Third party image removed*

Figure 1. Systematic diagram of bovine embryo development (Bazer, et al., 2009)

\subsubsection{CRISPR-Cas9 Nuclease-mediated Genome modification in livestock}

Though CRISPR-Cas research in farm animals is scarce (Crispo, et al., 2015), there are multiple reports of successful applications. It has been shown that the myostatin gene can be successfully knocked out in sheep models, showing that the cheap and easy nature of CRISPR applications extend to livestock as a source of genetic modification for uses such as biomedicine (Crispo, et al., 2015). Research has also shown development of transgenic pigs using CRISPR-Cas9 (Whitworth, et al., 2014). Mutations were introduced in genes CD163 and CD1D in Porcine somatic cells, which then underwent nuclear transfer into porcine oocytes (Whitworth, et al., 2014). Not only did Whitworth et al. find that they could target CD163, CD1D and eGFP, they also found targeting two genes at once conferred a double knockout (Whitworth, et al., 2014). 
Whitworth et al. went on to find that direct injection of CRISPR-Cas9 into the cytoplasm of zygotes also resulted in transgenic piglets, with only one pig (a CD1D mutant) showing a mosaic phenotype (Whitworth, et al., 2014).

The lack of research into CRISPR-Cas9 on livestock models, particularly bovine, reveals a niche that requires investigation. Other species, such as zebrafish, have been used in successful CRISPR experiments which have resulted in optimization of the CRISPR system for genomic editing (Vejnar, Moreno-Mateos, Cifuentes, Bazzini, \& Giraldez, 2016).

\subsubsection{Embryo modification using CRISPR-Cas9}

There are various methods described to modify embryos or oocytes using CRISPR-Cas9 (Whitworth, et al., 2014; Ikawa, Tanaka, Kao, \& Verma, 2003; Miao, et al., 2011). Direct injection of CRISPR/Cas9 mRNA or protein into the cytoplasm of zygotes is a common practice in embryo modification with CRISPR (Whitworth, et al., 2014). More recently, success has been achieved in studies that have soaked embryos in lentivirus containing CRISPR-Cas9 and injected lentiviral transgene into the perivitelline space of the oocyte, therefore we will also employ these techniques to determine the most efficient.

Transgenic mice have been developed by soaking embryos in lentivirus containing eGFP expression cassettes (Ikawa, Tanaka, Kao, \& Verma, 2003). Two-cell embryos had their zona pellucida (a proteinaceous covering surrounding embryo) removed and were incubated with lentiviral vectors until differentiated to blastocysts, which were then implanted into the uterus of foster mice. When offspring were examined, one of the lentiviral plasmids transduced into blastocysts ( $L V-C M V-E G F P)$ resulting in 4 out of 6 pups producing eGFP (Ikawa, Tanaka, Kao, \& Verma, 2003). 
Methods such as direct injection of CRISPR-Cas9 mRNA or protein into the cytoplasm of zygotes are established, but can often require expensive equipment or skilled personnel (Sato, Ohtsuka, Watanabe, \& Gurumurthy, 2016). Despite the difficulty involved with direct injection of protein or nucleic acid into the cytoplasm, success has been shown by injecting embryos with lentiviral vectors containing CRISPR-Cas9 DNA. Injection of lentiviral vectors into the perivitelline space has become the standard method of delivery when transducing mammalian oocytes or 1-cell embryos (Miao, et al., 2011) (Lois, Hong, Pease, Brown, \& Baltimore, 2002). Methods have also been developed to inject lentivirus, using a Piezo impact micro-manipulator, into the sub-zonal space of 2-cell embryos to produce transgenic blastocysts (Miao, et al., 2011). Miao et al. found that they could increase the survival rate of one-cell embryos with virus injected into the perivitelline space by treating the embryos with sucrose first (Miao, et al., 2011). While one-cell stage embryo survival efficiency had been increased using sucrose treatment, Miao et al. found that the most efficient method of lentiviral delivery was into the perivitelline space of twocell stage embryos for successful development of transgenic embryos to blastocyst stage (Miao, et al., 2011). eGFP observed in blastocysts derived from two-cell infected embryos was significantly more fluorescent and observed in more cells. This indicated that the larger area of the perivitelline space allowed for greater lentiviral coverage and higher transcriptional activity of two-cell embryos produced more eGFP (Miao, et al., 2011). Similar results were seen even using low-titer lentivirus, indicating the efficiency of transduction was more related to the embryonic stage than the viral titer.

Though there are other emerging methods of embryo transduction, such as electroporation (Hashimoto \& Takemoto, 2015), the accessibility of soaking embryos in lentivirus made this method most applicable to the present research. To test for successful embryo infection using lentivirus we examined 
the presence of eGFP and mCHERRY integrated into the host genome by lentiviral particles.

\subsection{Lentiviral Transduction systems}

\subsubsection{Delivery mechanisms for CRISPR-Cas9}

Due to embryo transfection being difficult, viral vectors or direct injection of protein or nucleic acid are becoming more common as methods of transferring CRISPR-Cas9 systems into target cells (Sato, et al., 2015; Ikawa, Tanaka, Kao, \& Verma, 2003).

In addition to direct injection of CRISPR-Cas9 systems, there are a range of vectors that can be chosen to deliver CRISPR-Cas9, each with benefits and shortcomings. Retroviruses, adenoviruses, adeno-associated viruses (AAV) and lentiviruses have all been tested as transport systems for CRISPR-Cas9 technology (Schmidt \& Grimm, 2015). While adenoviruses and AAVs provide viable vectors for some CRISPR-Cas9 experiments, the plasmids become too large for viral packaging after the addition of sgRNA sequences. Though lentiviral vectors must integrate their genetic material into the host genome, their superior capacity results in less limitations when using CRISPR-Cas9. lentiviral vectors have also become popular in instances where cells are difficult to infect, such as embryo modification, this is due to their broad range of non-dividing and dividing infectible hosts. (Schmidt \& Grimm, 2015) Another main reason viral vectors such as lentivirus are used to transport CRISPR-Cas9 systems is the ability to manipulate cell selectivity using techniques such as pseudotyping. (Schmidt \& Grimm, 2015). Pseudotyping is a process of introducing foreign viral envelope proteins during viral production, allowing altering of host tropism or viral stability (Bouard, Alazard-Dany, \& Cosset, 2009)

Due to their efficacy in previous livestock embryo genome modification, lentiviral vectors were the proposed vectors of choice to edit the genomes of in vitro cultured bovine embryos. 


\subsubsection{Growth of lentivirus}

Ease of culturing and transfection makes HEK293 cells the most popular host choice when producing viral vectors (Anderson, Haskell, Xia, Roessler, \& Davidson, 2000). HEK293 cells have been modified in previous research to express the SV40 Large T-antigen, to create the HEK293T line, which allows for episomal replication of plasmids containing the SV40 origin of replication (DuBridge, et al., 1987). This modification significantly increases the rate of replication and thus expression of the plasmid. HEK293T cells are popular in the field of virus production as they provide high transfection efficiency and titer, thus maximising the yield of the virus to be produced. A strain of HEK293T was produced that showed high transfectability, named HEK293T/17, which made them ideal for lentiviral production. For this reason, HEK293T/17 cell lines were used in the research to produce high titer lentivirus. The lentiviral particles were packaged with current CRISPR-Cas9 systems to transduce cattle embryos in an attempt to induce integration of transgenic material, subsequently causing knock-out of the GATA6 gene.

\subsection{Biological function of CRISPR-Cas9 and use as a genetic editing tool}

CRISPR-Cas systems are genetic editing tools utilized by bacteria and archaea that act as a form of adaptive immunity against invading pathogens (Briner \& Barrangou, 2016). The mechanism of action of CRISPR-Cas systems have been well characterized and can be segregated into 2 major classes, with 5 types and 16 subtypes (Briner \& Barrangou, 2016). In 2010 it was found that the type II relied only on the Cas9 protein for catalytic activity, where other CRISPR-Cas systems were more complex and require multiple proteins (Hsu, Lander, \& Zhang, 2015). In type II systems Cas9 attacks and cleaves invading double-stranded DNA sequences when guided by associated RNAs (Jinek, et al., 2012).

In viral invasion of bacteria, 3 steps are involved with CRISPR-Cas interference. The first step is protospacer acquisition, this involves Cas proteins Cas1 and Cas 2 incorporating 
regions of an invading pathogenic double-stranded DNA sequence into the bacterial CRISPR array (Amitai \& Sorek, 2016). The CRISPR array is located in the bacterial genome downstream of other CRISPR-Cas components. When the pathogen returns, the CRISPR array RNA (crRNA) specific to the invading sequence is processed by associated Cas proteins to produce an RNA product that is used to target the invading sequence (Amitai \& Sorek, 2016). Processed crRNA binds to catalytic Cas enzymes, which then targets and cleaves invading sequences with active endonuclease sites, neutralising the threat (Amitai \& Sorek, 2016).

Cas9 has a bi-lobed morphology consisting of a larger alpha-helical lobe and a smaller nuclease lobe. Together these lobes form a clam shape (Jinek, et al., 2014; Nishimasu, et al., 2014). To provide structural support and the ability to bind to Cas9, the variable crRNA forms a complex with a common RNA sequence, adjacent to the CRISPR array, known as trans-activating RNA (tracrRNA). The crRNA: tracrRNA duplex (also known collectively as guide RNA, or gRNA) is bound through Arginine rich motifs at the alphahelical lobe, where the two lobes meet. A conformational change occurs upon crRNA:tracrRNA binding that reorients endonuclease domains to either side of the central cavity, optimizing opportunity for target cleavage (Jinek, et al., 2014; Nishimasu, et al., 2014). gRNA specificity decreases chances of off target binding, providing protection to the bacteria's own chromosome from CRISPR-Cas9.

The viral target sequence is also located by CRISPR-Cas9 through the recognition of protospacer adjacent motif (PAM) sequence adjacent to the target gene/sequence (Gasiunas, Barrangou, Horvath, \& Siksnys, 2012; Jinek, et al., 2012; Fonfara, et al., 2013). Cas9 complex associates and dissociates along DNA strands until a PAM motif is recognised (Sternberg, Redding, Jinek, Greene, \& Doudna, 2014), inducing a further conformational change that locks the target DNA in place inside the central cavity of the CRISPR-Cas9 construct (Jinek, et al., 2014; Nishimasu, et al., 2014). 
PAM interaction leads to DNA destabilization and allows the gRNA to bind (Jinek, et al., 2014; Nishimasu, et al., 2014), resulting in an RNA:DNA heteroduplex forming between the gRNA and the target sequence (Anders, Niewoehner, Duerst, \& Jinek, 2014; Jinek, et al., 2014; Nishimasu, et al., 2014). The separation of the DNA heteroduplex results in the separated strands becoming metal-ion dependent active sites for endonuclease cleavage (Jinek, et al., 2014; Nishimasu, et al., 2014). The separated strands of DNA strand bound to gRNA/Cas9 is cleaved 3 nucleotides upstream of the PAM sequence. The HNH nuclease domain located on the Cas9 complex cleaves the complementary strand to the gRNA, while the non-complementary strand is cleaved by the RuvC nuclease domain at an endonuclease site adjacent to the HNH site (Jinek, et al., 2012; Jinek, et al., 2014; Nishimasu, et al., 2014). In bacterial systems, invading viral nucleic acid can be diverse in structure (from single stranded RNA to double stranded DNA), thus the double stranded breaks induced through specific targeting by CRISPR is an efficient way of neutralizing all types of invading nucleic acids.

*Third party image removed*

Figure 2. Cas9 mechanism of action. (The Cell Culture Dish, 2016)

When compared to the more complex Cas systems, the simplicity of CRISPR-Cas9 made it a suitable system for use as a genetic engineering tool and its use has become common in genetic modification. By designing the crRNA:tracrRNA duplex, the 
protospacer acquisition step was removed and any $\sim 20$ bp sequence upstream of a PAM site could be targeted (Jinek, et al., 2012). The modified CRISPR-Cas9 system was further optimized by fusing the crRNA and tracrRNA into a single-guide RNA (sgRNA) strand (Jinek, et al., 2012). The simplicity of this system allowed all-in-one plasmids to be produced that provide all the components of CRISPR-Cas9 necessary to modify genes, with sgRNA regions to allow simple transformation of a target sequence (Jinek, et al., 2012).

When using CRISPR in eukaryotic cells, Double Stranded Breaks (DSBs) induced by CRISPR-Cas9 will generally activate the cell's DNA repair mechanisms - either non-homologous end joining (NHEJ) or homology-directed recombination (HDR). NHEJ results in the processing of the cleaved ends of the DNA strand and subsequent backbone ligation. When DNA overhangs are not compatible processing and re-ligation results in loss of gene function due to the interrupted gene sequence (Moore \& Haber, 1996), thus providing a mechanism for generating genetic knock-outs. Homology directed recombination (HDR) occurs when the cell has a homologous sequence available to copy and replace the old sequence ( $\mathrm{He}$, et al., 2016). As the new sequence is homologous to the damaged one, the repair should return function to the gene. HDR also allows gene knock-in if an oligo template is additionally provided (He, et al., 2016). If the knock-out with Cas9 is not bi-allelic, there is risk of HDR repairing the damaged gene and not generating a knock-out. 
*Third party image removed*

Figure 3. a) DNA repair mechanisms that result from Cas9 cleavage-induced DSB. NHEJ leads to knock-out mutation, while HDR results in either gene replacement or knock-in mutation. b) Cas9 mechanism that leads to DSB (Shan, et al., 2014) 


\section{Chapter 2 - Methods and Materials}

\subsection{Cell culture}

All cell culture was done employing aseptic technique, and where applicable, performed in a laminar flow hood.

\subsubsection{Media}

All cell culture was done using Dulbecco's modified eagle medium (DMEM), with $10 \%$ heat inactivated Fetal calf serum (FCS), 1\% penicillin/streptomycin. Media that did not contain sodium pyruvate was supplemented with $1 \%$ sodium pyruvate. All medium was filter sterilized using $0.22 \mu \mathrm{m}$ pore filters prior to addition of FCS. Medium was pre-warmed to $37^{\circ} \mathrm{C}$ in a heated waterbath prior to any use in cell culture.

\subsubsection{Thawing cells}

Cells were stored in liquid nitrogen $\left(-200^{\circ} \mathrm{C}\right)$ and thawed by suspending tubes in $37^{\circ} \mathrm{C}$ waterbath for $\sim 2$ minutes. $1 \mathrm{~mL}$ of cells was then immediately transferred to a microcentrifuge tube (very gently) containing $9 \mathrm{~mL}$ of $37^{\circ} \mathrm{C}$ supplemented DMEM and centrifuged for 4 minutes at $430 \mathrm{rpm}$. After centrifugation, media was aspirated from the cell pellet and cells were resuspended in $6 \mathrm{~mL} 37^{\circ} \mathrm{C}$ supplemented DMEM. The cell suspension is then transferred to a $25 \mathrm{~cm}^{2}$ tissue culture growth flask, and placed in an incubator set to $37^{\circ} \mathrm{C}, 5 \% \mathrm{CO}_{2}$.

\subsubsection{Passaging cells}

Cell cultures were monitored daily and when cells reached $60-80 \%$ confluency they were passaged. The following is for $10 \mathrm{~cm}^{2}$ growth surface, for larger or smaller surfaces volumes were adjusted proportionally to relative surface area. The first step of passaging was to remove the growth medium and wash cells with $5 \mathrm{~mL}$ PBS. After aspirating PBS, $1 \mathrm{~mL}$ of Trypsin solution (TrypLE) was used to detach the cells from the growth surface. The cells were then flushed off the growth surface using $5 \mathrm{~mL} 37^{\circ} \mathrm{C}$ supplemented DMEM and transferred to a 15 $\mathrm{mL}$ centrifuge tube. Cell suspension was then centrifuged at $430 \mathrm{rpm}$ for 4 
minutes. After centrifugation, the TrypLE-containing media was removed, and the cell pellet was resuspended in $37^{\circ} \mathrm{C}$ supplemented DMEM. To split cells, the amount of DMEM used to resuspend pellet was proportional to the confluency of the cells at time of passage. If cells were $80 \%$ confluent, pellet was resuspended in 8mL DMEM and then split 1:8 (i.e. 1 $\mathrm{mL}$ out of $8 \mathrm{~mL}$ ). The $1 \mathrm{~mL}$ was then added to $9 \mathrm{~mL} 37^{\circ} \mathrm{C}$ supplemented DMEM and transferred to a new $10 \mathrm{~cm}^{2}$ growth flask/dish.

\subsubsection{Seeding Cells}

Cells often needed to be seeded at a specific density to prepare for experiments. To do this, $10 \mu \mathrm{L}$ of cell suspension was taken after passaging and added to $10 \mu \mathrm{L}$ Trypan blue. The cells $/ \mathrm{mL}$ were then counted on a haemocytometer. Cell suspension was subsequently diluted according to the growth surface to be transferred into. Often cells needed to be diluted to $1 \times 10^{5}$ cells $/ \mathrm{mL}$ to be seeded into 6 well plates.

\subsubsection{Freezing cells}

To prepare cells for freezing, $6 \mathrm{~mL}$ freeze media was prepared containing FCS + $16 \%$ DMSO and chilled to $4{ }^{\circ} \mathrm{C}$. After passaging, $6 \mathrm{~mL}$ of cell suspension containing $1-3 \times 10^{6}$ cells $/ \mathrm{mL}$ was prepared and then added to the prechilled $6 \mathrm{~mL}$ freeze media, dropwise. $1 \mathrm{~mL}$ aliquots were immediately transferred to cryovials and place in a 'freezer buddy' and then into the $-80^{\circ} \mathrm{C}$ freezer. The freezer buddy ensured the cells cooled at a standard rate so as to maximise the quality of the frozen stocks. The next day, the cryovials containing frozen cell stocks were transferred into the liquid nitrogen storage $\left(-200^{\circ} \mathrm{C}\right)$

\subsection{Plasmid amplification and isolation}

\subsubsection{Plasmid acquisition}

Plasmids were received in 2 forms - transformed into Escherichia coli in an agar stab or as free DNA spotted onto filter paper. E. coli from agar stabs was streaked on Luria Broth (LB) agar plates and incubated at $37^{\circ} \mathrm{C}$ overnight. Plasmid shipped on filter paper 
was resuspended in TE by soaking filter paper, then plasmid DNA was transformed into $E$. coli as per 2.2.5. After transformation, E. coli cells were streaked onto LB agar and incubated at $37^{\circ} \mathrm{C}$ overnight.

\subsubsection{Lentiviral packaging plasmids}

Generation 2 lentiviral packaging plasmids were used for our lentivirus production. These use fewer plasmids than $3^{\text {rd }}$ generation lentiviral vectors ( 3 rather than 4) and thus were beneficial to the calcium phosphate method of transfection as it is an older transfection method and is negatively impacted by increased numbers of plasmid used. The 3 plasmids included in $2^{\text {nd }}$ generation lentiviral vectors are the 2 packaging plasmids (we used pMD2.G and psPAX2) and the transfer plasmid to be packaged into the lentiviral vectors.

\subsubsection{1 pMD2.G}

pMD2.G is a vector that encodes VSV-G, a crucial envelope protein for lentiviral assembly. The expression of vesicular stomatitis Indiana virus G (VSV-G), an envelope protein that mediates viral entry into the target cell, is enhanced by the CMV promoter. Restriction sites are labelled too. The plasmid additionally contains the SV40 origin of replication to allow the large T antigen expressed in HEK293T/17 cells to increase replication of plasmid. Ampicillin resistance is encoded to allow for selection when growing plasmid in bacteria. Restriction sites are as labelled. 


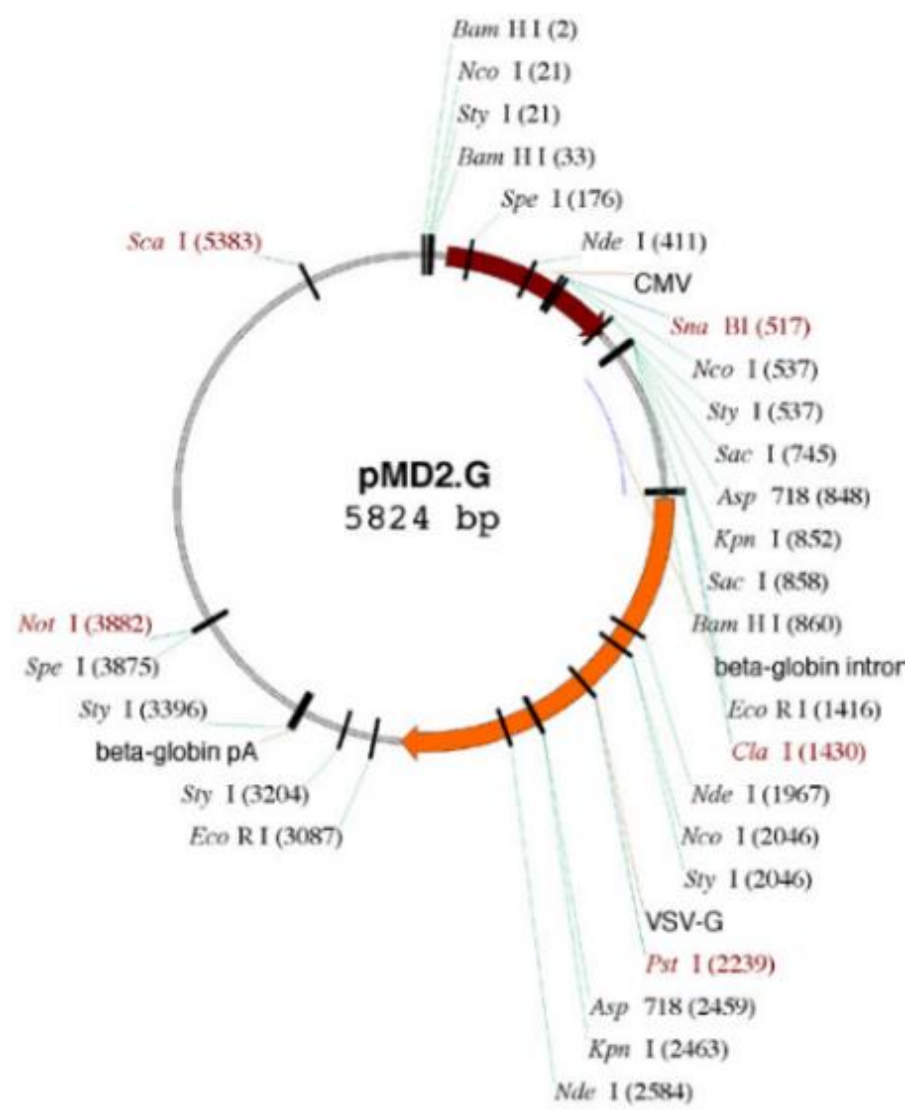

Figure 4. Plasmid map of pMD2.G (Addgene, n.d.)

\subsubsection{2 psPAX6}

psPAX2 is the packaging vector which uses a CMV promoter and TATA box to increase expression of Group specific antigen (Gag), protease, reverse transcriptase (Pol), tat/rev and rev-response element. These enzymes are all involved in the packaging and proper functioning of the lentivirus, to be paired with a VSV-G expressing vector. The plasmid also contains the SV40 origin of replication to allow the large T antigen expressed in HEK293T/17 cells to increase replication of plasmid. Ampicillin resistance is encoded to allow for selection when growing plasmid in bacteria. Restriction sites are as labelled. 


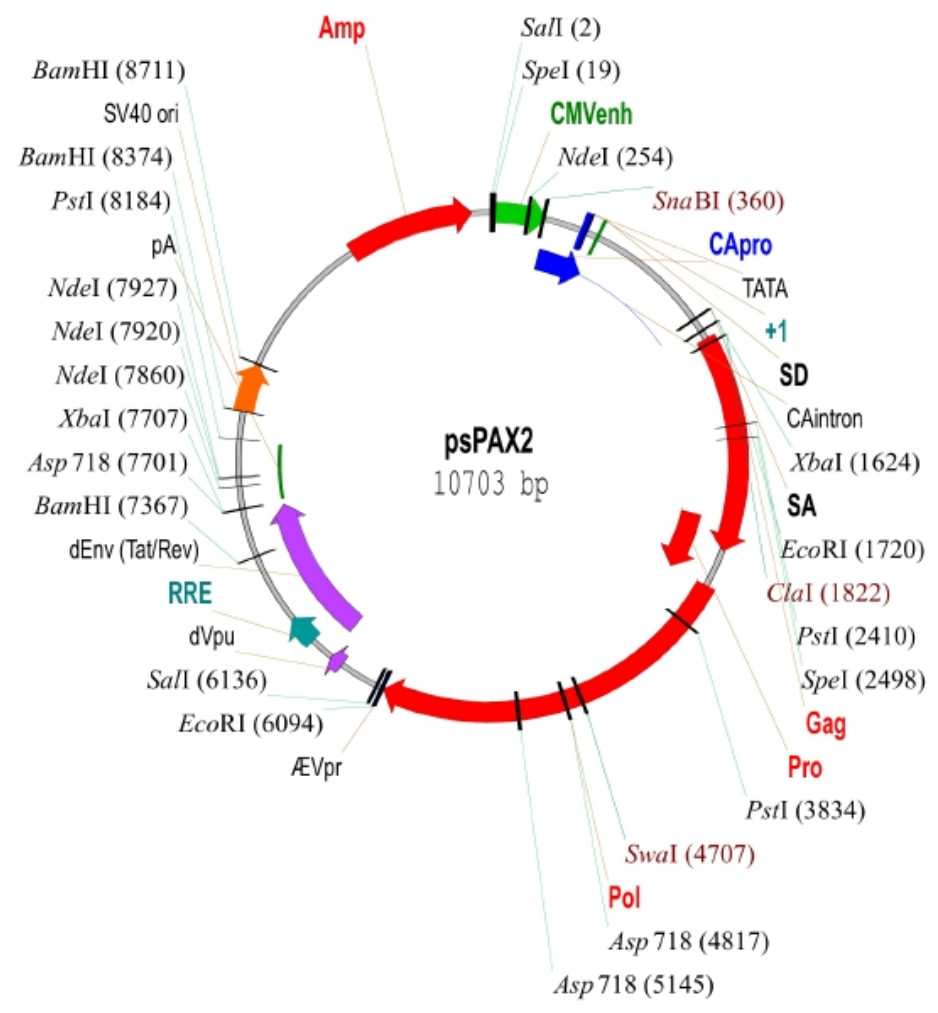

Figure 5. Plasmid map of psPAX2 (Addgene, n.d.)

\subsubsection{Lentiviral Transfer Plasmids}

These were the plasmids used that encoded the genes of interest, to be packaged by the cells when co-transfected with psPAX2 and pMD2.G.

Plasmids containing eGFP, Cas9 and gRNAs were used. 


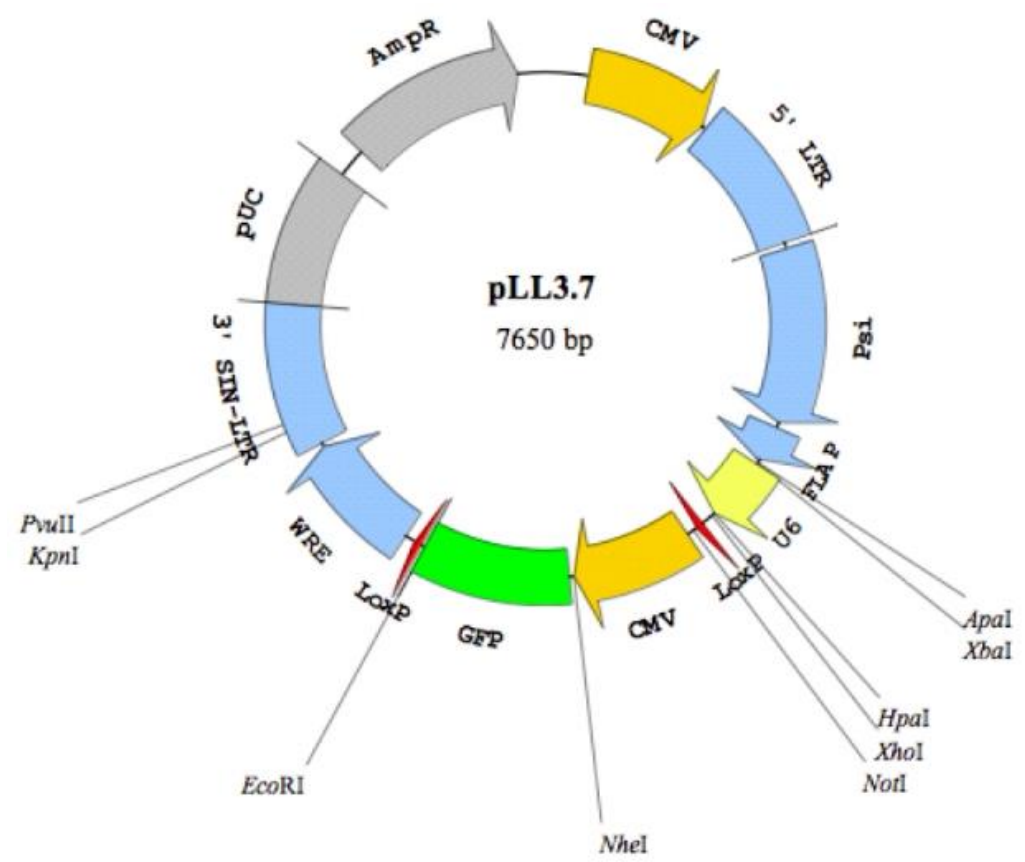

Figure 6. Plasmid map of pll3.7 (Rubinson, et al., 2003)

pll3.7 is a transfer vector containing eGFP as a fluorescent reporter. A CMV promoter drives expression of eGFP. The psi sequence and flanking LTRs allow the eGFP sequence to be packed into lentiviral particles when expressed with packaging plasmids (pMD2.G and psPAX6). pll3.7 also contains an ampicillin resistance gene which allows for selection when amplifying in bacteria. 


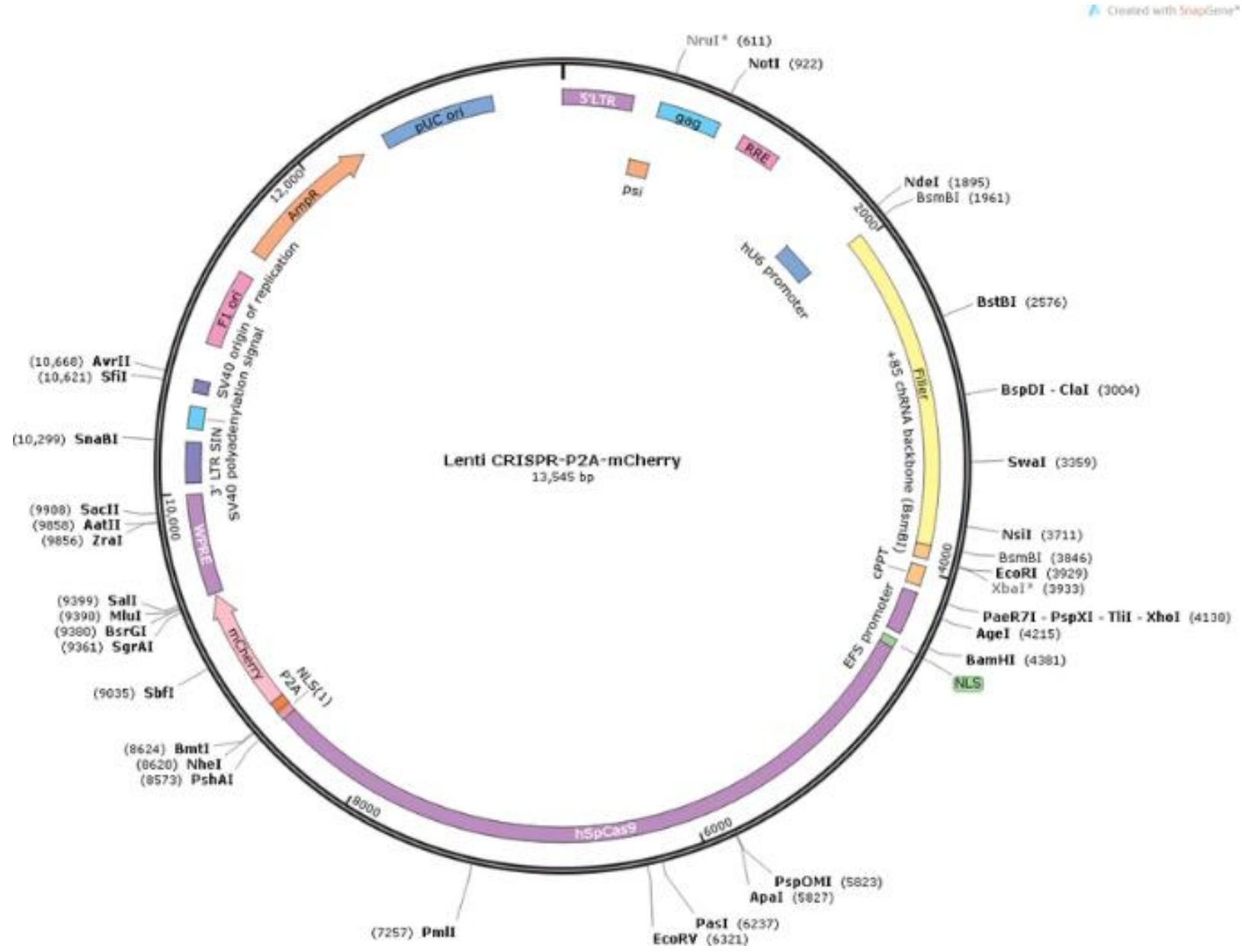

Figure 7. Plasmid map of pLENTI-CRISPR-MCHERRY (McComb, et al., 2016)

pLENTI-CRISPR-mCHERRY is an all-in-one plasmid expressing Cas9 and an excisable filler sequence flanked by BsmBI restriction sites. It also contains a cassette encoding Cas9 fused to mCHERRY, promoted by an EFS promotor sequence. The plasmid also contains the SV40 origin of replication to allow the large T antigen expressed in HEK293T/17 cells to increase replication of plasmid. The psi sequence and flanking LTRs allow the Cas9 and gRNA sequence to be packed into lentiviral particles when expressed with packaging plasmids (pMD2.G and psPAX6). 


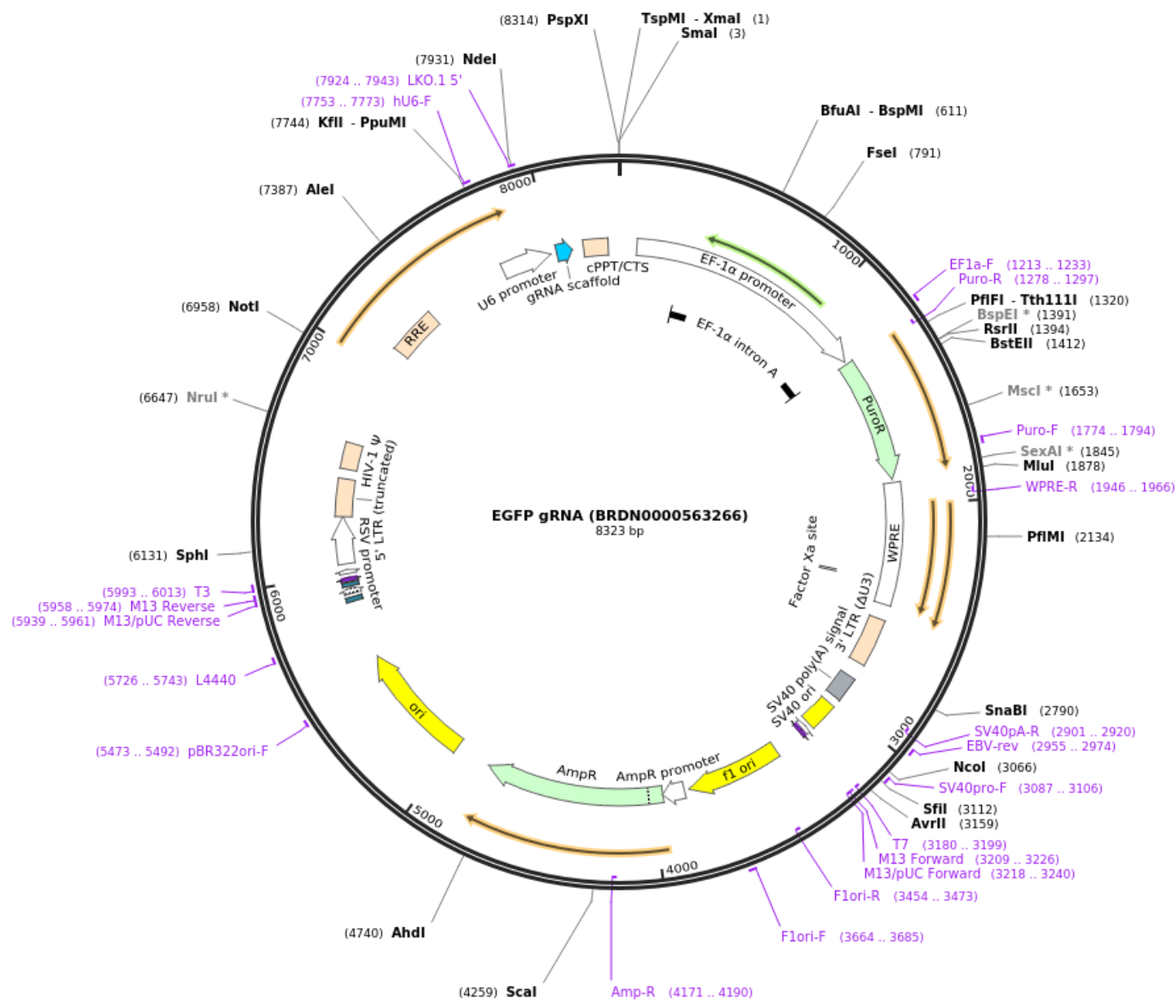

Figure 8. Plasmid map of EGFP gRNA (Doench, et al., 2016)

eGFP gRNA is a plasmid encoding a gRNA targeted at eGFP. It contains cassettes encoding puromycin and ampicillin resistance for selection in bacteria/eukaryotic cells. The plasmid also contains the SV40 origin of replication to allow the large T antigen expressed in HEK293T/17 cells to increase replication of plasmid. The psi sequence and flanking LTRs allow the sequence containing eGFP-gRNA to be packed into lentiviral particles when expressed with packaging plasmids (pMD2.G and psPAX6)

eGFP gRNA sequence - GAGCTGGACGGCGACGTAAA 


\subsubsection{Bacterial Transformation by Heat Shock}

Competent $E$. coli cells were thawed on ice. 1 to $5 \mu \mathrm{L}$ of plasmid or ligation mix was added to competent bacteria ( 25 or $50 \mu \mathrm{L}$ ) while tapping gently or rotating solution around with pipette tip. Competent cells were then incubated on ice for 20-30 minutes.

After incubation, cells were heat shocked by immersing in $42{ }^{\circ} \mathrm{C}$ waterbath. homemade competent E. coli were immersed for 75 seconds, whereas One Shot ${ }^{\circledR}$ TOP10 Chemically Competent E. coli (Invitrogen, NZ) were immersed for 45 seconds. After heat shock, cells were plunged into ice for 2 minutes. 1 $\mathrm{mL}$ LB broth or SOC medium ( $37^{\circ} \mathrm{C}$, no antibiotic) was then added, and cells were incubated in an orbital shaker at 200-250 rpm for 1 hour at $37{ }^{\circ} \mathrm{C}$

Cells were then centrifuged on a tabletop centrifuge at $10000 \mathrm{rpm}$ for $1 \mathrm{~min}$, $900 \mu \mathrm{L}$ of supernatant was removed and concentrated bacteria were spread onto an agar plate containing ampicillin $(100 \mu \mathrm{g} / \mathrm{mL})$. Plates were left to air dry for 5 minutes then incubated overnight at $37^{\circ} \mathrm{C}$.

\subsubsection{Bacterial Transformation by Electroporation}

\subsubsection{Preparing electrocompetent E. coli}

DH5 alpha E. coli were inoculated into $50 \mathrm{~mL}$ LB from a colony on a LB agar plate and grown overnight at $37{ }^{\circ} \mathrm{C}, 200 \mathrm{rpm}$. Using the overnight culture, $400 \mathrm{~mL}$ LB was inoculated, and referenced with a starting OD600 of 0.1 . The culture was grown until an OD600 of 0.35-0.434 was reached, at which point it was transferred to 8 sterile $50 \mathrm{~mL}$ tubes and cooled on ice for 30 minutes. Cells were then centrifuged for 15 minutes at $2700 \mathrm{~g}, 4^{\circ} \mathrm{C}$. For the first wash step, pellets were washed with ice cold sterile $\mathrm{ddH} 2 \mathrm{O}$ by gentle pipetting. The pellets were resuspended in $200 \mathrm{~mL}$ ice cold sterile $10 \%$ glycerol. Cells were pelleted again through centrifugation, and this time the pellet was resuspended in $100 \mathrm{~mL}$ ice cold sterile $10 \%$ glycerol. Cells were then finally collected through 
centrifugation and the pellet was resuspended in $300-500 \mu \mathrm{L}$ of ice cold sterile $10 \%$ glycerol. Sixty $\mu \mathrm{L}$ aliquots were transferred to prechilled $1.5 \mathrm{~mL}$ microcentrifuge tubes. Cell aliquots were then snap frozen and stored at $-80^{\circ} \mathrm{C}$.

\subsubsection{Transforming electrocompetent $E_{\text {. coli }}$}

Competent cells were thawed on ice. 1 to $5 \mu \mathrm{L}$ of plasmid or ligation mix was added to competent bacteria (75-100 $\mu \mathrm{L}$ ) while tapping gently or rotating solution around with pipette tip. Competent cells were then incubated on ice for 2-5 minutes.

After incubation, cells were transferred to electrocuvettes and placed in the electroporator and pulsed at preset settings.

After electroporation, cells were transferred to microcentrifuge tubes. $900 \mu \mathrm{L}$ LB medium ( $37^{\circ} \mathrm{C}$, no antibiotic) was then added, and cells were incubated in an orbital shaker at $200-250 \mathrm{rpm}$ for 1 hour at $37^{\circ} \mathrm{C}$

After incubation, $200 \mu \mathrm{L}$ of culture was plated onto LB agar plates containing ampicillin $(100 \mu \mathrm{g} / \mathrm{mL})$.

\subsubsection{Bacterial culture}

Bacteria containing plasmids of interest were grown in LB medium, supplemented with $100 \mathrm{mg} / \mathrm{mL}$ ampicillin. Liquid cultures were inoculated from single colonies from LB agar plates to ensure selection of one plasmid. Cultures were incubated in a heated shaking incubator at $37^{\circ} \mathrm{C}, 250 \mathrm{rpm}$

\subsubsection{Midiprep protocol}

Overnight inoculations were transferred into $50 \mathrm{~mL}$ falcon tubes (10 total, 2 for each $100 \mathrm{~mL}$ inoculation) and centrifuged at $4000 \mathrm{rpm}$ for 30 minutes to pellet bacteria. Supernatant was discarded and the bacterial pellet resuspended in $4 \mathrm{~mL}$ of buffer $\mathrm{p} 1$ (resuspension buffer, Qiagen.), the solution was then mixed 
thoroughly. Next, $4 \mathrm{~mL}$ of buffer p2 (lysis buffer, Qiagen.) was added and solution was mixed by inversion (not vigorously). When using Lyseblue reagent the successful lysis of bacteria was indicated by a royal blue colour. $4 \mathrm{~mL}$ buffer p3 (neutralization buffer, Qiagen.) was then added and solution was mixed by inversion until all blue traces were gone. The solution was then incubated on ice for 20-30 minutes. After incubation, solution was centrifuged at $4000 \mathrm{rpm}$ for 30 minutes to separate precipitant (cellular debris and genomic DNA) from supernatant (plasmid DNA). To further clarify supernatant, it was transferred into $15 \mathrm{~mL}$ falcon tubes (avoiding carryover of debris) and centrifuged again at $4000 \mathrm{rpm}$ for 15 minutes. During the final centrifugation of step ii, Qiagen Midiprep columns (Qiagen.) were prepared by putting the holding-ring on columns and placing onto $100 \mathrm{~mL}$ conical flasks (to collect liquid waste). The columns were then equilibrated by adding $4 \mathrm{~mL}$ of Buffer QBT (equilibration buffer, Qiagen) and allowing them to drain by the force of gravity. When ready, supernatant from plasmid-containing solution was added to columns, ensuring only to run $10-12 \mathrm{~mL}$ at a time to not over fill the column. Each 10-12 mL was allowed to drain by the force of gravity. Captured plasmid was washed by adding 2x $10 \mathrm{~mL}$ Buffer QC (wash buffer, Qiagen.), allowing each $10 \mathrm{~mL}$ to drain by force of gravity. Columns were then transferred to $15 \mathrm{~mL}$ falcon tubes, (attached using masking tape) and plasmid DNA was eluted by adding $5 \mathrm{~mL}$ Buffer QF (elution buffer, Qiagen.) to columns, allowing to drain by the force of gravity. Plasmid DNA in elute was then precipitated by adding $3.5 \mathrm{~mL}$ isopropanol and mixing, followed by centrifugation of solution at $4000 \mathrm{rpm}$ for 30 minutes. After centrifugation, all supernatant was carefully decanted without disturbing DNA pellet, then $2 \mathrm{~mL} 70 \%$ ethanol was added gently. plasmid DNA + ethanol solution was then centrifuged at $4000 \mathrm{rpm}$ for 15 minutes. The supernatant was carefully decanted, and the DNA pellet allowed to air dry in a laminar flow hood for 5-10 minutes. DNA pellets were resuspended in appropriate amount of TE buffer and stored at $-20^{\circ} \mathrm{C}$. 
For Mini and Maxiprep protocols, see manufacturer's recommendations.

\subsubsection{Restriction digestion}

In order to analyse and modify the plasmids we received, restriction enzymes were used to digest sequences. To perform restriction digestion the following was prepared in a microcentrifuge tube:

- 5-17 $\mu \mathrm{L}$ of DNA (suspended in $\mathrm{H}_{2} \mathrm{O}$ or TE buffer) - volume dependent on concentration of DNA

- $1 \mu \mathrm{L}$ of each respective enzyme (New England Biolab; Genesearch, NZ)

- $2 \mu \mathrm{L}$ Cutsmart buffer or buffer 3.1 (10\% of final volume) (New England Biolab)

- $\mathrm{ddH}_{2} \mathrm{O}$ to make total up to $20 \mu \mathrm{L}$

This reaction mixture was incubated at temperatures according to the requirements of the enzyme used $\left(37^{\circ} \mathrm{C}\right.$ or $\left.55^{\circ} \mathrm{C}\right)$ for $1.5-2$ hours.

\subsubsection{Agarose Gel Electrophoresis}

To analyse the products of restriction digestion, DNA was separated by band size using agarose gel electrophoresis. To make a $1 \%$ agarose gel, $0.40 \mathrm{~g}$ of LE agarose was dissolved in $40 \mathrm{~mL} 1 x$ Tris base, acetic acid and EDTA (TAE) buffer and weighed, then microwaved $4 \times 15$ seconds, swirling at the intervals. Additional 1x TAE was added after microwaving to account for lost water, usually 5-10 mL. When dissolved gel was cool enough to hold, $2 \mu \mathrm{L}$ ethidium bromide (10 $\mathrm{\mu g} / \mathrm{mL}$; Sigma, NZ) was added and swirled until sufficiently mixed. The gel was then poured into a gel dock and a gel comb with sufficient wells was added. The gel was set under a polystyrene box to protect the ethidium bromide from light damage. Once set, the gel dock was loaded into the electrophoresis machine and 1X TAE was added until gel was submerged. Wells were then loaded, with $1 \mathrm{~kb}+$ DNA ladder (Invitrogen, NZ) in the first lane and controls/tests in subsequent lanes. Gels were run 
for 15-45 minutes at 90-120 V, dependent on size of gel and DNA fragments.

\subsubsection{Colony Forming Unit assay}

To calculate colony forming units per ug DNA added, $E$. coli were transformed (protocol 2.2.4) with $0.1 \mathrm{pg}$ plasmid DNA and grown overnight at $37^{\circ} \mathrm{C}$. the following day, colonies were counted, and number of colony forming units were multiplied by $10^{8}$ to adjust to $1 \mu \mathrm{g}$ DNA (after using 0.1pg DNA)

\subsubsection{Creating Cas9/sgRNA-bGATA6 expressing plasmid}

\subsubsection{Plasmid and Fragments}

Vector - To design a plasmid containing Cas9 and a bovine GATA6 sgRNA, we used pLENTI-CRISPR-mCHERRY as a vector. The plasmid contains $2 \mathrm{BsmB}$ / restriction sites flanking a filler region, this is intended to be excised and replaced with an SgRNA sequence.

Insert - The insert for the pLENTI-CRISPR-mCHERRY plasmid was designed as a bovine GATA6 sgRNA with overhangs complementary to those on the vector following BsmBI digestion. Oligos came as ssDNA that needed to be annealed before ligation.

\subsubsection{2 sgRNA design and acquisition}

To design a sgRNA complementary to the bovine GATA6 gene, the program CHOP CHOP v2 (Labun, Montague, Gagnon, Thyme, \& Valen, 2016) was used. This program allowed selection of sequences with minimal off target binding sites, decreasing the chance of off target binding by Cas9. Our selected sequences had 0 off target binding sites according to the CHOP CHOP v2 database.

\subsubsection{Restriction Digestion}

To digest pLENTI-CRISPR-mCHERRY and excise the filler sequence, the following restriction digest was prepared: 
- $2 \mu \mathrm{g}$ of DNA (suspended in $\mathrm{H}_{2} \mathrm{O}$ or TE buffer)

- $1 \mu \mathrm{L}$ of BsmBI enzyme (New England Biolab)

- $1 \mu \mathrm{L}$ buffer 3.1 (New England Biolab)

- $\mathrm{ddH}_{2} \mathrm{O}$ to make total up to $20 \mu \mathrm{L}$

this reaction mixture was then incubated for $1.5-2$ hours at $55^{\circ} \mathrm{C}$.

\subsubsection{Isolation of DNA from gel}

Following digestion, we prepared a $1 \% \mathrm{LE}$ agarose gel and placed in the electrophoresis dock. The first well was loaded with $1 \mathrm{kB}+\mathrm{DNA}$ ladder (Invitrogen, NZ), followed by the digestion products in subsequent wells. Gels were run at $90 \mathrm{mV}$ for $30-45$ minutes. After running, gels were viewed in a transilluminator for analysis and DNA excision. Using a scalpel, a gel slice containing the upper fragment representing the vector backbone was excised and transferred into a $1.5 \mathrm{~mL}$ microcentrifuge tube. DNA was then isolated from agarose gel using Wizard ${ }^{\circledR}$ SV Gel and PCR Clean-Up System (Promega, NZ), as per the manufacturer's instructions.

\subsubsection{Annealing of SSDNA fragments}

To prepare the bGATA6 insert, the 2 ssDNA strands needed to be annealed. This was done by first mixing equimolar concentrations of each strand in a microcentrifuge tube, then incubating the solution in a water bath for 5 minutes at $80^{\circ} \mathrm{C}$. Tubes were placed in a beaker containing $80^{\circ} \mathrm{C}$ water and allowed to cool to room temperature. This procedure yielded a dsDNA bGATA6 fragment with overhangs complementary to $B s m B I$ sites on the pLENTI-CRISPR-mCHERRY vector. 


\subsubsection{Ligation of fragments}

To ligate the fragment into the vector, first the two DNA fragments were mixed on ice at a ratio of $\sim 1: 3$ (vector:insert) in the smallest possible volume (ideally $1 \mu \mathrm{L}$ vector, $3 \mu \mathrm{L}$ insert). This was combined with an equal volume of TaKaRa Mighty Mix (Clontech) and incubated at $14{ }^{\circ} \mathrm{C}$ for 30 minutes.

\subsubsection{Transformation}

Ligation product was transformed into chemically competent $E$. coli by heat shock (as per protocol 2.2.4). After thawing cells on ice, 1-5 $\mu \mathrm{L}$ ligation mixture was added and cells were incubated for 20-30 minutes (on ice). After incubation, cells were heat shocked by placing in a 42 ${ }^{\circ} \mathrm{C}$ waterbath for 45 seconds, then immediately plunged into ice for 2 minutes. $900 \mu \mathrm{L} \mathrm{LB}$ medium or SOC medium was added $\left(37^{\circ} \mathrm{C}\right)$ and cells were incubated on an orbital shaker at 200-250 rpm for 1 hour, $37^{\circ} \mathrm{C}$. Cells were then spun down in a microcentrifuge at $10,000 \mathrm{rpm}$ for 1 minute, resuspended in $100 \mu \mathrm{L}$ LB broth and plated onto LB agar plates containing $100 \mathrm{mg} / \mathrm{mL}$ ampicillin. Plates were then placed into 37 ${ }^{\circ} \mathrm{C}$ incubator overnight.

\subsubsection{Plasmid analysis}

Individual colonies were taken from ligation plates and inoculated into $3 \mathrm{~mL}$ LB broth + ampicillin and grown overnight. The next day, $1 \mathrm{~mL}$ of overnight culture was processed using a Qiagen Miniprep Kit (Qiagen) (as per protocol 2.2.7) and plasmid DNA yielded was treated with restriction enzymes $\mathrm{Ndel}$ and BamHI. In the control (undigested) plasmid we expected to see a band at $2,486 \mathrm{bp}$ - this still contains the filler that we excised prior to ligation. In the ligation products, successful ligation was indicated by bands at $621 \mathrm{bp}$ - the original 2486 sequence, with the $1885 \mathrm{bp}$ filler sequence removed and the 20bp bGATA6 gRNA inserted. Running ligation products through agarose gel electrophoresis 
and analysing them with a transilluminator showed a positive result in the $34^{\text {th }}$ colony screened. This colony was then inoculated into $100 \mathrm{ml}$ LB + ampicillin and grown overnight at $37{ }^{\circ} \mathrm{C}, 200-250 \mathrm{rpm}$. The plasmid (and primers) was sent away for sequencing at the Waikato DNA Sequencing Facility at the University of Waikato.

\subsection{Calcium Phosphate Transfection}

\subsubsection{Plating Cells}

To prepare cells for transfection, plates needed to be prepared with an appropriate number of cells per plate/well. In test runs we used 6 well plates, seeded with $10^{5}$ cells/ well. When we were attempting to produce high titer lentiviral particles, we passaged 2 confluent $15 \mathrm{~cm}^{2}$ plates into $12 \times 15 \mathrm{~cm}^{2}$ plates ( $3.5 \times 10^{6}$ cells/plate)

\subsubsection{Calcium Phosphate Transfection mix}

To transfect target cells, the calcium phosphate components needed to be prepared and mixed with a solution containing associated plasmid DNA.

The following table was referred to when producing Lentiviral particles:

Table 1 Volumes of DNA used for calcium phosphate transfection using $15 \mathrm{~cm}^{2}$ and $10 \mathrm{~cm}^{2}$ plates (Addgene, n.d.)

\begin{tabular}{|l|l|l|l|}
\hline ID & & & \\
\hline $15-\mathrm{cm}$ dish & & $10-\mathrm{cm}$ dish & \\
\hline $\mathrm{H}_{2} \mathrm{O}$ & $\mu \mathrm{l}$ & $\mathrm{H}_{2} \mathrm{O}$ & $\mu \mathrm{l}$ \\
\hline $\begin{array}{l}\text { Transfer vector } \\
(60 \mu \mathrm{g})\end{array}$ & $\mu \mathrm{l}$ & $\begin{array}{l}\text { Transfer vector } \\
(20 \mu \mathrm{g})\end{array}$ & $\mu \mathrm{l}$ \\
\hline psPAX2 $(45 \mu \mathrm{g})$ & $\mu \mathrm{l}$ & psPAX2 $(15 \mu \mathrm{g})$ & $\mu \mathrm{l}$ \\
\hline $\begin{array}{l}\text { pMD2.G envelop } \\
\text { plasmid }(18 \mu \mathrm{g})\end{array}$ & $\mu \mathrm{l}$ & pMD2.G $(6 \mu \mathrm{g})$ & $\mu \mathrm{l}$ \\
\hline $2.5 \mathrm{M} \mathrm{CaCl}{ }_{2}$ & $150 \mu \mathrm{l}$ & $2.5 \mathrm{M} \mathrm{CaCl} 2$ & $50 \mu \mathrm{l}$ \\
\hline Total Volume & $1.5 \mathrm{ml}$ & Total volume & $0.5 \mathrm{ml}$ \\
\hline
\end{tabular}


Once the solution containing $\mathrm{CaCl}_{2}$ and plasmid DNA was prepared, it was added to an equal volume of $2 x$ hepes buffered saline (HBS) solution and incubated at room temp for 15 minutes.

\subsubsection{Transfection}

After the transfection mixture had been allowed to incubate at room temperature for 15 minutes, it was applied to prepared cells which were then incubated at $37^{\circ} \mathrm{C}, 5 \% \mathrm{CO}_{2}$ for 6 hours. After incubation, medium containing transfection mixture was aspirated and replaced with fresh $37{ }^{\circ} \mathrm{C}$, supplemented DMEM.

\subsection{Lentivirus production}

\subsubsection{Lentivirus Harvest}

After transfection, cells producing lentivirus were monitored each day. Cells were observed for signs of "ballooning" and increased levels of eGFP expression, indicative of viral particle production. After 2 days, viral supernatant was aspirated, filtered through a $0.45 \mu \mathrm{m}$ filter tip, and transferred into $6 \times 50 \mathrm{~mL}$ centrifuge tubes and stored overnight at $4{ }^{\circ} \mathrm{C}$. Producer cells were replenished with another $15 \mathrm{~mL}$ supplemented DMEM and incubated for a further 24 hours at $37^{\circ} \mathrm{C}, 5 \% \mathrm{CO}_{2}$. After 24 hours, the supernatant was aspirated from producer cells, filtered through a 0.45 um filter tip, and transferred into $6 \times 50 \mathrm{~mL}$ centrifuge tubes.

\subsubsection{Lentivirus Concentration}

The first harvest of viral solution was then centrifuged at $70,000 \mathrm{~g}$, the supernatant was removed and the remaining viral solution (harvest \#2) was added. After another centrifugation at 70,000 g, viral pellets contained all harvested virus. Viral pellets were then resuspended in $100 \mu \mathrm{L} 1 \mathrm{x}$ Hank's balanced salt solution (HBSS) (Sigma) and transferred to a microcentrifuge tube. A further $100 \mu \mathrm{l} 1 \mathrm{x}$ HBSS was used to 'rinse' the centrifuge tubes, collecting any remaining viral particles, this was pooled with previous viral suspension 
yielding a total volume of $200 \mu \mathrm{L}$. The concentrated viral suspension was then vortexed for 15-30 minutes and briefly centrifuged to clear.

\subsubsection{Lentivirus Purification}

After centrifugation and resuspension in $200 \mu \mathrm{L} 1 \times$ HBSS, the solution containing viral particles was layered on top of $1.5 \mathrm{~mL} 20 \%$ sucrose, and centrifuged for 2 hours at 50,000 g, $20^{\circ} \mathrm{C}$. After centrifugation, supernatant was aspirated and viral pellets were resuspended in $100 \mu \mathrm{L} 1 \mathrm{x}$ HBSS and transferred to a sterile microcentrifuge tube. A further $100 \mu \mathrm{L} 1 \mathrm{x}$ HBSS was used to 'rinse' the microcentrifuge tube, collecting any remaining viral particles, this was pooled with previous viral suspension yielding a total volume of $200 \mu \mathrm{L}$. The concentrated viral suspension was then vortexed for 15-30 minutes and briefly centrifuged to clear. $20 \mu \mathrm{L}$ Aliquots of concentrated virus were stored at $-80^{\circ} \mathrm{C}$ for experimental use.

\subsection{Transduction of HEK293T/17 cells with Lentivirus}

\subsubsection{Initial lentivirus test}

To initially test the lentiviral particles, HEK293T/17 cells were transduced with raw supernatant from HEK293T/17 cells producing lentivirus. After 2 days of virus production, supernatant was harvested from producer cells. $2 \times 10^{6}$ cells were seeded into $10 \mathrm{~cm}^{2}$ growth plates, which then had $1 \mathrm{~mL}, 3 \mathrm{~mL}$ or $5 \mathrm{~mL}$ of lentiviral supernatant added. The cells were monitored for eGFP expression after 72 hours. After observing positive eGFP expression, $5 \mathrm{~mL}$ samples were passaged and continually cultured for the next 10 days.

\subsubsection{Lentivirus Titer}

To calculate the biological titer (transducing units per $\mathrm{mL}$ ) of the lentiviral particles, transduction assays were performed. The biological titer was calculated by first seeding $10^{5}$ cells in 6 well plates. Serial dilutions of concentrated virus were then prepared (undiluted to $10^{-6}$ ) and used to transduce the cells. After 2-3 days, the cells were analysed using fluorescence 
microscopy and the following formula was used to determine the number of transducing units/ $\mathrm{mL}$ :

"Calculate biological titer ( $\mathrm{BT}=\mathrm{TU} / \mathrm{ml}$, transducing units) according to the following formula: $T U / \mu L=(P \times N / 100 \times V) \times 1 / D F$, where $P=\% G F P+$ cells, $N$ $=$ number of cells at time of transduction $=105, \mathrm{~V}=$ volume of dilution added to each well $=20 \mu \mathrm{L}$ and $\mathrm{DF}=$ dilution factor $=1$ (undiluted), 10-1 (diluted 1/10), 10-2 (diluted 1/100), and so on" (Tiscornia, Singer, \& Verma, 2006)

\subsection{Bovine embryo production}

\subsubsection{Ovary Aspiration}

To aspirate oocyte complexes from ovaries, ovaries were first strained by hand over sink. ovaries were then placed in a wide-mouthed thermos and poured warm $\left(37^{\circ} \mathrm{C}\right)$ saline over them, using enough to cover them. The ovaries were rinsed by agitation using hands. Ovaries were then strained again and saline was replaced. This was continued until there was no blood present in the saline. We then took aspiration media $\left(37^{\circ} \mathrm{C}\right)$ and poured approximately $2 \mathrm{~mL}$ in $15 \mathrm{~mL}$ centrifuge tubes $\left(37^{\circ} \mathrm{C}\right)$ for each cow ovary. The tubes were then placed in warming tray $\left(30-35^{\circ} \mathrm{C}\right)$. After setting up the vacuum aspirator, take an ovary and remove excess saline using a paper towel. Firmly holding the ovary (using washed gloves) we selected clear, yellow follicles (3 mm - $10 \mathrm{~mm}$ diameter). To aspirate we inserted the aspiration needle into one of the selected follicles and ensured the pressure on the aspiration pump is $40-50$ $\mathrm{mm} \mathrm{Hg}$. The needle was moved around inside the follicle, trying to be thorough in extracting all the follicular fluid to increase the chance of aspirating the oocyte. This process was repeated on other selected follicles. If blood was aspirated, tubes were changed immediately. Aspiration tubes were changed when $3 / 4$ full. 


\subsubsection{In Vitro Maturation of bovine oocytes}

\subsubsection{IVM Plate preparation}

IVM media was made afternoon prior to use (see appendix, page 96).

On day of use, cysteamine was added to media and swirled. Using a sterile tip and electronic pipettor we put $40 \mu \mathrm{L}$ droplets of IVM media in 10 $\mathrm{cm}$ dishes respective to the number of oocytes we had. Usually 10 droplets were used per dish, in the following fashion:

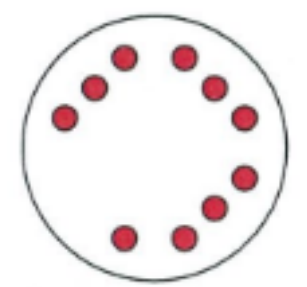

Figure 9. Diagram depicting culture droplet layout of IVM plate

Dishes were then placed in $38.5{ }^{\circ} \mathrm{C}, 5 \% \mathrm{CO}_{2}$ incubator for 2 hours to equilibrate

\subsubsection{0ocyte transfer to IVM drops}

To transfer oocytes to IVM drops, aspiration tubes were placed in rack and put on a warm box. An appropriate number of $90 \mathrm{~mm}$ dishes (1 dish per 23 aspiration tubes) were placed on a warm box, then enough aspiration medium was added to cover the base of the dishes.

Two $35 \mathrm{~mm}$ dishes were put on a warm box and a few $\mathrm{mL}$ of H199 $+10 \%$ FCS was added to each dish. Sediment in aspiration tubes was drawn up and expelled into a $35 \mathrm{~mm}$ dish, then allowed to settle. The petri dish was placed on a warm stage on a microscope and oocytes were searched for using a grid plate. The oocytes were picked up and placed in a $35 \mathrm{~mm}$ dish with $\mathrm{H} 199+10 \% \mathrm{FCS}$. Each oocyte was then transferred into a new $35 \mathrm{~mm}$ dish containing B199+10\%FCS 
Oocytes were then immediately transferred to pre-prepared IVM plates, transferring $10 \mu \mathrm{l}$ containing up to 10 oocytes into each drop. Plates were incubated at $38.5^{\circ} \mathrm{C}, 5 \% \mathrm{CO}_{2}$ for $22-26$ hours

\subsubsection{In Vitro Fertilisation of bovine oocytes}

\subsubsection{IVF plate preparation}

$30 \mu \mathrm{l}$ drops of IVF + penicillamine/hypotaurine, pyruvate and heparin (PPHH)

medium were placed in each plate - 1 drop per 5 oocytes, 10 drops per plate.

\subsubsection{Sperm preparation}

A Percoll gradient was prepared by adding $1 \mathrm{~mL} 45 \%$ percoll solution to a 15 $\mathrm{mL}$ centrifuge tube, then underlaying this with $1 \mathrm{~mL} 90 \%$ percoll solution. (1 gradient facilitates 2 semen straws, 120 oocytes per straw at 1.5 million sperm $/ \mathrm{mL}$ ). Sperm straws were removed from liquid nitrogen and thawed in air for 10 seconds, then in $35^{\circ} \mathrm{C}$ waterbath for 30 seconds. Straw was then dried in a laminar flow hood and the ends wiped with $70 \%$ ethanol. The end of the straw was cut off and placed in a sterile tube, then the other end was cut off, releasing the straw contents into the tube. The thawed semen was aspirated and gently layered on top of the percoll gradient. Sperm motility was then checked using a compound microscope - motility needed to be $>50 \%$. The percoll gradient tube was centrifuged at $700 \mathrm{~g}$ for 20 minutes. During the 20 minute centrifugation, oocytes were prepared (see 2.6.3.3). Immediately after the centrifuge stopped, samples were removed, and the supernatant was carefully aspirated. Sperm pellet was gently aspirated from the bottom of the tube by adding a small quantity of $20{ }^{\circ} \mathrm{C}$ HEPES synthetic oviduct fluid (HSOF). Sperm were added slowly to the tube containing $1 \mathrm{~mL}$ HSOF, mixed gently and centrifuge at $200 \mathrm{~g}$ for 10 minutes. After centrifugation, supernatant was removed and sperm pellet was resuspended in $200 \mu$ IVF+PPHH medium $\left(38.5^{\circ} \mathrm{C}, 5 \% \mathrm{CO}_{2}\right)$. A $10 \mu$ l aliquot of sperm suspension 
was then added to $190 \mu \mathrm{L} \mathrm{ddH}_{2} \mathrm{O}$ (1:20 dilution), the remaining sperm preparation was measured, and sperm concentration was determined.

\subsubsection{Oocyte preparation}

Oocytes were transferred from IVM drops and placed in a $35 \mathrm{~mm}$ dish containing HSOF. Oocyte complexes were then pipetted up and down loosen cumulus cells, being gentle so as not to strip the oocytes completely. Oocytes were then washed by transferring to new $35 \mathrm{~mm}$ dish containing HSOF. Oocytes were then transferred to a third $35 \mathrm{~mm}$ dish containing IVF+PPHH medium $\left(38.5{ }^{\circ} \mathrm{C}\right) .10 \mu \mathrm{L} \quad \mathrm{IVF}+\mathrm{PPHH}$ containing 5 oocytes was then taken and put each drop on preprepared IVF plates, which were returned to incubator at $38.5^{\circ} \mathrm{C}, \mathrm{CO}_{2}$.

\subsubsection{Oocyte fertilisation}

$10 \mu \mathrm{L}$ of diluted sperm preparation was added to each $40 \mu \mathrm{L}$ droplet on IVF plates. IVF drops were checked under microscope for sperm presence and motility

\subsubsection{In Vitro Culture of bovine embryos}

\subsubsection{IVC Plate preparation}

$20 \mu \mathrm{L}$ drops of early synthetic oviduct fluid (ESOF) medium was placed on each plate, 5 droplets around the edges of the dish and a $40 \mu \mathrm{L}$ wash drop in the centre. Droplets were then overlayed with $3 \mathrm{~mL}$ Sigma mineral oil. IVC dishes were then placed in a pre-equilibrated incubation chamber (i.e. flying saucer) for 2 hours after gassing with $5 \% \mathrm{CO}_{2}, 7 \% \mathrm{O}_{2}, 88 \% \mathrm{~N}_{2}$ gas 


\subsubsection{Embryo culture}

Oocytes/zygotes were transferred from IVF droplets to $35 \mathrm{~mm}$ dish containing HSOF. Cumulus complexes were pipetted up and down to remove cumulus cells around the oocyte/zygote, which were then transferred to second $35 \mathrm{~mm}$ wash dish (containing HSOF). oocytes/zygotes were repeatedly pipetted up and down again to strip any remaining cells off embryos.

Embryos were then quickly placed in the wash drop on the IVC plate and placed in flying saucer. When all plates were in the flying saucer it was sealed and re-gassed with $5 \% \mathrm{CO}_{2}, 7 \% \mathrm{O}_{2}, 88 \% \mathrm{~N} 2$ gas, at vigorous flow $(15-20 \mathrm{~L} / \mathrm{min})$ for 5 minutes, then normal flow. On day 5 embryos were transferred to fresh late synthetic oviduct fluid (LSOF) medium drops, ensuring to first transfer to central wash drop, then to subsequent drop. Plates were returned to flying saucer and saucer it was sealed and re-gassed with $5 \% \mathrm{CO}_{2}, 7 \% \mathrm{O}_{2}, 88 \% \mathrm{~N}_{2}$ gas, at vigorous flow $(15-20 \mathrm{~L} / \mathrm{min})$ for 5 minutes, then normal flow.

\subsection{Zona Pellucida removal in bovine embryos}

Protease solution was prepared by adding purified protease powder to HSOF media, to a final volume of $0.2 \% \mathrm{w} / \mathrm{v}$. Embryos were transferred to $35 \mathrm{~mm}$ dish with HSOF + $0.2 \%$ protease, and monitored for zona thinning and digestion. Following incubation times, embryos were immediately removed from protease solution and transferred to a wash droplet on an IVC plate. Embryos were then transferred to another wash drop, before being placed in incubation droplets on IVC plate. Plates were returned to flying saucer and saucer it was sealed and re-gassed with $5 \% \mathrm{CO}_{2}, 7 \% \mathrm{O}_{2}, 88 \% \mathrm{~N}_{2}$ gas, at vigorous flow (15-20 L/min) for 5 minutes, then normal flow. 


\subsection{Bovine embryo transduction}

Bovine embryos were transduced either immediately after zona pellucida digestion, or the next day. $10 \mu \mathrm{L}$ purified virus was added to droplets containing 1-3 embryos. Embryos incubated with virus until ready to be transferred into plates containing laterstage media. Reporter fluorescence was monitored using microscopy every 24 hours following transduction if embryos survived (1-2 days).

\subsection{Monitoring eGFP excision by Cas9 activity in HEK293T cells}

Following transfection of pLENTI-CRISPR-mCHERRY and eGFP-sgRNA (see 2.3), HEK293T/17 cells were assayed for eGFP and mCHERRY fluorescence every 24 hours. Sample images were overlaid to compare fluorescence profiles of cells in controls and tests. 


\section{Chapter 3 - Results}

\subsection{Results I: Optimisation of Calcium phosphate transfection}

In order to transduce embryos using lentiviruses, a high titer is generally required (Miao, et al., 2011). This meant that high transfection efficiency of host cells with the 3 plasmids necessary to produce lentiviral particles was essential. Using a protocol from Addgene (Addgene, n.d.) yielded poor transfection efficiencies, ranging between $10 \%-50 \%, I$ therefore altered the parameters of the transfection to optimize efficiency.

\subsubsection{Adjustment of DNA concentration}

By adjusting the DNA concentration cells were exposed to, it was found that a 3-fold increase in DNA concentration increased the number of transfected cells by $\sim 20 \%$. The increase in transfection efficiency, when adjusting the DNA concentration of protocol, can be seen in figure 10. Note how the highest concentration of DNA produced the most eGFP expression.

\subsubsection{Adjustment of Calcium Phosphate components}

An even greater increase in transfection efficiency was observed when the levels of calcium chloride in the transfection mixture were altered. Figure 11 depicts the larger and more abundant calcium phosphate crystals observed when 1.5-2x the recommended amount of $\mathrm{CaCl}_{2}$ was used compared to the original transfection protocol (protocol 2.3.6.). Transfection efficiencies of pll3.7 became consistently greater than $80 \%$ using the modified protocol. The effects of the optimised calcium phosphate transfection can be seen in figure 12, where the transfection efficiency of viral production plasmids increased to $>95 \%$ after increasing $\mathrm{CaCl} 2$. While increasing the DNA concentration was successful, it was more beneficial to adjust the calcium phosphate components in the experiments using multiple plasmids (i.e. viral packaging plasmids psPAX2 and pMD2.G), as increasing the DNA concentrations required larger quantities of DNA to be produced. 


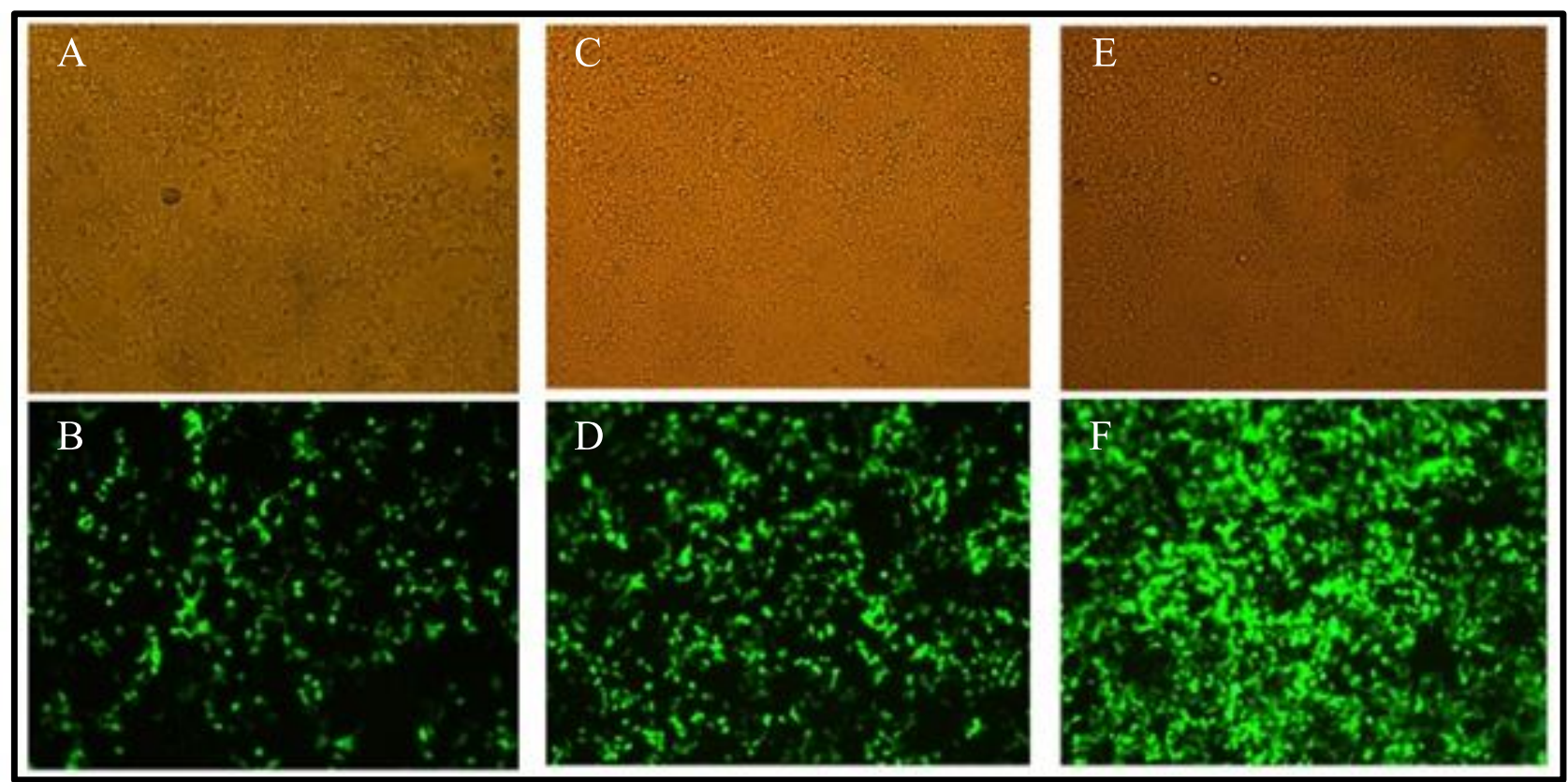

Figure 10. Calcium phosphate transfection of HEK293T/17 cells with varying DNA concentrations added

A) brightfield, $10 \mu \mathrm{g}$ p/l3.7 B) Fluorescence analysis, $10 \mu \mathrm{g}$ p/l3.7 C) brightfield, $20 \mu \mathrm{g}$ pll3.7 D) Fluorescence analysis, $20 \mu \mathrm{g}$ pll3.7 E) brightfield, $30 \mu \mathrm{g}$ pll3 F) Fluorescence analysis, $30 \mu \mathrm{g}$ pll3.7

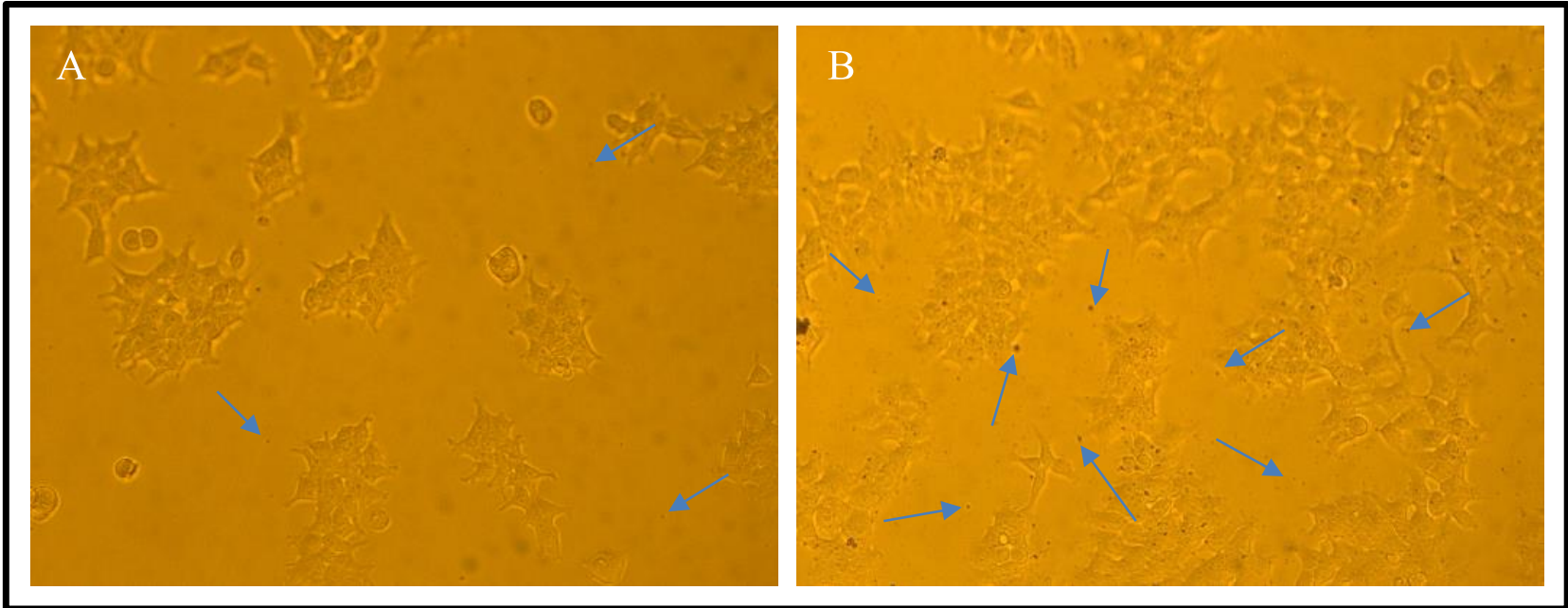

Figure 11. Increased calcium phosphate crystal size/abundance after increasing $\mathrm{CaCl} 2$ concentration during transfection. Arrows indicate calcium phosphate crystals, notice increase in size and abundance in panel B). A) $50 \mu \mathrm{L} 2.5 \mathrm{M} \mathrm{CaCl} 2 \mathrm{~B}$ ) $100 \mu \mathrm{L} 2.5 \mathrm{M} \mathrm{CaCl} 2$ 


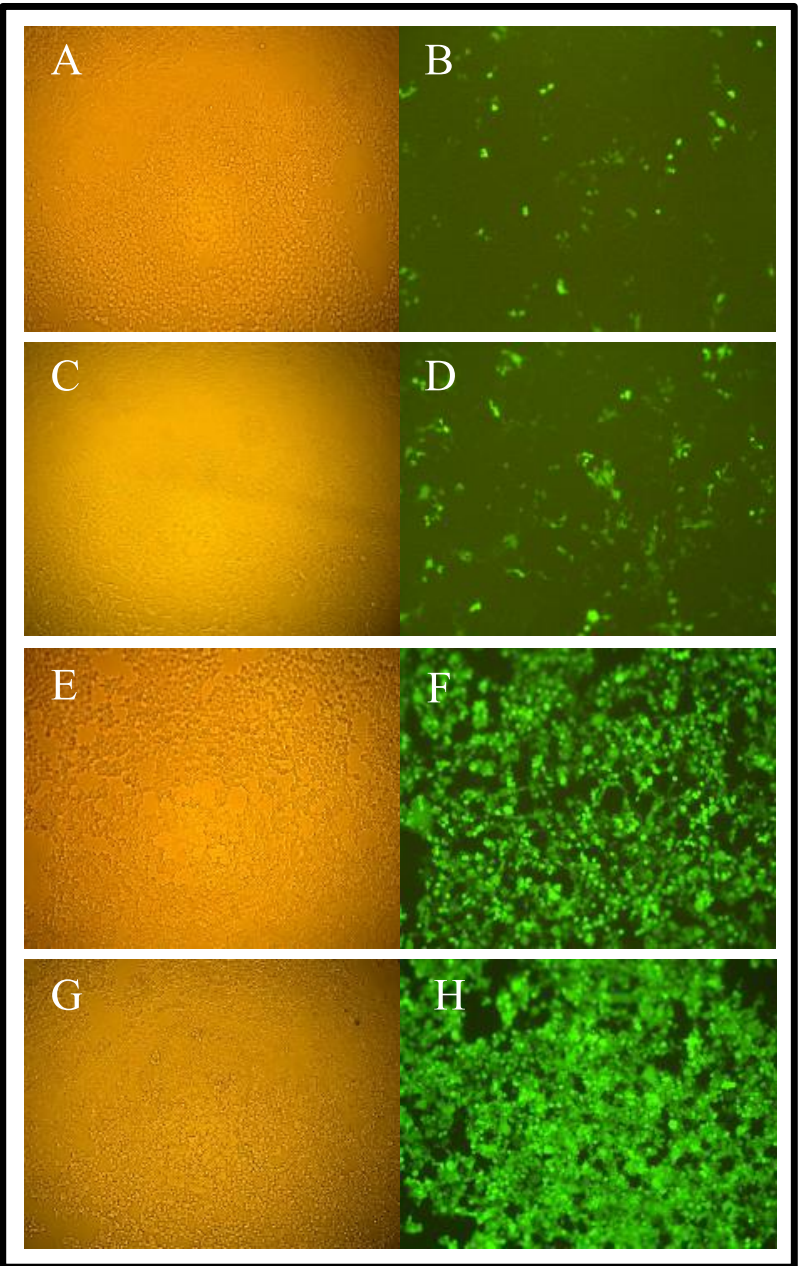

Figure 12. 24- and 48-hour post transfection comparisons of cells transfected with $20 \mu \mathrm{g}$ pll3.7 at varying concentrations of $\mathrm{CaCl} 2$

A) Brightfield, 24 hours, $50 \mu \mathrm{L} \mathrm{CaCl} 2$ B) Fluorescence analysis, 24 hours, $50 \mu \mathrm{L} \mathrm{CaCl} 2 \mathrm{C}$ ) Brightfield, 48 hours, $50 \mu \mathrm{L} \mathrm{CaCl} 2 \mathrm{D}$ ) Fluorescence analysis, 48 hours, $50 \mu \mathrm{L} \mathrm{CaCl} 2 \mathrm{E})$ Brightfield, 24 hours, $100 \mu \mathrm{L} \mathrm{CaCl} 2 \mathrm{~F}$ ) Fluorescence analysis, 24 hours, $100 \mu \mathrm{L} \mathrm{CaCl} 2 \mathrm{G})$ Brightfield, 48 hours, $100 \mu \mathrm{L} \mathrm{CaCl} 2$ H) Fluorescence analysis, 48 hours, $100 \mu \mathrm{L} \mathrm{CaCl} 2$

\subsection{Results II: Production and Titer of GFP lentiviral particles}

Initial attempts at creating lentivirus yielded poor transduction efficiencies, with titers of $<10^{4} \mathrm{TU} / \mathrm{mL}$ (Figure $13 \mathrm{~A}$ ). This was achieved using the original Addgene calcium phosphate transfection protocol. Consistently low titer highlighted the need for optimized transfection efficiencies. Increasing volume of $2.5 \mathrm{M} \mathrm{CaCl}_{2}$ from $50 \mu \mathrm{L}$ to 100 
$\mu \mathrm{L}$ increased the transducing units $/ \mathrm{mL}$ by $>10^{6}$ fold (Figure $13 \mathrm{~B}$ ). Increased transfection efficiency resulted in a consistent titer of $10^{9}-10^{10} \mathrm{TU} / \mathrm{mL}$ (with GFP virus). Figure 13 shows the vast difference in transduction efficiencies between lentivirus derived from the original transfection protocol and lentivirus derived after optimisation.

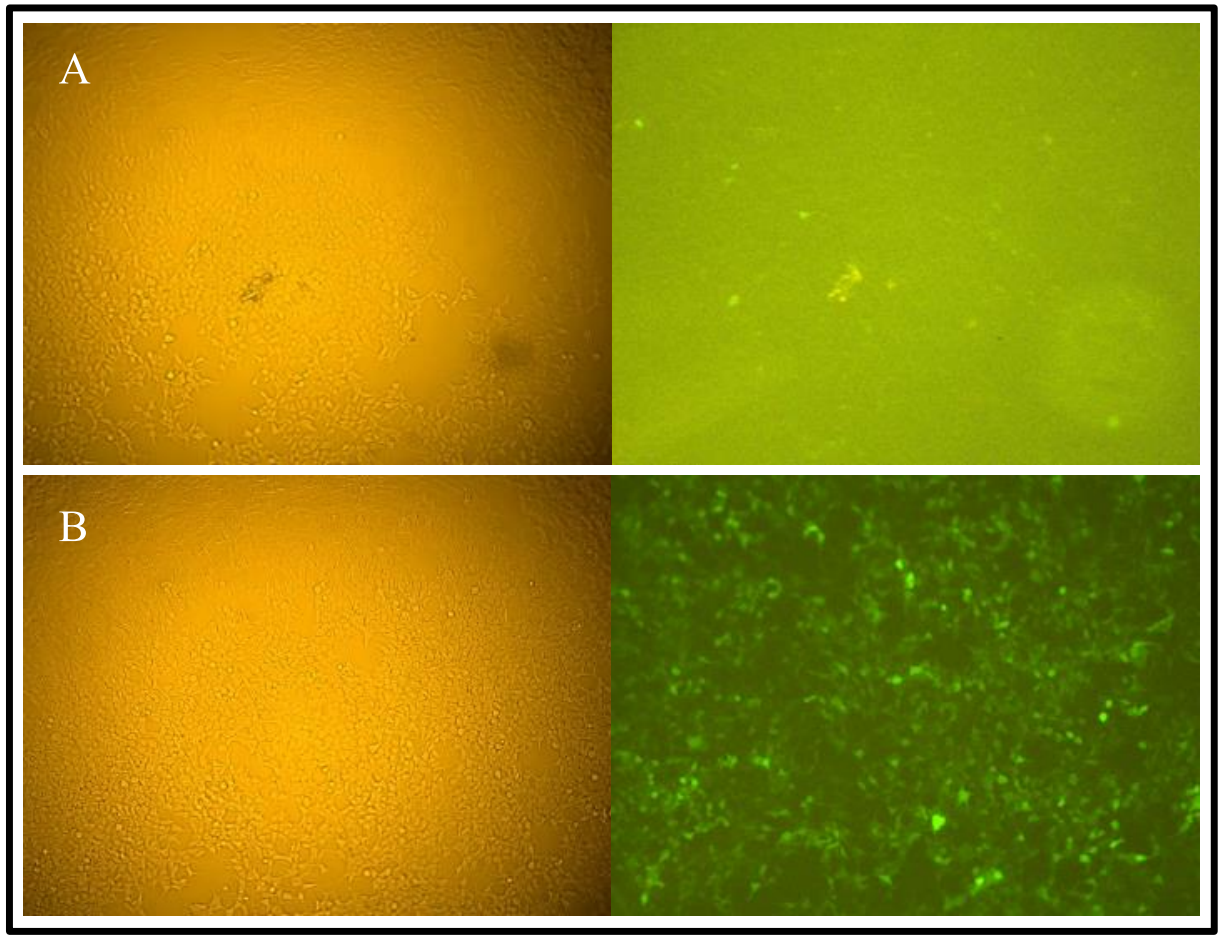

Figure 13. HEK293T/17 cells 24 hours post-transduction using pll3.7 lentivirus derived from producer cells transfected with varying $\mathrm{CaCl} 2$ concentrations

A) Brightfield and fluorescence analysis of $L V$ derived from cells transfected with $50 \mu \mathrm{L} \mathrm{CaCl} 2$

$B$ ) Brightfield and fluorescence analysis of $L V$ derived from cells transfected with $100 \mu \mathrm{L} \mathrm{CaCl} 2$

\subsection{Results III: Creation of GFP expressing HEK293T/17 using lentivirus}

Using high titer eGFP lentivirus, HEK293T cells were transduced and allowed to incubate for 24 hours. 24 hours after transduction it was evident that the transgenic material had transferred to the HEK293T/17 cells and was being expressed, with >90\% of cells expressing eGFP.

Figure 14 shows an analysis over a 10-day period, monitoring the eGFP expression of cells each day. Positive eGFP expression after this extended culture shows that the eGFP gene has been functionally integrated into the host genome. 


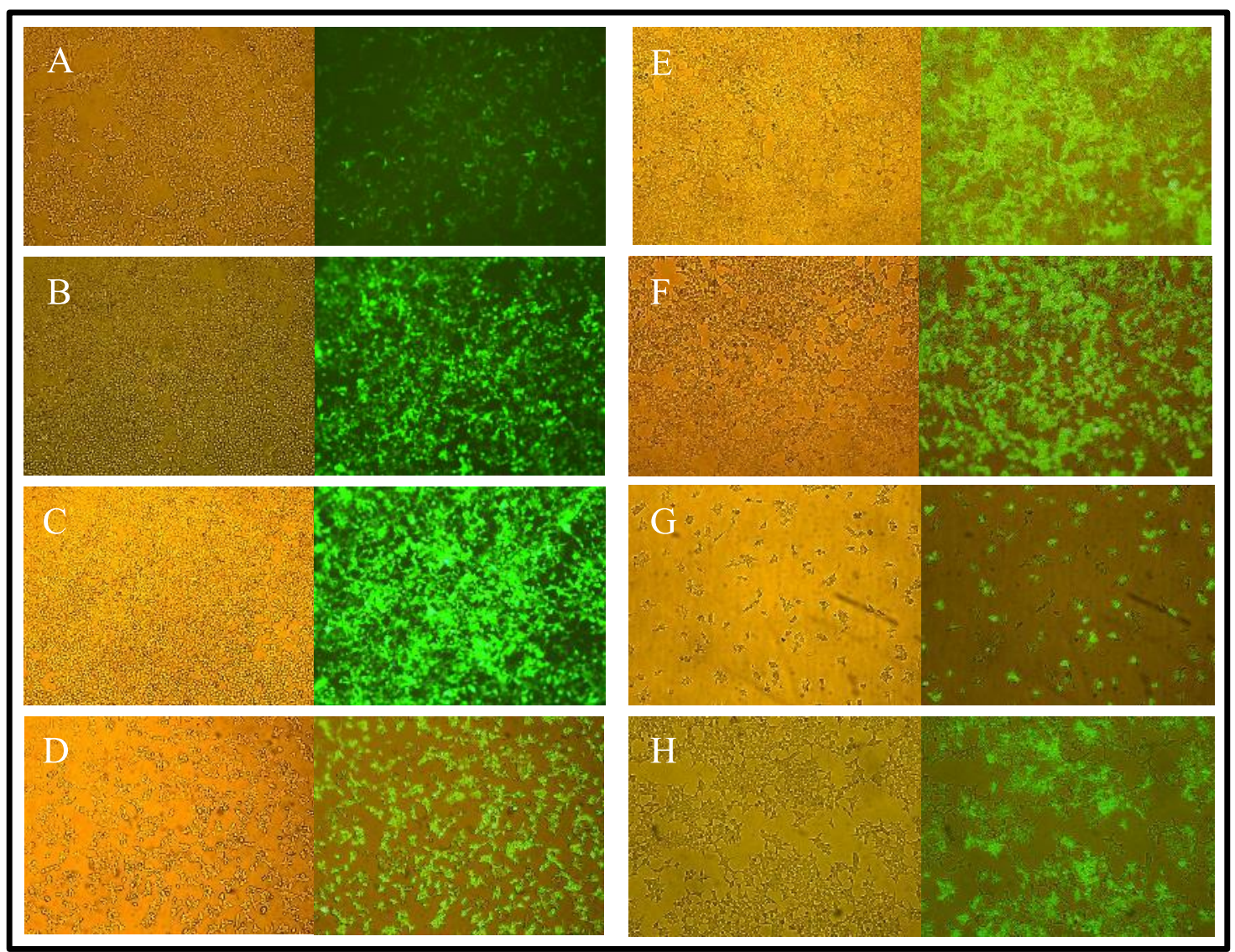

Figure 14. Time series monitoring brightfield and eGFP expression post-transduction of HEK293T/17 transduced with lentivirus containing pll3.7 over 10 days.

A) 24 hours B) 48 hours C) 72 hours D) 96 hours E) 144 hours F) 192 hours G) 216 hours H) 240 hours

\subsection{Results IV: Transduction of Bovine cells associated with embryo culture using GFP lentiviral particles}

\subsubsection{Transduction of Bovine fibroblast cells with eGFP lentivirus}

Bovine Fibroblast cells, among other bovine cells, were a by-product of embryo culture/ culture of oocytes. As another method of testing the efficacy of the lentiviruses in bovine cells, we transduced these fibroblasts with $10 \mu \mathrm{L}$ concentrated lentiviral particles containing pll3.7 (an eGFP expressing plasmid packaged by lentiviral particles) and monitored the expression of eGFP in the following days. 
Figure 15 shows bovine fibroblasts 36 hours after transduction. Fibroblasts were exhibiting eGFP expression, confirming successful transgene integration by lentiviral particles.

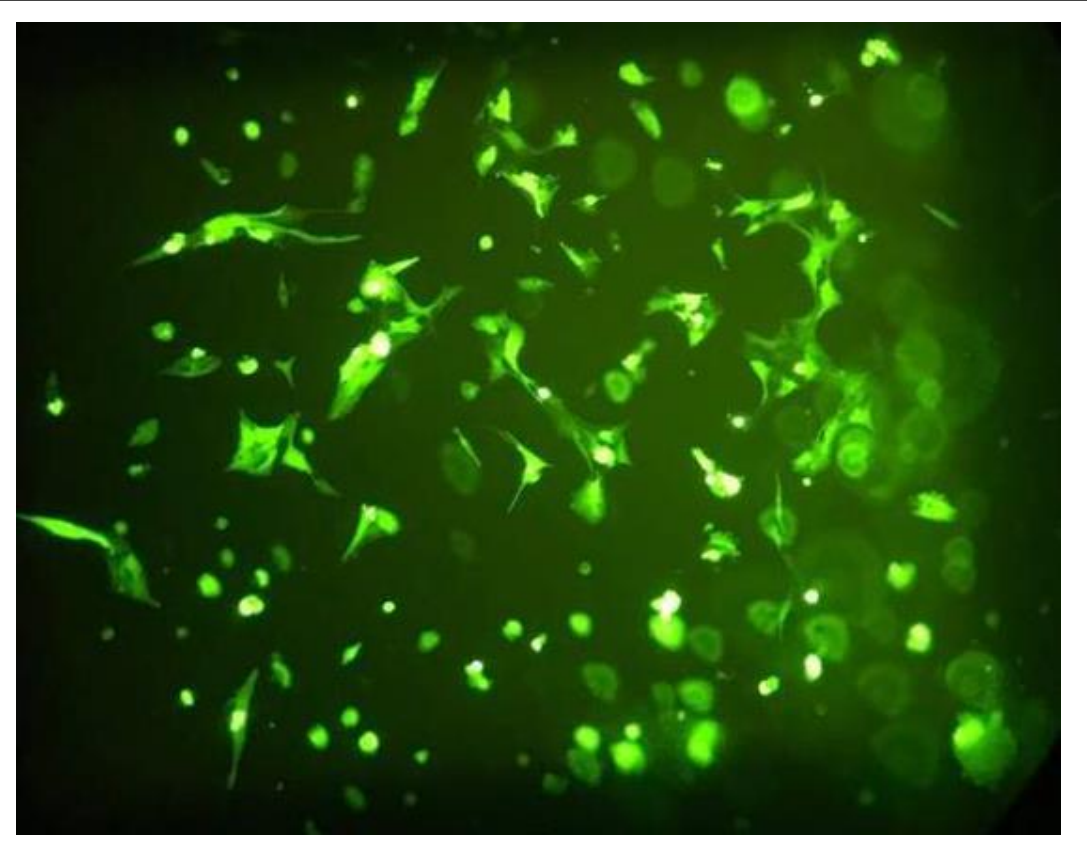

Figure 15. Bovine Fibroblast cells showing expression of eGFP following transduction with lentivirus containing p/l3.7

\subsubsection{Lentiviral transduction of Cumulus oocyte complex cells}

As another method of testing the pll3.7 lentiviral particles in bovine cells, lentivirus was incubated with cumulus-oocyte-complexes (COCs) in an attempt to integrate eGFP into the oocyte or cells surrounding the oocyte. After aspiration from the ovary, excess cells were stripped from the oocyte leaving the oocyte and closely attached cells. $10 \mu \mathrm{L}$ of concentrated virus containing pll3.7 was added to media droplets containing 4-5 COCs, and GFP expression was monitored in the following days. Figure 16 shows COCs $36 \mathrm{~h}$ after transduction with lentiviral particles containing pll3.7. Positive eGFP expression was observed in each COC transduced with lentivirus, however not all cells were transduced nor was the oocyte itself. This could be due to inaccessibility of cells and/or insufficient titer. 


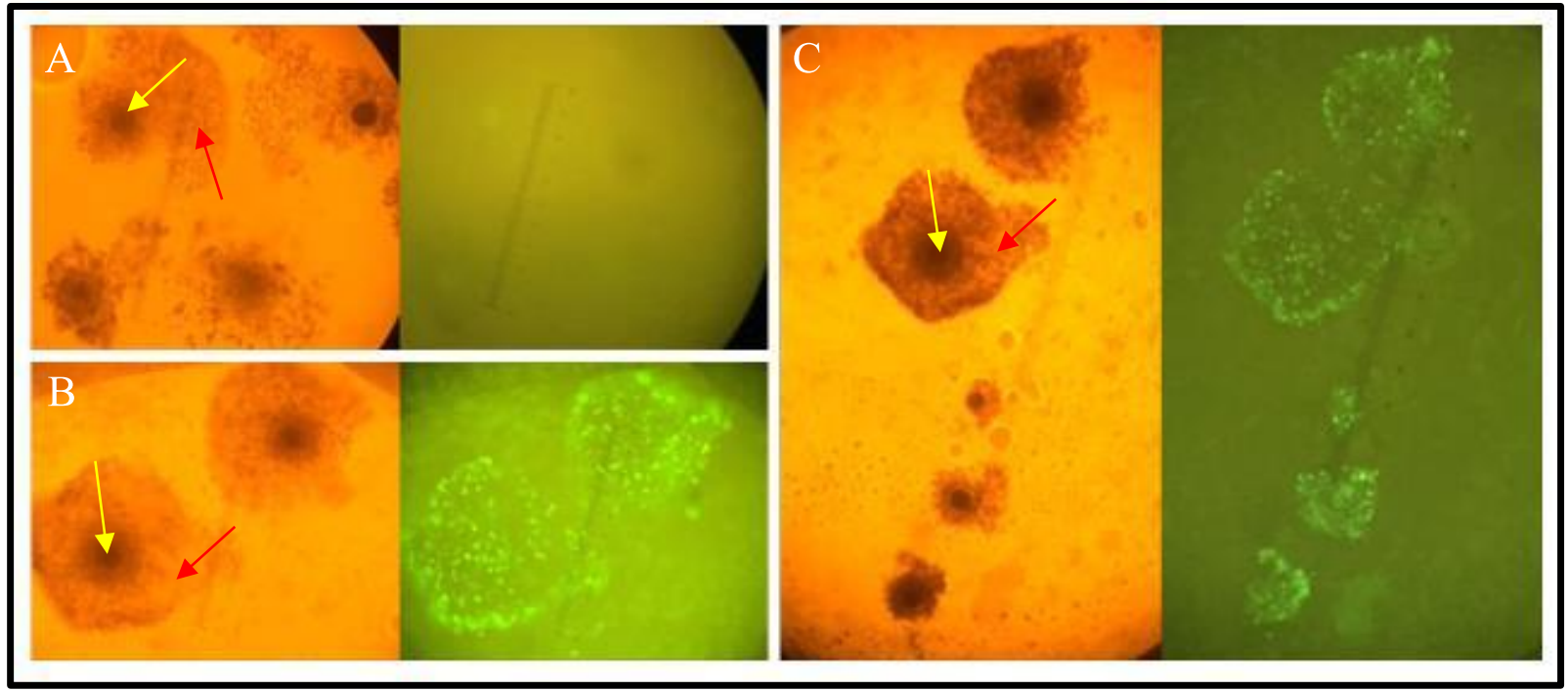

Figure 16. Cumulus-Oocyte complex cells showing positive eGFP expression following transduction with lentiviral particles containing pll3.7.

Red arrows indicate cumulus cells, yellow arrows indicate oocytes A) negative control B) pll3.7 lentiviral particles, 10x magnification C) pll3.7 lentiviral particles, $4 x$ magnification

\subsubsection{Lentiviral transduction during fertilisation}

To see if transgenes could be integrated into oocytes without affecting the zona pellucida, $10 \mu \mathrm{L}$ of concentrated lentiviral particles containing pll3.7 was supplied when sperm was added during in vitro fertilization.

In tests where higher concentration of lentivirus was added, eGFP expression was localized to most cumulus cells, particularly those with high sperm counts around them, this is shown in figure 17. In tests with lower concentrations of virus added, eGFP expression was localized to more central areas in the COC, often directly surrounding the oocyte as can be observed in figure 18. We attributed this to sperm travelling toward the oocyte carrying virus through cumulus cells. 


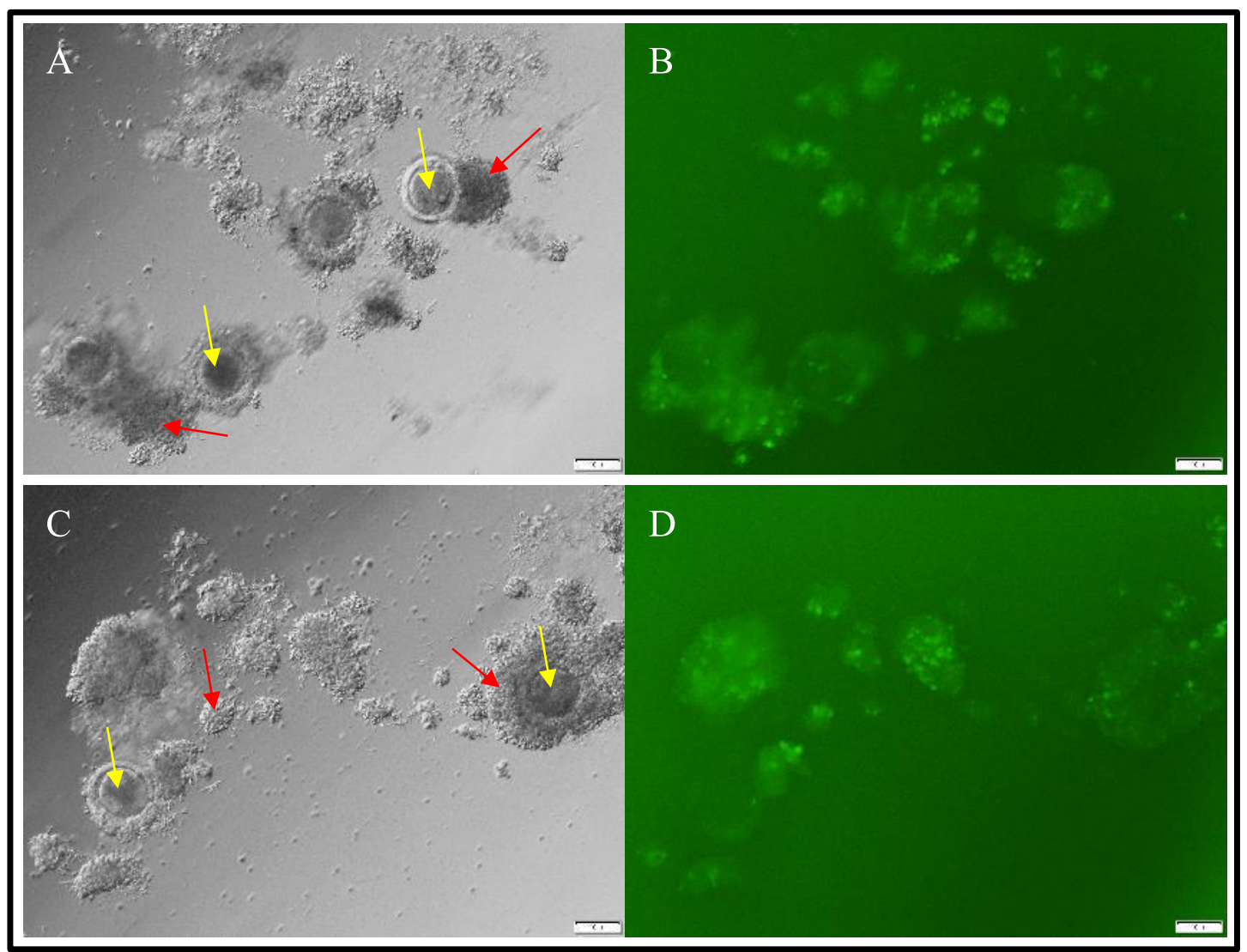

Figure 17. Bovine Cumulus-oocyte complexes transduced with higher concentration lentivirus ( $10^{9} \mathrm{TU} / \mathrm{mL}$ ) containing pll3.7 at time of fertilisation with bull sperm.

Red arrows indicate cumulus cells, yellow arrows indicate oocytes. A) brightfield B)

fluorescence analysis C) brightfield D) fluorescence analysis

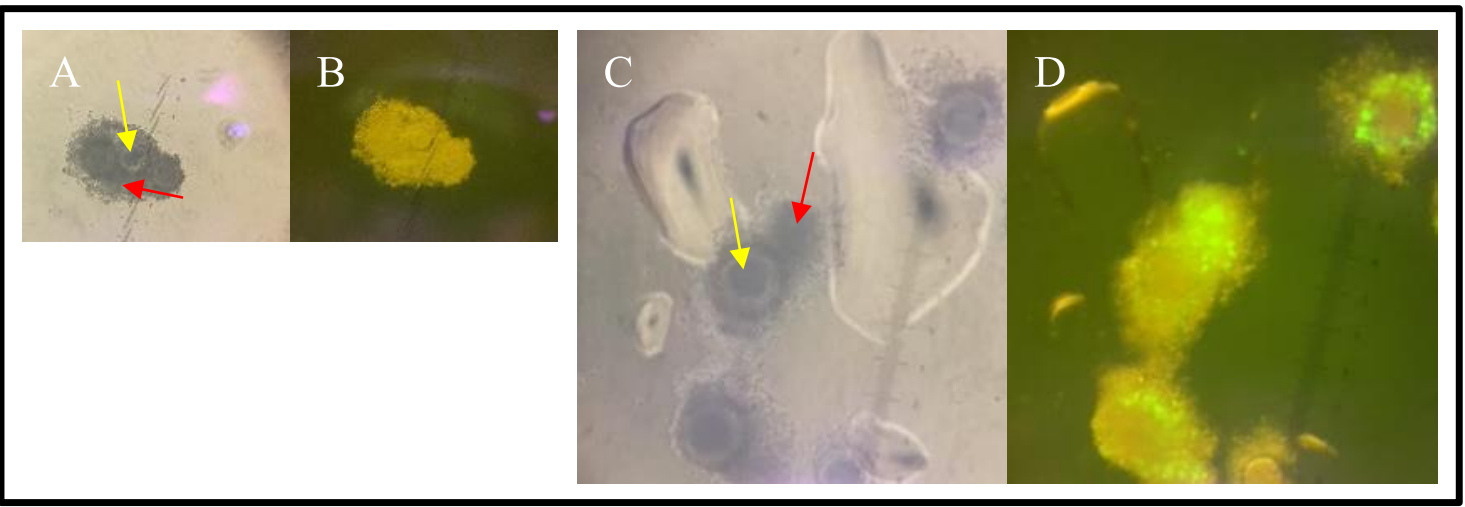

Figure 18. Bovine Cumulus-oocyte complexes transduced with lower concentration lentivirus ( $\left.10^{7} \mathrm{TU} / \mathrm{mL}\right)$ containing pll3.7 at time of fertilisation with bull sperm.

Red arrows indicate cumulus cells, yellow arrows indicate oocytes. A) negative control (no transduction), brightfield $B$ ) negative control (no transduction), fluorescence analysis $C$ ) test (pll3.7 transduction), brightfield D) test (pll3.7 transduction), fluorescence analysis 


\subsection{Results V: Removal of zona pellucida from bovine embryos}

The zona pellucida surrounding oocytes/embryos caused lentiviral transductions in early experiments to fail, thus it was necessary to develop a method of either getting the virus underneath the zona or removing it altogether. As we did not have access to a micro-manipulator, microinjection of our lentiviral particles under the zona was not an option. The next strategy was to remove the zona by protease digestion.

\subsubsection{Pooled protease digestion of zona pellucida}

Digestion of the zona pellucida was done alongside Kate Isaac, who assisted with much of the embryo manipulation and care. Initial pooled tests showed successful digestion (Figure 19), however, issues arose using this method. Using the pooled digestion method embryos tended to become either over- or under-digested. With large amounts of variation, it became difficult to produce a consistent level of digestion. Over-digested embryos became prone to blastomere separation, while under-digested embryos showed no signs of transduction by lentiviral particles.

In initial protease treatments, early stage (2-6 cell) bovine embryos were incubated in $\mathrm{HSOF}+0.2 \%$ Protease and changes in the zona structure monitored. We observed an expanding and thinning of the zona followed by eventual disappearance. Embryo culture following protease treatment using this method yielded mostly digested embryos that did not survive treatment, with some embryos showing little signs of digestion. The variable levels of zona digestion can be seen in figure 19 . Note how certain embryos have become severely digested, whereas others have had little change in zona structure. 


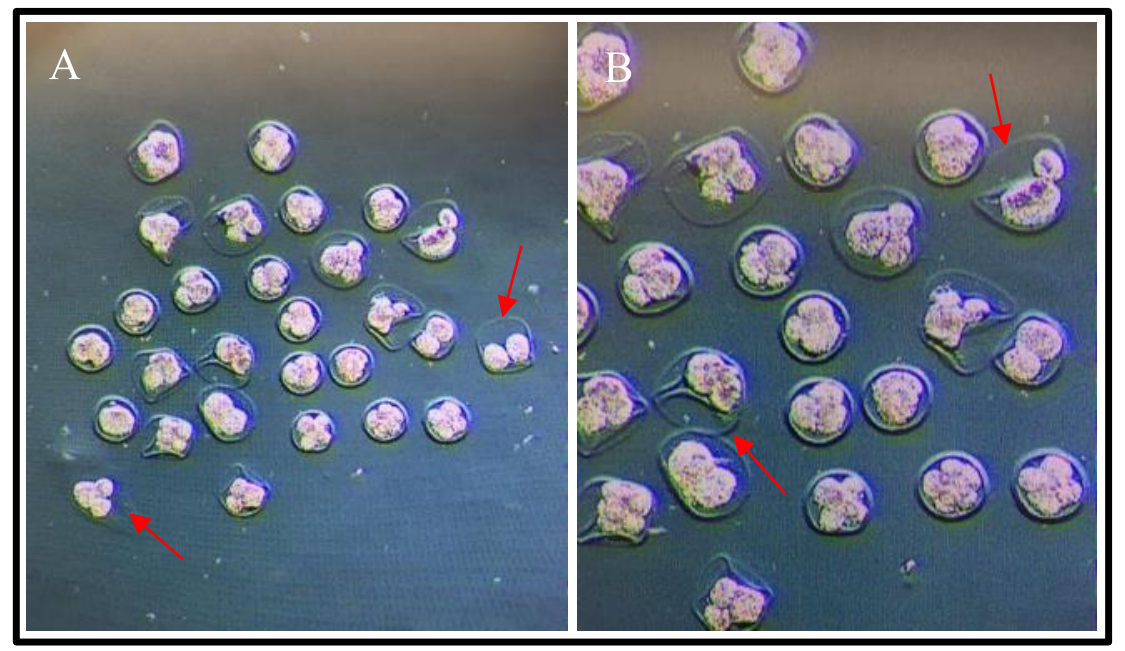

Figure 19. Pooled treatment of $0.2 \%$ protease on bovine embryos.

Arrows indicate zona pellucida thinning and digestion A) 4x Magnification B) 10x Magnification

\subsubsection{Timed protease digestion on early stage embryos}

After difficulty establishing consistent zona removal using the pooled method, we attempted to digest smaller groups of embryos for set time periods and treat each group with $10 \mu \mathrm{L}$ concentrated lentiviral particles containing pll3.7.

Initially the timed trials were performed on 1-2 cell embryos. Early stage embryos tended to fall apart more, this can be seen in figure 20 . We attributed this to be a result of early cell-cell junctions vs stronger/ more complex junctions at compaction. Once compaction commences at about the 16-cell stage, outer cells form tight junctions, but will also preclude inner cells from being transduced by lentiviruses. 


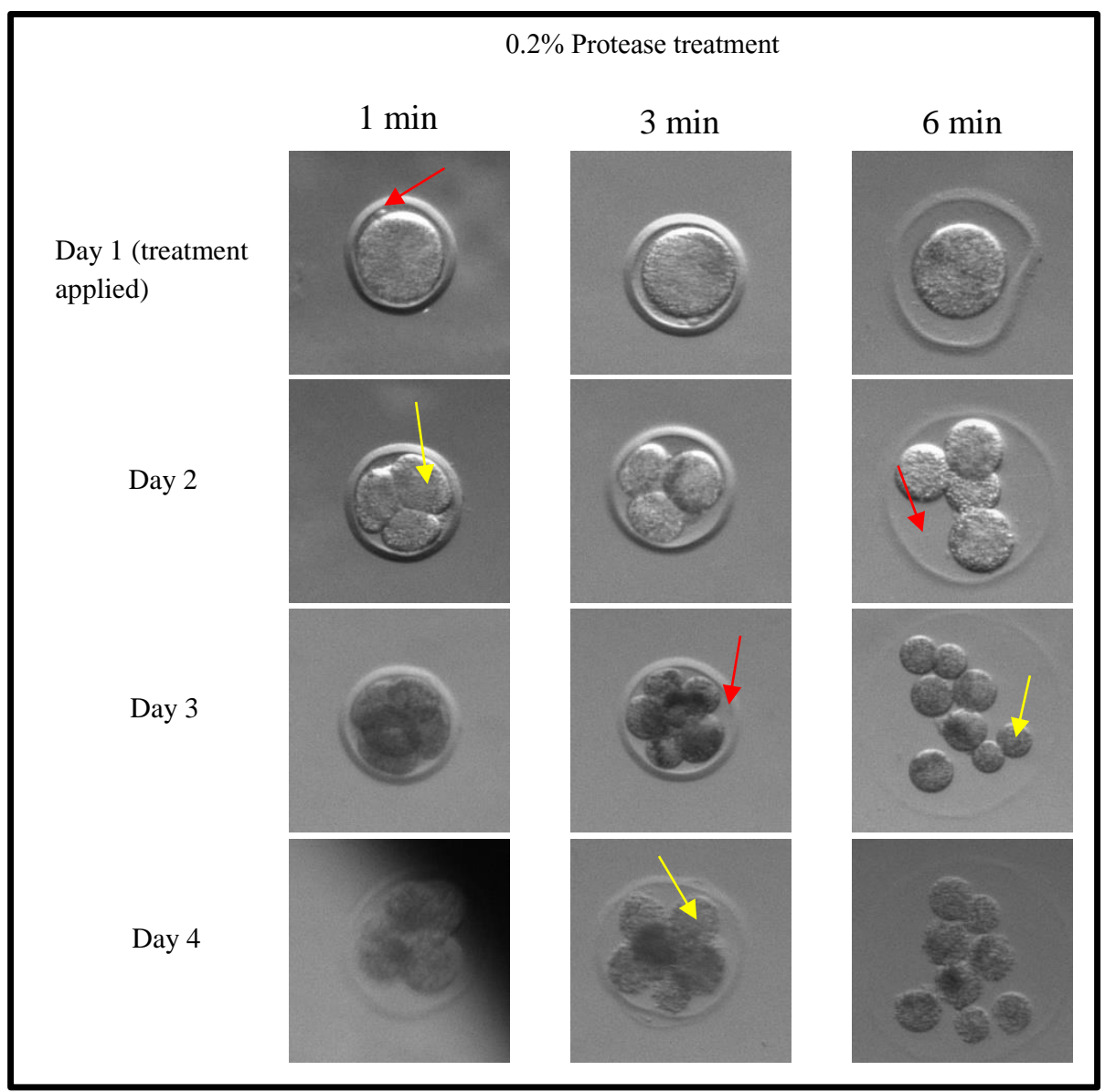

Figure 20. 4-day monitoring of bovine embryos treated with $0.2 \% \mathrm{w} / \mathrm{v}$ protease for lengths of 1 minutes, 3 minutes and 5 minutes.

Red arrows indicate zona pellucida, yellow arrows indicate blastomeres.

\subsubsection{Timed protease digestion on compact morulas}

After tests with early stage embryos yielding low survival rates, we thought we might have more success digesting the zona at a later stage of development, when cell-cell junctions had become more complex such as during compaction. To test this, embryos were taken from incubators and placed in droplets with $0.2 \% \mathrm{w} / \mathrm{v}$ protease. After monitoring zona digestion, embryos were taken out in groups of 3 at set intervals 1 min after the first group had been removed ( 7 minutes).

Figure 21 shows the effects of different time treatments of $0.2 \% \mathrm{w} / \mathrm{v}$ protease on compact morulas. Zona thinning and expansion can be observed in the 7 
minute group. In the 8 minute group the Zona has become thinner and more expanded, with more distortion in shape. By 9 minutes the zona has become so expanded and thin it is almost transparent, and by 10 minutes it has disappeared.

7 minutes $\mathrm{HSOF}+0.2 \%$

Protease
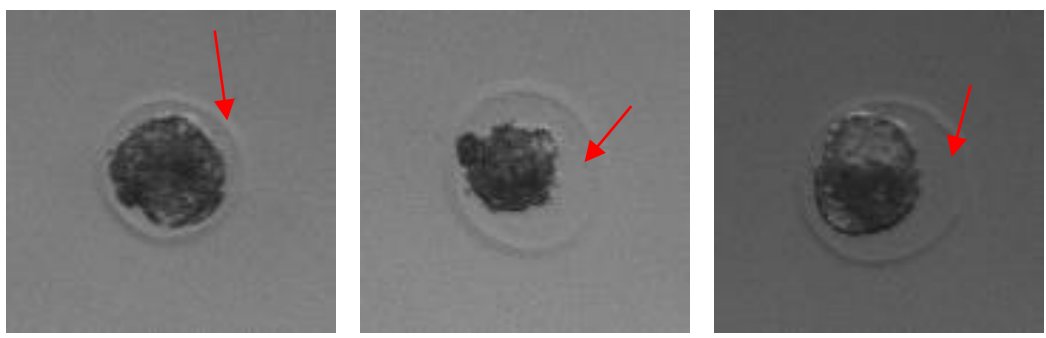

8 minutes

$\mathrm{HSOF}+0.2 \%$

Protease
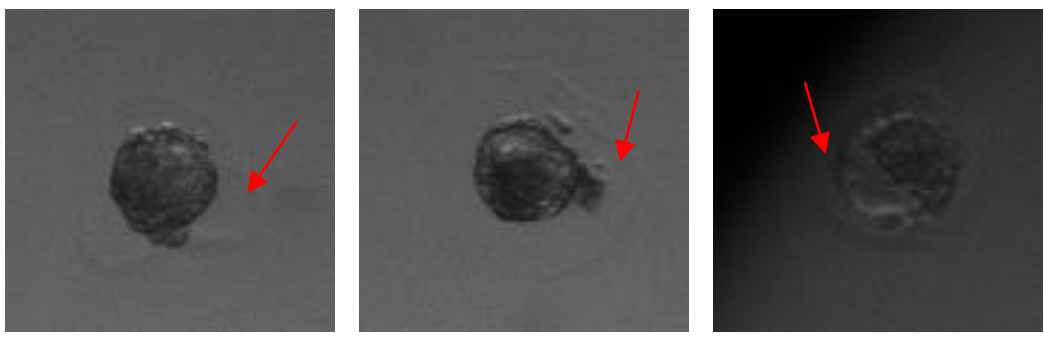

9 minutes $\mathrm{HSOF}+0.2 \%$

Protease
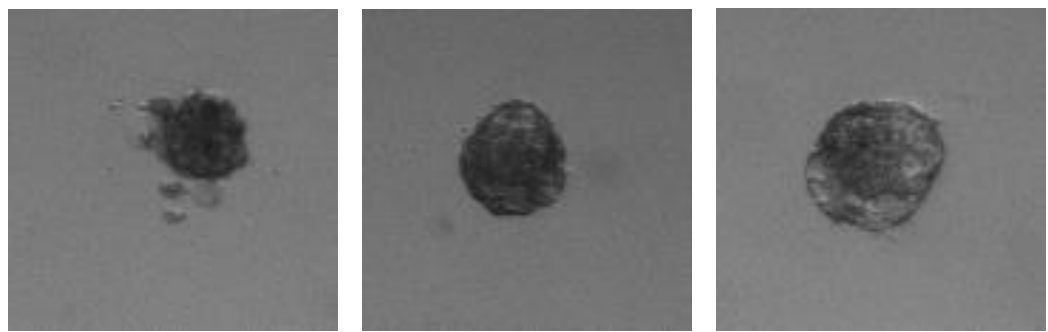

10 minutes

$\mathrm{HSOF}+0.2 \%$

Protease
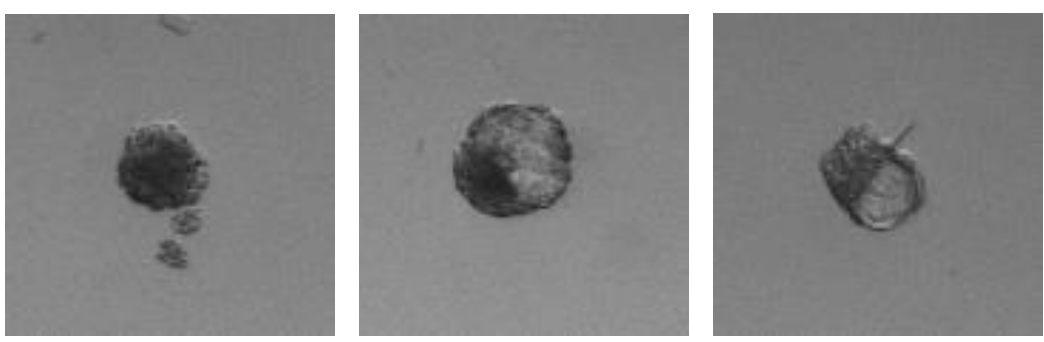

Figure 21. Groups of bovine compact morulas treated with varying exposure times to $0.2 \%$ protease. Red arrows indicate zona, note absence in 9-10 minute groups 


\subsubsection{Lentiviral Transduction of protease-treated embryos}

24 hours after the timed protease treatment and lentiviral transduction of 12 bovine compact morulas in groups of 3 , fluorescence microscopy analysis showed that treatment with $0.2 \% \mathrm{w} / \mathrm{v}$ protease for $8-10$ minutes yielded the best transduction efficiencies. Interestingly this group of 12 morulas also had the highest rate of embryo survival at $83.7 \%$ (10/12 embryos) after protease treatment.

Figure 22 depicts embryos exposed to $0.2 \% \mathrm{w} / \mathrm{v}$ protease for 8 minutes exhibiting faint eGFP expression in trophectoderm cells compared with controls. Compact morulas treated with $9-10$ minutes of $0.2 \% \mathrm{w} / \mathrm{v}$ protease showed considerably higher expression of eGFP than morulas treated with protease for shorter time periods, with cells in the Inner Cell Mass (ICM) also exhibiting expression. This large increase in eGFP expression is assumed to be the result of easier access to the embryo for viral particles due to the mostly/completely digested zona pellucida. 


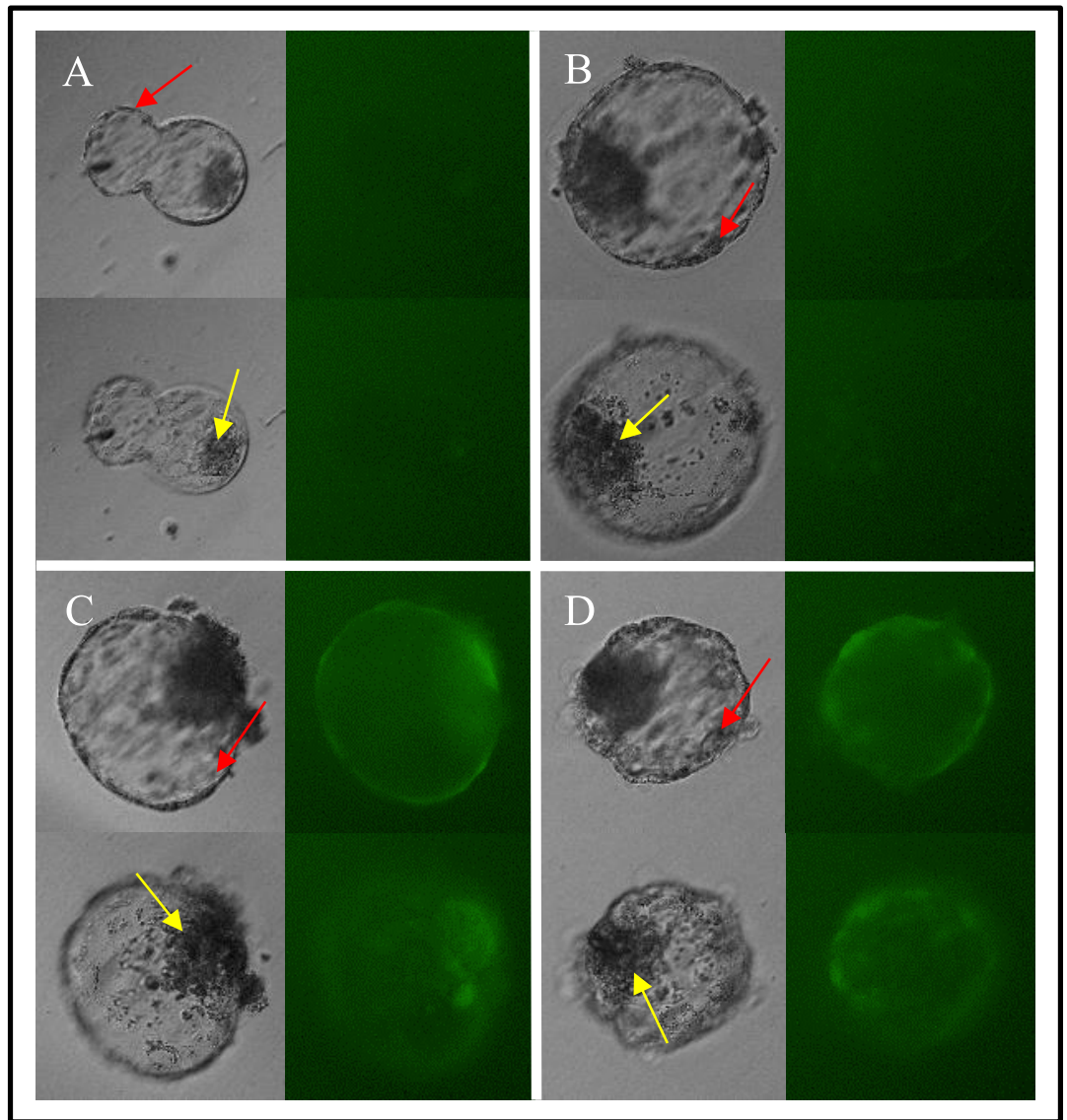

Figure 22. Bovine blasts expressing eGFP following $0.2 \%$ protease digestion of zona and lentiviral transduction during morula stage.

Top fields focus on trophectoderm cells (red arrows), bottom field focus on the inner cell mass (yellow arrows) A) Negative control B) 8 minute exposure C) 9 minute exposure D) 10 minute exposure

\subsection{Results VI: Co-transfection of GFP-HEK293T/17 with Cas9 and eGFP-} SgRNA

To test the Cas9 system, the eGFP gene was targeted for knock-out (see figures 23 and 24). For this experiment the eGFP-expressing cells created in Section 3.3 (Fig. 13) were co-transfected with plasmids encoding the Cas9-mCHERRY fusion and sgRNA targeted to eGFP, respectively.

Fluorescence microscopy assays over the following days revealed increasing numbers of cells that exhibited positive expression of MCHERRY (indicating that the expression plasmid encoding the Cas9-Cherry fusion had entered and was expressed in these cells) 
but no expression of eGFP, indicating that eGFP expression has been interrupted by Cas9 binding via eGFP-sgRNA.

Figures 23 and 24 show examples of cells exhibiting mCHERRY expression without eGFP expression. Many are surrounded by green cells, of which the daughter cells should express eGFP. This is a good indication that these cells obtained enough DNA encoding Cas9 and eGFP-sgRNA to excise the gene, causing a lack of eGFP expression. Though this is a good indication, further analysis needs to be done to be certain. This is due to the fact that this was a mixed population of host cells, thus some did not express eGFP in the first place. While greater than $90 \%$ of cells expressed eGFP, a more efficient knock out of eGFP is needed ensure Cas9 activity.

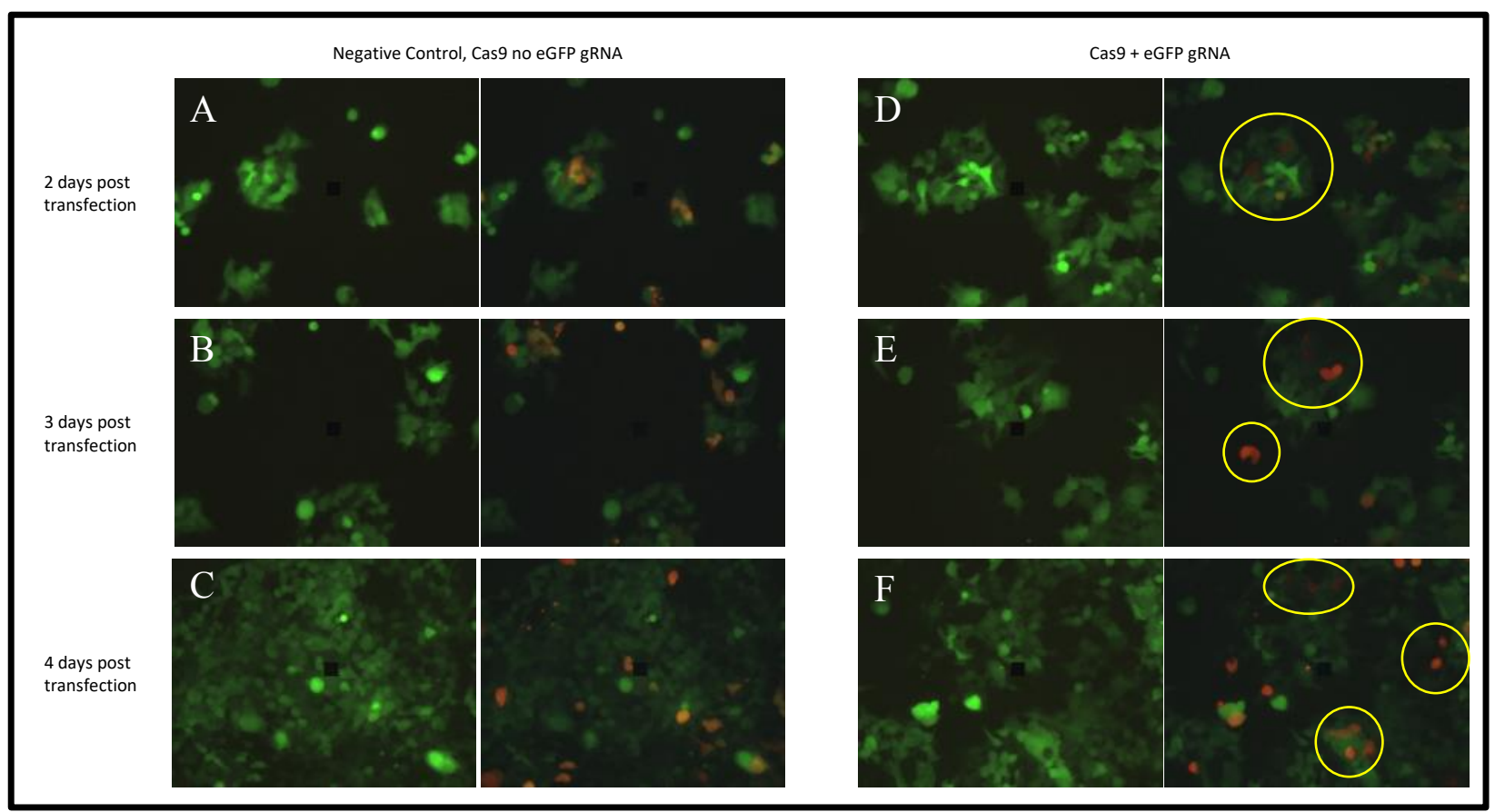

Figure 23. eGFP and mCHERRY analysis of HEK293T cells over 4 days post transfection with pLENTI-CRISPR-mCHERRY and eGFPsgRNA.

Circled areas on right panels highlights cells expressing $M C H E R R Y$ and lacking eGFP expression. A) Control, transfected with pLENTI-CRISPR-mCHERRY, 48 hours post transfection B) Control, transfected with pLENTI-CRISPR-mCHERRY, 72 hours post transfection C) Control, transfected with pLENTI-CRISPR-MCHERRY, 96 hours post transfection D) Test, transfected with pLENTICRISPR-mCHERRY and eGFP-sgRNA, 48 hours post transfection E) Test, transfected with pLENTI-CRISPR-mCHERRY and eGFPsgRNA, 72 hours post transfection F) Test, transfected with pLENTI-CRISPR-mCHERRY and eGFP-sgRNA, 96 hours post transfection 


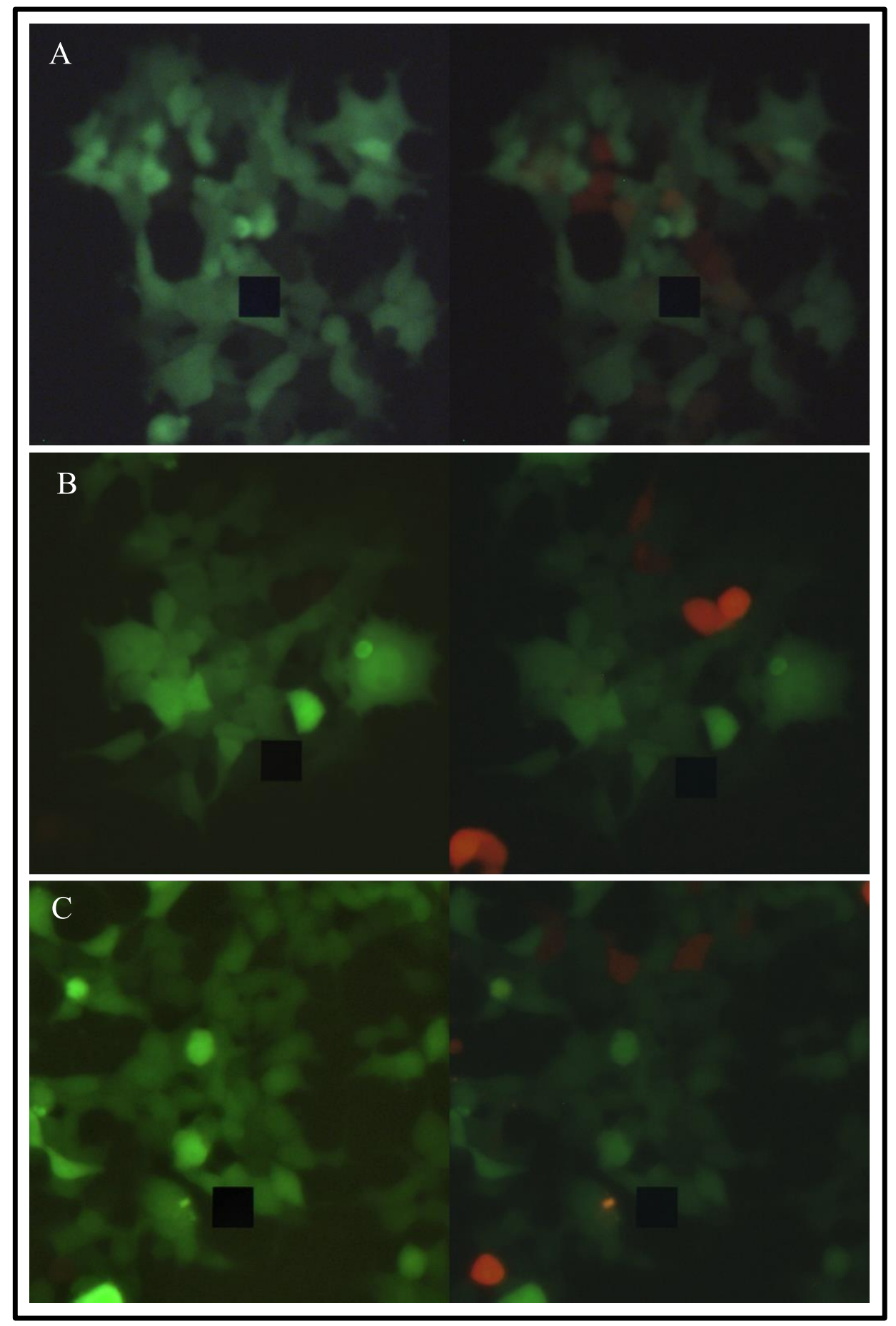

Figure 24. Close-up eGFP and mCHERRY analysis of HEK293T after transfection with pLENTICRISPR-MCHERRY and EGFP-sgRNA

A) 48 hours post transfection B) 72 hours post transfection C) 96 hours post transfection 


\subsection{Results VII: Production of Lentiviral particles containing Cas9 expressing}

plasmid

Production of Cas9 plasmid-containing lentivirus was difficult due to transfection issues. When first transfecting cells with pLENTI-CRISPR-mCHERRY and packaging plasmids, the transfection protocol we had optimised yielded efficiencies of $<50 \%$ (see figure 25). When titering the Cas9 lentiviral particles using HEK293T cells (see protocol 2.5.2), low yields were observed with early runs producing titers $<10^{4} \mathrm{TU} / \mathrm{mL}$. Research has shown that transfection of large plasmids ( $11 \mathrm{kB}+$ ) in human cells can result in low transfection efficiencies (Campeau, et al., 2001), and thus the low titers we observed were attributed to poor transfection efficiencies. Towards the end of the Master's research, transfection efficiencies of $70 \%$ were achieved by increasing DNA concentration of transfer plasmids (30-35 $\mu \mathrm{g}$ for $10 \mathrm{~cm}$ plates) while lowering the concentrations of packaging plasmids by $20 \%$ each, thus we were confident higher titers of pLENTI-CRISPR-mCHERRY virus could be achieved. Figure 26 exhibits the low transduction efficiencies witnessed over 3 days after transduction with pLENTI-CRISPR-mCHERRY. Despite low transduction efficiency, the increase in mCHERRY fluorescence is a good indication that the transfer material has been integrated into the host cell genome, though further testing is required to confirm this. 


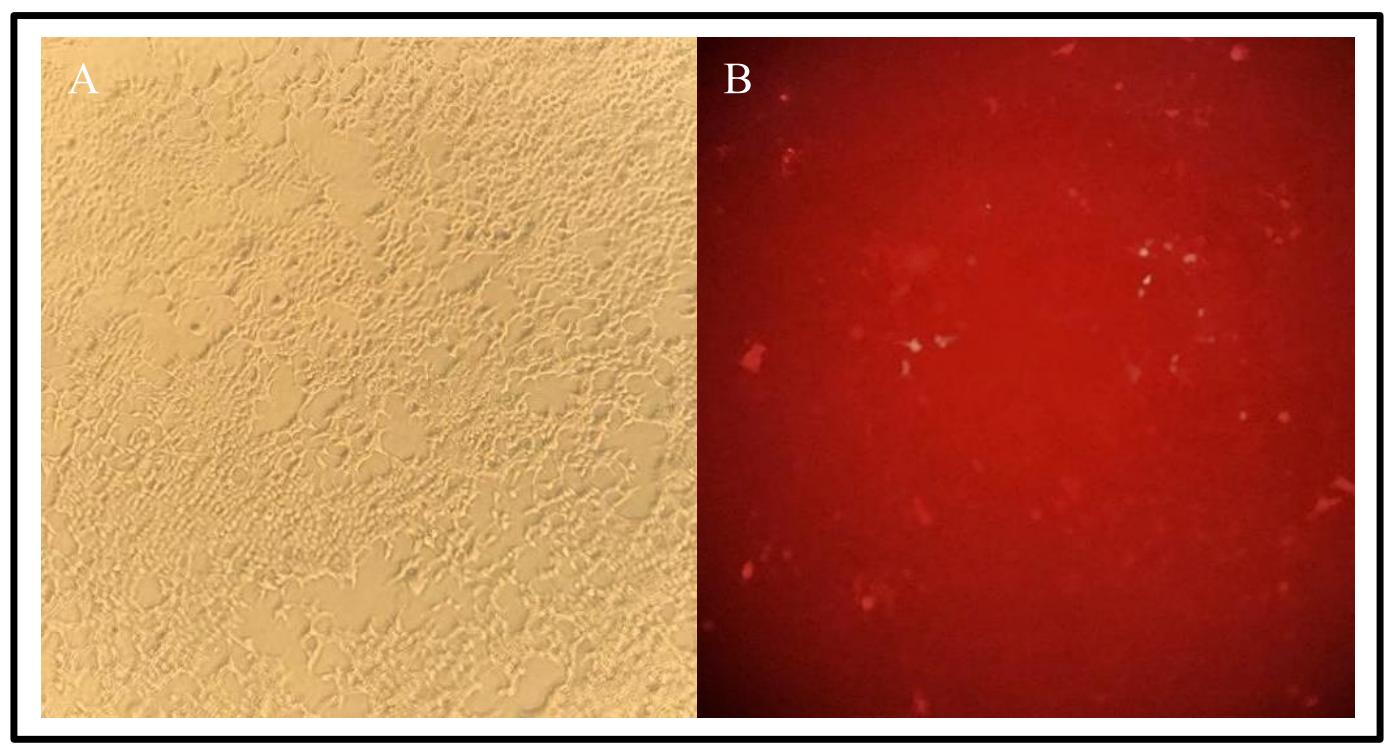

Figure 25 HEK293T cells transfected with $20 \mu \mathrm{g}$ pLENTI-CRISPR-mCHERRY, $16 \mu \mathrm{g}$ psPAX2 and $6 \mu \mathrm{g}$ pMD2.G using optimised calcium phosphate transfection method.

A) Brightfield B) $m C H E R R Y$ fluorescence analysis

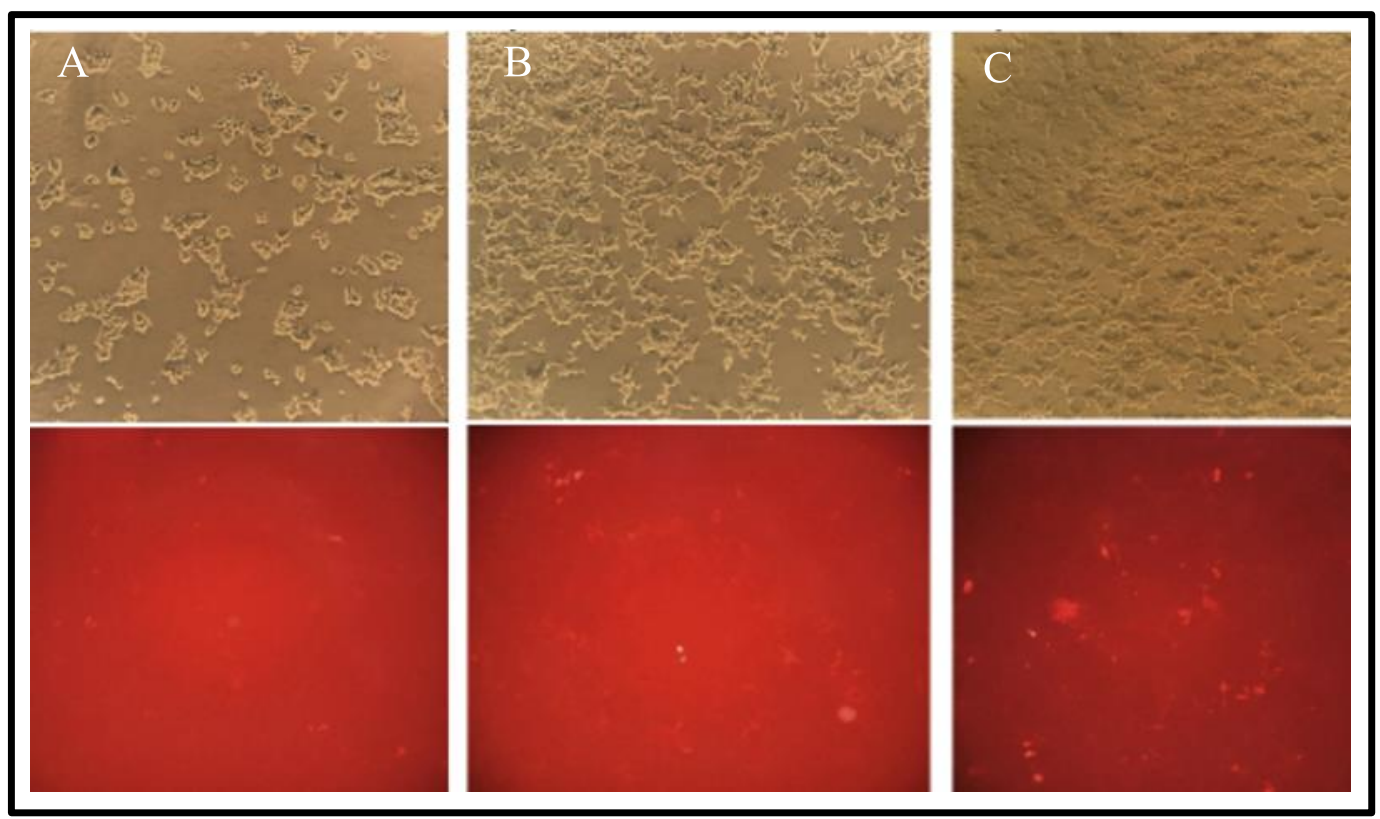

Figure 26. HEK293T/17 cells transduced with lentiviral particles containing pLENTI-CRISPR-mCHERRY A) 24 hours post transduction A) 48 hours post transduction C) 72 hours post transduction 


\subsection{Results VIII: Production of Cas9/sgRNA-bGATA6 plasmid}

To create a plasmid containing Cas9 and an sgRNA targeting bovine GATA6, the pLENTI-CRISPR-mCHERRY plasmid needed to be modified and the bGATA6 sgRNA sequence ligated in. Starting with the original pLENTI-CRISPR-mCHERRY vector, the filler sequence was excised by digestion with the restriction enzyme BsmBI. BsmBI digestion leaves non-compatible ends $3^{\prime}$ downstream from the recognition sequence with 'sticky' (4 base pair 5') overhangs (see figure 27). Non-compatibility encourages proper insertion of the oligo, while overhangs encourage ease of insertion.

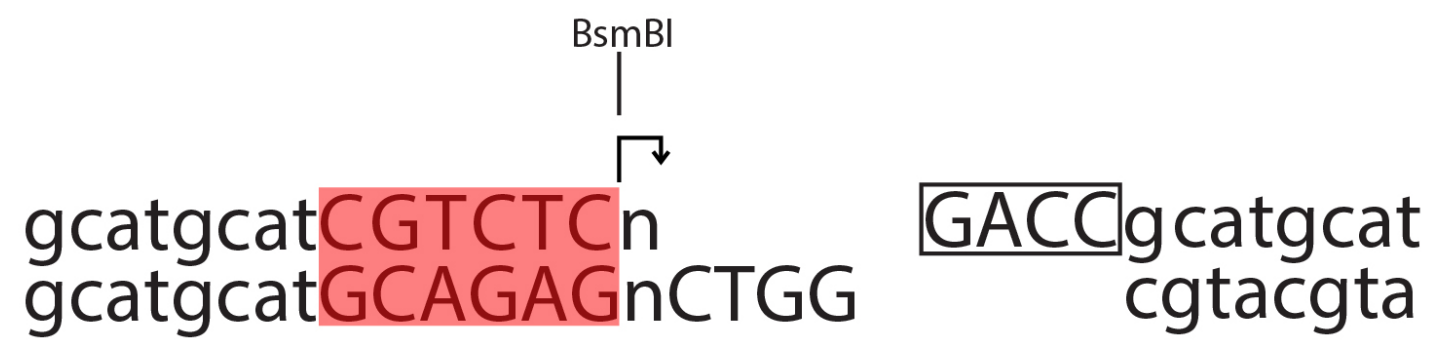

Figure 27. diagram depicting the cleavage of DNA by BsmBI digestion (Berkley University of California, n.d.)

After digesting the pLENTI-CRISPR-mCHERRY vector plasmid, the main sequence of the vector was isolated from the filler sequence using agarose gel electrophoresis, from which it was then extracted. After annealing the forward and reverse strand of the bGATA6-sgRNA oligos, the double stranded oligo, now containing 5' overhangs compatible with the respective overhangs left after BsmBI digestion of the vector backbone, was ligated into the digested pLENTI-CRISPR-mCHERRY vector. Many ligation attempts failed, resulting in the need to analyse the ligation and transformation parameters to ensure all elements were functioning properly.

\subsubsection{Ligase test}

To ensure the ligase was not the problem in failed ligation experiments, a test was done on the TaKaRa ligation mix compared to a T4 DNA ligase obtained from an adjacent laboratory. Figure 28 shows an agarose gel containing wells with an uncut pLENTI-CRISPR-mCHERRY as a control, pLENTI-CRISPR-mCHERRY 
digested with BsmBI and pLENTI-CRISPR-mCHERRY digested with BsmBI then treated with either Ligase. As both ligases indicated successful ligation by disappearance of the fragment band and shifting of the vector fragment to uncut level, the TaKaRa Mighty Mix (protocol 2.2.6.10) was ruled out as the problem with ligations.

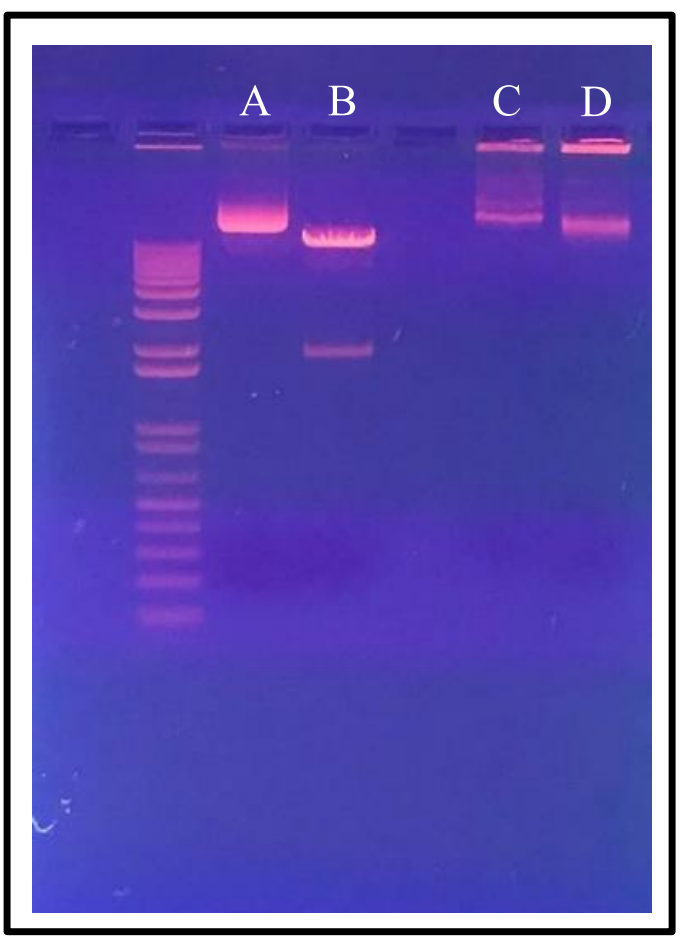

Figure 28. Agarose gel electrophoresis showing ligation of filler sequence back into PLENTI-CRISPR-MCHERRY

A) Uncut control B) digested with $B s m B I C$ ) digested with $B s m B I$ then treated with TaKaRa mighty mix D) digested with $B s m B I$ then treated with T4 DNA ligase 


\subsubsection{Colony Forming Unit calculation}

The next step in solving ligation issues was to test the $E$. coli we were transforming our ligation products into. To did this, we measured the colony forming units per microgram of DNA added to cells.

Performing a colony forming unit assay (protocol 2.6.10) revealed that chemically competent $E$. coli stocks yielded $\sim 1 \times 10^{5} \mathrm{CFU} / \mathrm{ug}$, this count was considered too low and likely to be the problem with failed ligations.

After discovering low $\mathrm{CFU} / \mathrm{mL}$ count, new chemically competent 'One Shot' E.coli were ordered. Subsequent CFU assay revealed $10^{9} \mathrm{CFU} / \mathrm{ug}$ DNA. This higher CFU count was a much more appropriate result for ligation experiments.

\subsubsection{Agarose gel electrophoresis of prospect ligation success}

While many of the ligation attempts failed, ligation attempts using new 'One Shot' E. coli yielded colonies after transformation. After analysis of 36 colonies, only the $31^{\text {st }}$ colony exhibited a band that indicated successful ligation (Band in the 620 bp region). Figure 29 depicts an agarose gel with plasmid isolated from prospect successful ligations from colonies 25, 27, 29, 30, 36, 31, 32, 34 and 35. Colonies outside these nine all yielded fragments representing the filler sequence and were therefore removed from subsequent tests. The arrow in Figure 29 A) highlights the band in the 620 bp region, potentially representing successful ligation of our fragment. Figure 29 B) shows BsmBI digestion of our ligation product in well 4 , and BsmBI digestion of the original pLENTI-CRISPRmCHERRY plasmid in well 5, highlighting the removal of filler sequence and potential replacement by the bGATA6-gRNA ligated in.

The plasmid derived from colony 31 was amplified and sent to Waikato DNA Sequencing Facility at the University of Waikato for sequence analysis at the end of the Master's research. 


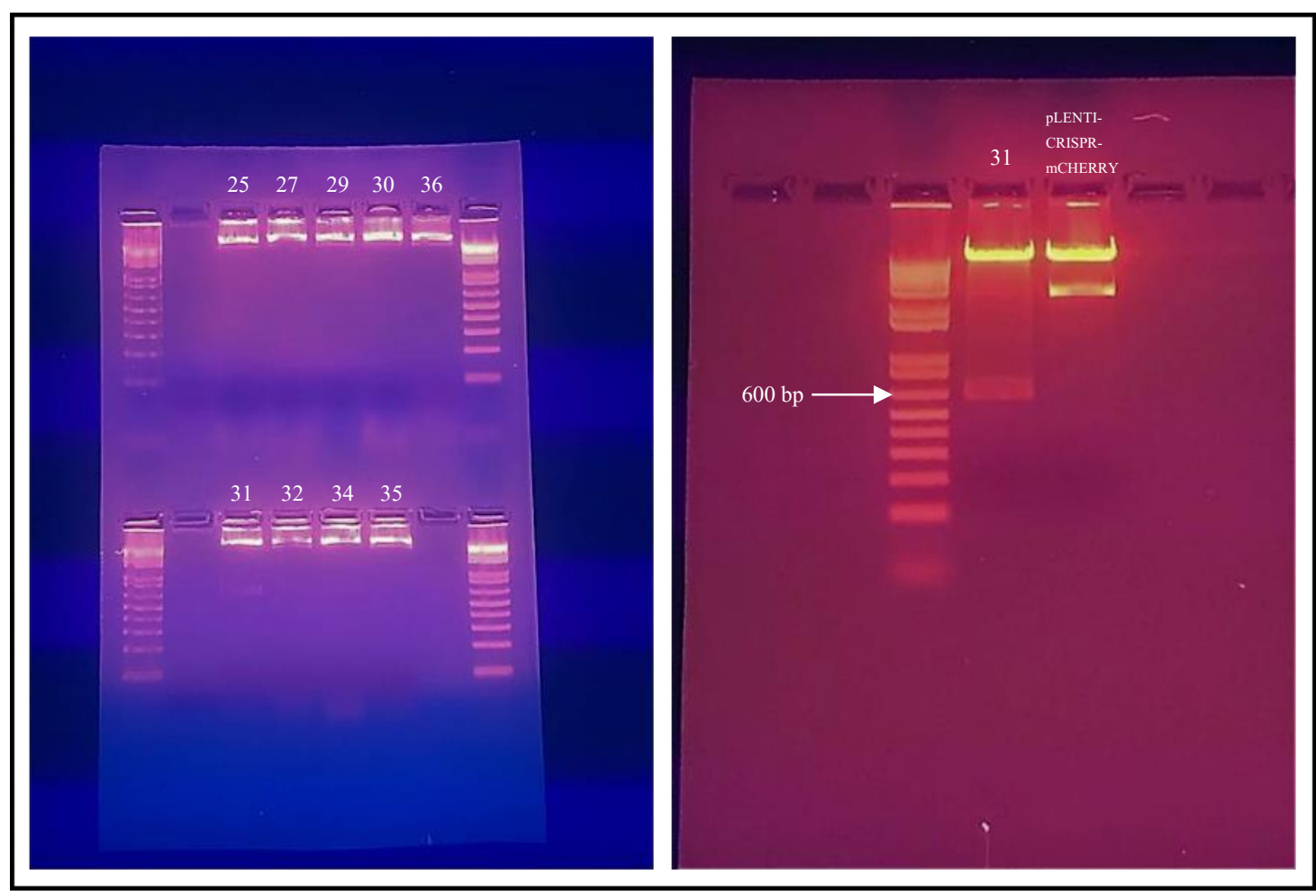

Figure 29. A) Agarose gel of plasmid DNA isolated from ligation colonies

TOP 25, 27, 29, 30 BOTTOM 31, 32 ,34, 35. Band at 620 indicated by arrow B) Agarose gel analysis showing lane 1) DNA ladder 2) plasmid DNA isolated from colony 34, digested with BsmBI 3) pLENTI-CRISPR-mCHERRY digested with BsmBI 


\section{Chapter 4 - Discussion}

\subsection{General Discussion}

Production of transgenic livestock is becoming a more extensively studied field as the capacity and efficiency of genetic editing tools has increased (Whitworth, et al., 2014; Crispo, et al., 2015). Livestock are an important aspect of agriculture, providing much of the food and milk we consume in New Zealand and worldwide. Cattle are one of New Zealand's main livestock sources and supply our economy with large incomes, such as the $\$ 6.7$ billion New Zealand red meat exports made over the 2017-2018 period (Beef + Lamb New Zealand, 2018). The use of CRISPR/Cas9 systems as a means of genetic editing is becoming one of the most popular methods due to its specificity and potential ease of application. Use of CRISPR/Cas9 systems in generation of transgenic cattle has been reported (Gao, et al., 2017), yet research utilizing lentiviral delivery of CRISPR/Cas9 to bovine embryos is still a relatively new field. Our research aimed to create a novel lentivirus particle that was capable of infecting and genetically modifying a developing bovine embryo. Subsequent experiments aimed to produce a lentiviral particle containing a plasmid expressing Cas9 and an associated sgRNA targeting bovine GATA6. As a micromanipulator was unavailable to perform microinjection of lentiviral particles under the zona pellucida, protease digestion was explored as an alternative method delivering lentivirus to the embryo.

Genetic modification in our research refers to two events. Firstly, the integration of transgenic material by reverse transcription following lentiviral transduction, and secondly through excision of target genes by expression of integrated Cas9 and associated gRNA. We used fluorescent reporters to monitor transfection and transduction as they allow visual analysis through fluorescence microscopy.

Using lentiviruses derived from early experiments, we intended on inducing an insertion of the eGFP gene into the embryonic genome. Fluorescence analysis in the days following transduction showed whether genetic integration was successful. 
Subsequent viruses aimed to integrate pLENTI-CRISPR-mCHERRY, a plasmid containing Cas9 and bGATA6-gRNA, inducing knock-out of the GATA6 gene.

The results presented in our research aimed to expand the current literature (Mizuno, et al., 2018; Hofmann, et al., 2003) on viral vectors and CRISPR/Cas9 when used on bovine cells, and embryos at various stages of development.

HEK293 cells are easy to culture and divide every 24 hours, hence they make ideal hosts for viral production (Anderson, et al., 2000). HEK293T/17 is a variation of the HEK293 cell line optimised for transfection. This quality was ideal for the proposed research, as viral production requires transfections of three to four plasmids at once. When the HEK293T/17 cells arrived after ordering, an unusually low number of cells was observed after thawing and seeding when compared to stocks of similar cell concentrations. This indicated that either cells had died in the transportation process (perhaps from thawing) or the cell count supplied was different to the records. The extremely low seeding density meant that over the following 2 days, cells had to be allowed to grow in clusters until there were enough to re-seed. Unfortunately, this caused the cells to adopt tendencies to cluster.

Initial transfection experiments yielded very poor efficiencies. Before optimizing the calcium phosphate transfection protocol, the transfection efficiencies when using all 3 lentiviral plasmids ranged between $10 \%$ and $30 \%$.

To increase the low transfection efficiencies two strategies were tested. The first strategy was to increase the amount of total DNA in the transfection mix. The second strategy was to increase the quantities of calcium phosphate components. Increasing the amount of pll3.7 added to the transfection mixture from $20 \mu \mathrm{g}$ to $30 \mu \mathrm{g}$ caused $>20 \%$ increase in eGFP expression, and increased transfection efficiency from approximately $50 \%-70 \%$. While a good result, when considering the increase in DNA required when transfecting with 3 plasmids, DNA-induced cytotoxicity became a problem. It was assumed that there were ample amounts of DNA going into the mixture, however it wasn't being transferred to the HEK293T/17 cells efficiently. To try 
a different strategy, the $\mathrm{CaCl}_{2}$ and $2 x$ HBS volumes were increased from $50-100 \mu \mathrm{L}$ and $500-1000 \mu \mathrm{L}$ for $10 \mathrm{~cm}^{2}$ and $15 \mathrm{~cm}^{2}$ plates, respectively. The idea was to produce larger and/or more abundant crystals that could bind more DNA, thus when endocytosed by cells would confer greater efficiency. This method was successful, producing both larger and more abundant calcium phosphate crystals. A greater increase in transfection efficiency was seen when adjusting $\mathrm{CaCl}_{2}$ than in the previous test adjusting DNA. Subsequent transfections revealed the difference in calcium phosphate crystals was caused by the increase in $\mathrm{CaCl}_{2}$, as reducing 2x HBS to original levels caused no decrease in transfection efficiency. This was ideal as it meant the total transfection volume could be reduced, relieving cells of the additional stress brought about by excess transfection mixture. Reducing DNA to levels in the original protocol also showed little effect on transfection efficiency following $\mathrm{CaCl}_{2}$ adjustment. Another factor contributing to adjusting the $2.5 \mathrm{M} \mathrm{CaCl}_{2}$ volume rather than the DNA concentration was cost and time, as DNA was more expensive and time consuming to produce. For these reasons, later transfections were done using $75-100 \mu \mathrm{L} 2.5 \mathrm{M} \mathrm{CaCl}_{2}$ rather than $50 \mu \mathrm{L}$. Equivalent adjustments were made when transfecting cells on different sized growth surfaces.

Transfection efficiency of the transfer plasmids pll3.7 and pLENTI-CRISPR-mCHERRY tended to decrease when co-transduced with psPAX2 and pMD2.G. this was seen from the decreased expression of eGFP in lentivirus producer HEK293T/17 cells even though both were supplied with $20 \mu \mathrm{g}$ pll3.7 DNA. This was assumed given that producer cells also had psPAX2 and pMD2.G transfected alongside the pll3.7 plasmid. One of the main issues encountered during the transfection process was the discrepancy in transfection efficiency between small and large plasmids. When cells were transfected with plasmids greater than $11 \mathrm{~kb}$, transfection efficiencies of $>60 \%$ became hard to consistently achieve if used in conjunction with the packaging plasmids PsPAX2 and PMD2.G. 
Lentiviral vectors have been shown to be an efficient way of transferring genetic material to primary cell lines and embryos (Hofmann, et al., 2003). Lentiviruses, unlike many other viral vectors, can package large inserts $(10 \mathrm{kB}+)$. This factor makes them ideal for applications involving CRISPR/Cas9 as plasmids involved are generally large. Though lentiviral vectors have been shown to package inserts up to $18 \mathrm{kB}$ (Kumar, et al., 2001), lentiviral titers tend to decrease with insert size, this was an important aspect of my research. Studies using mouse, human and livestock cells have all shown positive transductions by lentiviral particles (Rubinson, et al., 2003; Hofmann, et al., 2003), thus these were a prime candidate for transducing bovine embryos.

The first lentiviral transduction experiments yielded no eGFP expression. During research preparation (BMSC580) the first plasmids that were attempted to package showed good transfection efficiency ( 80\%) when transfected into HEK293T/17 cells with lentiviral packaging plasmids (psPAX2, pMD2.G) after transfection optimisation. Despite this, fluorescence analysis in the days following lentiviral transduction showed no change in eGFP expression. All plasmids were analysed for integrity by restriction digest, all returning expected results. Testing with these plasmids ceased at the start of second year of the Master's research, when a lentiviral transfer plasmid encoding an eGFP gene (pll3.7) was obtained from a colleague of Peter Pfeffer's. When the lentivirus particles I made using pll3.7 were harvested and tested, I found that they transduced target cells at a high efficiency. This was the first time working lentiviruses had been seen in our research after failures with initially ordered plasmids.

To ensure the lentiviral particles were successfully integrating transgenes, transduced HEK293T/17 cells were cultured for 10 days and their eGFP expression was monitored using fluorescence microscopy. The positive eGFP expression throughout the ongoing culture showed that the transgene was being functionally integrated into the HEK293T/17 cell genome. These cells could also later be used for testing the Cas9 system by targeting the eGFP gene with an eGFP-sgRNA. 
During testing of the $p / 13.7$ lentiviral particles, a new Cas9 transfer plasmid was ordered (pLENTI-CRISPR-mCHERRY) containing expression cassettes for Cas9 fused with mCHERRY, and a filler sequence designed to be excised and replaced by a gRNA sequence. This all-in-one plasmid meant that the entire CRISPR/Cas9 system targeting bGATA6 could be packaged into each virus particle, ideal when considering labor of production and the ability to transduce with one virus rather than multiple. Initial transfections proved difficult and resulted in very low titers $\left(<10^{4} \mathrm{TU} / \mathrm{mL}\right)$.

The low transfection efficiencies seen in transfections involving large plasmids (11 kB+) and lentiviral packaging plasmids highlighted that finding the right balance of packaging plasmids to transfer plasmid is an essential consideration in lentiviral production. By slightly adjusting packaging plasmid concentrations, tenfold higher titers of lentiviral particles containing pLENTI-CRISPR-mCHERRY were able to be achieved $\left(\sim 10^{5} \mathrm{TU} / \mathrm{mL}\right)$, though this was not optimal for the research involving embryos. As this was toward the end of the research testing ceased until plasmids containing gRNA were obtained from cloning experiments.

While large plasmids proved to be a challenge when making viruses, smaller plasmids such as pll3.7 were able to be transfected at high efficiency in parallel with the packaging plasmids, resulting in high titer lentivirus production of $\geq 10^{9} \mathrm{TU} / \mathrm{mL}$. Although only moderate titers could be achieved with the Cas9 virus, the high titer pll3.7 virus allowed us to test the efficacy of lentiviral transduction on bovine embryos while Cas9 viral titers were improved.

One of the benefits of lentiviruses as a vector is their wide range of target cells and ability to transduce both dividing and non-dividing cells. It was important to be sure my lentiviral particles being produced were capable of transducing bovine cells if applications with embryos were to be successful. As the pll3.7 lentivirus was the first to be produced at high titer, the initial focus of experimentation was testing it's efficacy of transduction in bovine cells. This was intended to be done immediately in embryos, however when experiments with embryos began, the laboratory research was 
conducted in, was closed to move. This caused cessation of embryo cultures until the new laboratory was established. During the move, the mineral oil used to overlay the embryo culture droplets became compromised, causing embryos to die when culture resumed in the new lab. The degradation of the mineral oil was likely caused by exposure to sunlight, causing the generation of toxic peroxides. Troubleshooting took a number of months, so in the mean time we tested our viruses against other bovine cells that we had access to.

As well as the bovine embryos we were working with, we also noted that the cumulus/granulosa cells and bovine fibroblasts could be potential targets for lentiviral transduction. These were all primary-stage resources or by-products, thus could still be accessed despite the lack of living embryos. We initially wanted to test on oocytes and the cumulus and granulosa cells that are still surrounded oocytes after aspiration. After performing transduction experiments, we failed to achieve transduction in bovine oocytes. This was attributed to the fully intact zona pellucida being impenetrable by the lentiviral particles.

When we attempted to transduce oocyte cultures during fertilisation with lentiviral particles containing pll3.7, an interesting point to note was how no eGFP expression was observed in sperm cells. Due to the packaging of chromatin during spermiogenesis, sperm cells are transcriptionally inactive (Ren, Chen, Wang, \& Wang, 2017). Transcriptional inactivity results in no expression of eGFP in sperm cells, however, the transgene can still be integrated into the sperm cell genome by retrotranscription. While we observed no transgene expression after fertilisation with transduced sperm cells, other research has shown that transgenic pigs have been successfully created by inseminating sows with lentiviral transduced sperm cells (Zhang, et al., 2012). Further experimentation could reveal whether lentiviral delivery of Cas9/sgRNA to sperm is a viable method of delivery when producing transgenic cattle.

When new mineral oil arrived and bovine embryo culture resumed, lentivirus testing began immediately. Much of the bovine embryo culture was performed with the 
assistance of Kate Isaac. Kate's expertise in bovine embryo manipulation saved an immense amount of time, with the intricacies of embryo handling being a very timeconsuming process. Embryos in culture are extremely sensitive to changes in environment. One of the main challenges was ensuring all parameters were optimal to increase embryo survival rate. Factors such as virus purity, protease concentration and exposure time, extended periods of environmental change, and/or mineral oil changes were all seen to have a negative effect on embryo survival. Because of these factors, caution had to be taken when embryos needed to be transferred to microscopes and photographed. Large scale experiments became difficult as embryos tended to respond negatively to being kept too long out of the incubator during manipulations, often resulting in degeneration. This was observed in initial embryo experiments, so to avoid this in later experiments, work was done as quickly as possible and sample sizes were kept to 12 embryos.

The zona pellucida is a glycoprotein coat surrounding an embryo (Gilbert S. , 2013) that provides many defensive characteristics to keep the embryo from damage caused by external sources. The main functions of the zona pellucida are to ensure that only species-specific fertilization occurs, to prevent polyspermy and to facilitate the acrosome reaction upon sperm binding (Gupta, et al., 2009). In regard to our research, one of the other important functions of the zona is to act as a physical barrier to foreign invading pathogens, such as viruses and bacteria. When considering embryonic gene modification via viral vector delivery for our research, the zona was a barrier that needed to be overcome to be successful.

There are multiple ways of getting around the zona as a biological barrier to viruses. Methods such as zona-free culture, sub-zona microinjection and zona removal postfertilisation are among the most common methods currently used by embryologists (Vajta, et al., 2000; Hofmann, et al., 2003; McLeskey Kiefer \& Saling, 2002). Given the set-up required to produce genetically zona-free embryos, this method did not stand out as a viable option. One of the more promising prospects was sub-zona 
microinjection of our virus, being the most effective method currently in use (Hofmann, et al., 2003). As this method allows the zona to stay mostly intact, it provides the most natural environment post-transduction and thus increases the likelihood of embryo survival. As we did not have the resources for sub-zona microinjection, we decided to attempt zona removal by protease digestion.

Using the pooled method of digestion of the zona, it was difficult to optimize the process due to the variation between embryos in time taken for zona digestion. According to the original protocol (Augusto de Castro e Paula, et al., 2011), we were to use $0.1 \%$ protease and digest embryos for 1-5 minutes. When we attempted this, we found that zona digestion took much longer and thus needed to increase the protease concentration. At higher concentrations of protease $(0.5 \%)$, zona digestion was rapid, but embryos became digested and blastomeres had separated by the next day. Occasionally separated blastomeres would go through one more cell division, but always died at this point or earlier. At lower concentrations of protease $0.1 \%$, zona digestion took too long and caused embryos to be out for a long time, often resulting in embryo loss. Despite the zona not being fully digested, many embryos would still separate into individual blastomeres within the remaining zona in protease digestion experiments. The explanation for this is that the zona has undergone partial digestion, creating "holes" that protease would get into within the remaining membrane. Due to the overall decreased processing time, embryos treated with $0.2 \% \mathrm{w} / \mathrm{v}$ protease showed faster zona digestion and less embryo digestion than experiments using $0.1 \%$ protease, but less rapid than $0.5 \%$. This became the standard working concentration of our protease solution.

Research has shown in mice that the optimal time for lentiviral transduction is at the two-cell stage, when injecting virus under the perivitelline space (Miao, et al., 2011). When considering the protease digestion of the zona pellucida, our research indicated that the optimal time to transduce bovine embryos was later than this due to the tendencies of early stage embryos becoming digested before zona removal. Timed 
protease treatments in the research presented showed that the ideal stage for treatment and lentiviral transduction was around compaction events. This allowed embryos to develop more complex cell-cell junctions and withstand zona digestion.

A lot of our research involved growing bacteria containing plasmids of importance, isolating them with Qiagen prep kits and analyzing their sequences using restriction digestion and agarose gel electrophoresis. Initially we had issues with our prep kits, and found we were getting low yields after overnight culture. Given the quantity of DNA required for our research, this was not sufficient so we optimised our culture parameters in following extractions by monitoring growth time and plasmid yield. The plasmids we obtained were generally low in copy number, thus we found longer culture times were often essential to obtaining higher yields from our prep kits.

One aspect of our research that consumed a lot of time was the production of pLentiCRISPR-mCHERRY-bGATA6 sgRNA. Initially, the filler segment of the vector plasmid (pLENTI-CRISPR-mCHERRY) need to be excised by restriction digestion with BsmBI, followed by agarose gel electrophoresis and purification. Restriction digestion using BsmBI never caused any problems.

Much of our time spent was on trying to get ligations to work, which we had little success with over the course of our research. Due to the lack of success, we looked at each of the parameters involved with the ligation process and tested each parameter to ensure it was functioning properly. We first tested our TaKaRa Mighty Mix against T4 DNA Ligase borrowed from an adjacent lab group. The result of this test showed reintegration of the DNA fragment that was excised using $\mathrm{BsmBI}$, and thus we were satisfied our ligase was functional. The second parameter we tested was the $\mathrm{CFU} / \mathrm{mL}$ of our chemically competent $E$. coli stocks. When colonies were counted after heat shock transformation of puc16 the day before, our calculations showed a very low $\mathrm{CFU} / \mathrm{mL}$ count of $10^{5} \mathrm{CFU} / \mathrm{mL}$. Electrocompetent $E$. coli were made to attempt transformation using a different method, however these cells could not be produced at a high enough $\mathrm{CFU} / \mathrm{mL}$ concentration to deem this a viable option. 
New high-efficiency chemically competent cells were ordered, which yielded a much higher CFU $/ \mathrm{mL}$ count when transformed with pUC16 (>10 $\mathrm{CFU} / \mathrm{mL}$ )

Following restriction digestion of pLENTI-CRISPR-mCHERRY by BsmBI, the ssDNA strands of the bGATA6-gRNA sequence were annealed, forming the fragment to be ligated into the vector. Using new 'One Shot' chemically competent E. coli, ligations plates yielded colonies for the first time. Initially 24 colonies were picked and contained plasmids were analysed, however all were indicative of the parental pLENTI-CRISPRmCHERRY plasmid. This suggested that restriction digestion had been incomplete, and some parental plasmid remained. Despite this, 12 more colonies were analysed and 2 exhibited bands in the region we expected when looking for insertion of our bGATA6gRNA sequence in place of the filler. This occurred during the final weeks of research, and plasmids were only sent away for sequencing right at the end.

CRISPR modification in livestock is an exciting new field. Analysis of Cas9 induced gene modification can be done in various ways, popular methods include qPCR of target gene sequence (Falabella, et al., 2017), use of surveyor nucleases (AnnRan, et al., 2013) and, where applicable, monitoring of fluorescent reporters by fluorescence assays.

Despite not having a lentivirus containing Cas9 and a bGATA6 target sequence, testing of the Cas9 protein was still essential. The CRISPR/Cas9 experiments we conducted began very late in the research due to initial problems with transfection and virus experiments, thus they were still in very early stages.

Research has shown that lentiviral delivery of Cas9 and eGFP-gRNA can result in decreases in eGFP expression in HEK293 cells (Applied Biological Materials (abm) Inc.).

In initial CRISPR experiments, we planned to knock-out the eGFP gene previously integrated into HEK293T cells (see result 3.3). To do this, a lentiviral particle containing Cas9 would be produced, as well as a lentiviral particle containing eGFP-gRNA, and these would be co-transduced into the eGFP-HEK293T/17 cells. Due to delays with cloning and virus production, it was deemed that this process would cost too much 
time as there was no fluorescent marker on the plasmid, thus analysis would require PCR or a similar time-consuming process to titer. Because of this, preliminary tests were done by transfecting Cas9 and eGFP-gRNA plasmids directly into eGFP HEK293T/17 cells and performing fluorescence microscopy assays in the days following transfection. While this would not produce the integration we had hoped for with lentiviral delivery, cells may still be observed to have decreased eGFP expression in the days following transfection. Clusters of cells expressing eGFP have the gene integrated into the genome, and thus pass the gene on to daughter cells after division. We looked for cells that were expressing mCHERRY but not eGFP among these clusters as an indication of cells that may have CRISPR/Cas9 targeting of the eGFP gene using the eGFP-gRNA. While transfection efficiency did not reach all cells with eGFP expression, we did notice more cells expressing mCHERRY that completely lacked eGFP expression or showed decreased expression to the cells around it, compared to control transfections (see Figure 24). Given more time we would have been able to create the eGFP-gRNA lentivirus and integrate both Cas9 and eGFP-gRNA into the genome.

Off-target binding is a major issue when considering applications of CRISPR technology in producing transgenic animals. Unknown downstream effects of off-target binding could have devastating effects on organismal development and thus it was imperative to theoretically minimise off-target binding when designing a gRNA. Research has shown that CRISPR/Cas9 experiments can exhibit high off-target activity, at levels $>50 \%$ (Zhang, et al., 2015). When designing gRNAs, it was imperative to consider the number of off-target binding sites recognised by the CHOP CHOP v2 program. The gRNA sequences that were chosen had no known off target binding sites.

While CRISPR experiments were still in the process of being performed at the end of the Master's thesis, tests involving targeting of the eGFP gene in HEK293T cells highlighted the need for effective gene analysis after knock-out by Cas9.

My research has reinforced how commercially available lentiviral vectors can infect bovine cells and induce integration of transgenes into embryos. This highlights the 
potential uses of lentiviral vectors in production of transgenic cattle in future research. It was also shown that zona pellucida removal by protease digestion, followed by lentiviral transduction can produce living, transgenic bovine embryos, which could be transduced with lentivirus containing CRISPR/Cas9 systems in future research. The results obtained also suggest the CRISPR/Ca9 system worked, however more testing needs to be done to confirm this, as genetic analysis methods employed were inconclusive. While it wasn't achieved, these results indicate strongly towards the feasibility of inducing genetic knock-out in bovine embryos using lentiviral delivery of CRSIPR/Cas9.

\subsection{Future Directions}

While areas of the research were successful, considerations could be taken regarding the following parameters to increase success with future experiments.

CRISPR/Cas9 experiments have shown that targeting genes using only 1 gRNA sequence can result in incomplete knock-out by Cas9. This arises when only one copy of a gene with a homologous partner is cleaved, resulting in homologous repair by the cell. Given the tendency for this phenomenon to occur, recent CRISPR/Cas9 experiments have shown that targeting different regions of genes with multiple gRNAs increases knock out efficiency (Zuo, et al., 2017). With this research in mind, in final experiments of the research we aimed to create 2 lentivirus particles that targeted bGATA6 in different locations of the genetic sequence. Targeting bGATA6 in two places increases the likelihood that both copies of the gene will be cleaved by Cas9, resulting in a true knockout that cannot be repaired by homologous recombination. Difficulty with ligation experiments made focusing on one gRNA more resource effective, however in future research this parameter is essential to consider if efficient genetic knock-out is to be achieved.

Another aspect of the research that could be approached differently is getting through the zona pellucida. While results showed successful integration of transgene in bovine embryos after compaction, to achieve fully transgenic embryos, transduction at earlier stages of development is preferred. This is due to the number of cells that the virus 
needs to transduce for the embryo to become fully transgenic. If embryos can be transduced at the 1-4 cell stage, $100 \%$ transgenicity would be much easier to achieve than with embryos at later stages. Issues with embryo digestion when attempting to remove the zona pellucida by protease treatment meant that testing on early stage embryos resulted in high death rates, making efficient transduction difficult. In recent research, one of the most common methods of viral delivery to embryos has been microinjection into the sub-zonal space (Miao, et al., 2011). Microinjection of lentivirus under the perivitelline layer results in the zona staying mostly intact, allowing it to function properly post transduction. As this method allows direct application of virus to embryonic cells and minimal environmental change, this method would be optimal for viral delivery in future research.

An aspect of the research that could have been improved further was transduction efficiencies in primary cell lines and when using viruses with transfer plasmids of sizes greater than $11 \mathrm{~kb}$. Transduction in primary cell lines can be difficult to produce at high efficiencies, however, there are compounds that have been found to increase the transduction efficiencies of retroviruses. Hexadimethrine bromide (AKA Polybrene) is a cationic polymer that neutralizes the repulsion between sialic acid on the cell surface and viral particles, increasing transduction rates in some cells (Davis, et al., 2002; Davis, et al., 2004). It has been shown in previous research that treating cells with polycations prior to transduction with lentivirus increases the transduction efficiencies when compared to controls (Denning, et al., 2013). Given the difficulties encountered with lentiviral transduction efficiencies in the research, addition of polybrene to transduction protocols could assist in increasing efficiency. Future research involving lentiviral transduction, particularly when using large plasmids, should consider addition of polybrene. 
When deciding which lentiviral plasmids to use for our research, we considered what type of genetic modification we intended on introducing. Traditionally Cas9 induces a double stranded break at the target sequence but modifications have been made to the Cas9 protein in other research, resulting in deactivated cleavage sites. These proteins are known as dCas9 and are used as a targeting mechanism when supplied with gRNA sequences. dCas9 has been shown to be fused to other proteins that manipulate genetic expression (Gilbert, et al., 2014). The first plasmids purchased for our research contained dCas9 and an attached Kruppel-associated box (KRAB) known a dCas9-KRAB. KRAB is a repressive chromatin modifier domain that decreases the expression of target genes (Gilbert, et al., 2014), and thus when fused to dCas9 can be targeted to almost any gene. After difficulties with virus production, experimentation with this plasmid was discontinued. Despite this, showing effective manipulation of genetic expression by up- or down-regulating expression through dCas 9 and associated proteins would open up many more possibilities with bovine embryo genetic modification, and should still be considered for future research.

Analysis of gene modification by CRISPR/Cas9 was another aspect of the research that wasn't explored in sufficient depth. Due to time constraints methods of analysis such as GPCR and Surveyor Nuclease assays were hoped to be employed. Quantitative PCR on genes targeted by Cas9 would show a quantified level of change in gene presence. Surveyor nucleases only cleave target sequences if a mismatch is sensed, as Cas9 will induce mismatches, surveyor nuclease assay will confirm cleavage of target gene when amplified using PCR (Qiu, et al., 2004). Both methods could be used to analyse gene targeting by CRISPR/Cas9 and should be considered in future research. 


\section{Appendix}

\section{Bacterial culture (plasmid amplification)}

I. LB Agar + Ampicillin Recipe

i. In a 1 L Erlenmeyer flask, weigh:

- $5 \mathrm{~g} \mathrm{NaCl}$

- 5 g Tryptone

- 2.5 g Yeast Extract

- 7.5 g Agar

- $\mathrm{dd} \mathrm{H}_{2} \mathrm{O}$ to $500 \mathrm{~mL}$

ii. Mix contents into solution by swirling, ensuring to get all contents off sides of flask

iii. Loosely screw cap on and cover with tinfoil, label with autoclave tape

iv. Autoclave on liquid setting for 20 minutes

v. When autoclave is finished, remove flask and cool to $55^{\circ} \mathrm{C}$

vi. Add $500 \mathrm{uL}$ of $1000 \times 100 \mathrm{ug} / \mathrm{ml}$ ampicillin

vii. Pour plates next to a lit Bunsen burner to ensure sterility. Pour $20 \mathrm{~mL}$ of LB agar per $10 \mathrm{~cm}$ polystyrene Petri dish

viii. Return lids to place and allow to cool until solidified. Then invert plates, label, and store in plastic bags or sealed with parafilm at $4^{\circ} \mathrm{C}$

Adapted from: (Addgene: The nonprofit plasmid repository, n.d.)

II. LB Broth + Ampicillin Recipe

i. Weigh the following into a $1 \mathrm{~L}$ Erlenmeyer glass bottle:

- $8 \mathrm{~g} \mathrm{NaCl}$

- 8 g Tryptone 
- $4 \mathrm{~g}$ Yeast Extract

- $\mathrm{ddH}_{2} \mathrm{O}$ to $800 \mathrm{~mL}$

ii. Loosely screw the cap on and cover with tinfoil. Label with autoclave tape.

iii. Autoclave for 20 minutes.

iv. When broth is cool to touch, add $800 \mu \mathrm{L}$ of $1000 \times 100 \mu \mathrm{g} /$ $\mathrm{mL}$ Ampicillin.

v. Store at $-4^{\circ} \mathrm{C}$.

Adapted from: (Addgene: The nonprofit plasmid repository, n.d.)

III. Bacterial culture

i. Streak plates containing plasmid E. coli the afternoon before inoculations are to be made ( 5 plates total).

ii. Incubate plates at $37^{\circ} \mathrm{C}$ for $16-20$ hours.

iii. After incubation, pick a single colony off each plate and inoculate in $105 \mathrm{~mL}$ LB broth + ampicillin.

iv. Incubate liquid cultures on a shaking incubator set at $250 \mathrm{rpm}$, $37^{\circ} \mathrm{C}$ for $16-20$ hours.

IV. Making Glycerol stocks

i. Make $50 \%$ glycerol by adding $10 \mathrm{~mL} 100 \%$ glycerol to 10

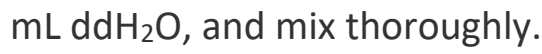

ii. Add $1 \mathrm{~mL}$ of bacterial culture and $1 \mathrm{~mL}$ of $50 \%$ glycerol to a microcentrifuge tube.

iii. Snap freeze by placing in liquid nitrogen or dry ice until frozen, then transfer to $-80^{\circ} \mathrm{C}$ for storage. 


\section{Plasmid isolation}

\section{Qiagen Midiprep}

i. Transfer overnight inoculations into $50 \mathrm{~mL}$ falcon tubes (10 total, 2 for each $100 \mathrm{~mL}$ inoculation) and centrifuge at $4000 \mathrm{rpm}$ for 30 minutes to pellet bacteria.

ii. Discard supernatant and resuspend bacterial pellet in $4 \mathrm{~mL}$ of buffer $\mathrm{p} 1$ (resuspension buffer), mix thoroughly.

iii. Add $4 \mathrm{~mL}$ buffer $\mathrm{p} 2$ (lysis buffer) and mix thoroughly. When using Lyseblue reagent the successful lysis of bacteria will be indicated by a royal blue colour.

iv. Add $4 \mathrm{~mL}$ buffer $\mathrm{p3}$ (neutralization buffer) and mix thoroughly.

v. Centrifuge mixed solution at $4000 \mathrm{rpm}$ for 30 minutes to separate precipitant (cellular debris and genomic DNA) from supernatant (plasmid DNA). To further clarify supernatant, transfer into 15 $\mathrm{mL}$ falcon tubes and centrifuge at $4000 \mathrm{rpm}$ for 15 minutes.

vi. During the final centrifugation of step ii, prepare 5 Qiagen midiprep columns by putting the holding-ring on columns and placing onto $100 \mathrm{~mL}$ conical flasks (to collect liquid waste). Equilibrate by adding $4 \mathrm{~mL}$ of Buffer QBT (equilibration buffer) to the columns and allow them to drain by the force of gravity.

vii. Add supernatant from step v. to columns, ensuring only to run 10-12 $\mathrm{mL}$ at a time so as to not over fill the column. Allow each 10-12 $\mathrm{mL}$ to drain by the force of gravity.

viii. Wash captured plasmid by adding 2x $10 \mathrm{~mL}$ Buffer QC, allowing each $10 \mathrm{~mL}$ to drain by force of gravity.

ix. Transfer columns to $15 \mathrm{~mL}$ falcon tubes, attach using masking tape. 
x. Elute plasmid DNA by adding $5 \mathrm{~mL}$ Buffer QF to columns, allowing to drain by the force of gravity.

xi. Precipitate plasmid DNA by adding $3.5 \mathrm{~mL}$ isopropanol and mixing.

xii. Centrifuge plasmid elutions at $4000 \mathrm{rpm}$ for 30 minutes.

xiii. Carefully decant all supernatant without disturbing DNA pellet, then add $2 \mathrm{~mL} 70 \%$ ethanol.

xiv. Centrifuge plasmid DNA + ethanol solution at $4000 \mathrm{rpm}$ for 15 minutes.

$x v$. Carefully decant supernatant, and allow DNA pellet to air dry in laminar flow hood for 5-10 minutes.

xvi. Resuspend DNA pellets in appropriate amount of TE buffer and store at $-20^{\circ} \mathrm{C}$.

Adapted from (Qiagen, 2012)

II. Quantification of Plasmid DNA using NanoDrop technology

i. Wipe stage clean.

ii. Initialize instrument with $2 \mu \mathrm{L}$ water, wipe stage when finished.

iii. Blank using $2 \mu \mathrm{L}$ TE buffer, wipe stage when finished.

iv. Load $2 \mu \mathrm{L}$ sample plasmid onto stage, measure and record concentration.

Adapted from (Thermo Fisher Scientific inc., 2013)

\section{DNA agarose gel electrophoresis}

I. Preparing 1.5\% Agarose gel 
i. Weigh out $0.6 \mathrm{~g}$ LE-Agar and add to $40 \mathrm{~mL}$ TAE buffer in 100 $\mathrm{mL}$ conical flask.

ii. Dissolve agar by microwaving solution for $3 \times 15$ seconds on high, swirling at each 15 second interval. Allow solution to cool until it is no longer too hot to touch yet still warm.

iii. Add $1.5 \mu \mathrm{L}$ ethidium bromide.

iv. Stick masking tape along either end of a $40 \mathrm{~mL}$ electrophoresis mould to form a well.

v. Add prepared agarose solution to mould, then attach the wellcomb.

vi. Allow gel to set by concealing from light (e.g. under box) and leaving for 30 minutes on benchtop.

vii. Remove comb and take gel out of mould when ready to run electrophoresis.

Adapted from (Addgene: The nonprofit plasmid repository, n.d.)

II. Performing restriction digests of plasmid DNA

i. Take $\sim 500 \mathrm{ng}$ each plasmid and transfer to new microcentrifuge tubes.

ii. Add $1 \mu \mathrm{L}$ of each plasmid-appropriate restriction enzyme $(2 \mu \mathrm{L}$ total, 2 restriction enzymes per plasmid) and $2 \mu \mathrm{L}$ cutsmart. Make solution up to $20 \mu \mathrm{L}$ total volume by adding distilled $\mathrm{H}_{2} \mathrm{O}$.

iii. Incubate solutions at $37^{\circ} \mathrm{C}$ for $\sim 2$ hours to allow optimize restriction digestion.

Adapted from (Addgene: The nonprofit plasmid repository, n.d.)

III. Agarose gel electrophoresis of plasmid

i. Add $2 \mu \mathrm{L}$ loading dye to each of the samples. 
ii. Place 1.5\% Agarose gel + ethidium bromide in electrophoresis machine and cover with TAE buffer.

iii. Load $1^{\text {st }}$ well with $1 \mathrm{~Kb}$ molecular DNA ladder, then add samples to subsequent wells.

iv. Attach lid to electrophoresis machine and run at $90 \mathrm{~V}$ for 45 minutes.

v. When run is complete, remove gel from machine and photograph using ethidium bromide UV photography.

Adapted from (Addgene: The nonprofit plasmid repository, n.d.)

\section{HEK293T culture}

All tubes may only be opened in a laminar flow hood and appropriate sterile technique should be employed at all times.

I. Thawing and seeding HEK293T/17 cells

i. Thaw HEK293T/17 cells by placing in 37C waterbath for $\sim 2$ minutes.

ii. Transfer cells to $15 \mathrm{~mL}$ falcon tube and dilute by adding $5 \mathrm{~mL}$ of media (DMEM + 10\% FCS, 1\% PS).

iii. Centrifuge at $430 \mathrm{rpm}$ for 4 minutes.

iv. While centrifuging, add $\sim 6 \mathrm{~mL}$ media to $\mathrm{T} 25 \mathrm{~cm}$ flask.

v. When centrifuge is finished, Discard supernatant and resuspend cells in $1 \mathrm{~mL}$ media.

vi. Transfer $1 \mathrm{~mL}$ cell solution into T25cm flask with $6 \mathrm{~mL}$ media and incubate at $37 \mathrm{C}, 5 \% \mathrm{CO}_{2}$.

Adapted from (American Type Tissue Culture, 2016)

II. Ongoing HEK293T cell culture - passaging/splitting (values provided are for T75 cm flasks, divide by 3 if using T25 cm flask) 
i. When cells reach appropriate confluency $(60-80 \%)$, first remove media and wash with $\sim 3 \mathrm{~mL}$ PBS $\left(37^{\circ} \mathrm{C}\right.$ ), then remove.

ii. To lift cells off growth surface, add $1 \mathrm{~mL} \operatorname{TrypLE}\left(37^{\circ} \mathrm{C}\right)$ and incubate at $37^{\circ} \mathrm{C}$ for 4 minutes.

iii. Flush cells off growth surface 2-3 times using $5 \mathrm{~mL}$ fresh media $\left(37^{\circ} \mathrm{C}\right)$, then transfer cell suspension to $15 \mathrm{~mL}$ falcon tube.

iv. Centrifuge Cell suspension at $430 \mathrm{rpm}$ for 4 minutes.

v. Without disturbing cell pellet, remove supernatant and resuspend cells in $6 \mathrm{~mL}$ (for 1:6 split) fresh media $\left(37^{\circ} \mathrm{C}\right)$.

vi. Add $1 \mathrm{~mL}$ of cell suspension to growth surface of $T 75 \mathrm{~cm}$ flask, then add 20-25 mL of fresh media.

Adapted from (American Type Tissue Culture, 2016)

III. Freezing HEK293T cells

i. When cells reach appropriate confluency $(60-80 \%)$, first remove media and wash with $\sim 3 \mathrm{mLPBS}\left(37^{\circ} \mathrm{C}\right)$, then remove.

ii. To lift cells off growth surface, add $1 \mathrm{~mL}$ TrypLE $\left(37^{\circ} \mathrm{C}\right)$ and incubate at $37^{\circ} \mathrm{C}$ for 4 minutes.

iii. Flush cells off growth surface 2-3 times using $5 \mathrm{~mL}$ fresh media $\left(37^{\circ} \mathrm{C}\right)$, then transfer cell suspension to $15 \mathrm{~mL}$ falcon tube.

iv. Centrifuge Cell suspension at $430 \mathrm{rpm}$ for 4 minutes.

v. Without disturbing cell pellet, remove supernatant and resuspend cells in 3-5 $\mathrm{mL}$ DMEM media $\left(4^{\circ} \mathrm{C}\right)$.

vi. Count cells using hemocytometer.

vii. Make cell suspension up to $3 \times 10^{6}-6 \times 10^{6}$ cells $/ \mathrm{mL}$ using DMEM, then add freeze media (FCS+16\%DMSO) at a 1:1 ratio to cell suspension. 
viii. Add $1 \mathrm{~mL}$ of cell suspension to cryovials and store in an insulated container that controls decrease in temperature $\left(-1^{\circ} \mathrm{C}\right.$ per minute) overnight at $-80^{\circ} \mathrm{C}$.

ix. The next day, place cryovials in liquid nitrogen for long term storage.

Adapted from (American Type Tissue Culture, 2016)

\section{HEK293T/17 Transfection}

I. Reagents

i. 2x HEPES-buffered Saline, pH 7.1 solution (HBS)

a. $2 x H e b s(200 \mathrm{~mL})$

- Mix together $2.00 \mathrm{~g}$ HEPES and $3.39 \mathrm{~g}$ $\mathrm{NaCl}$, adjust to $190 \mathrm{~mL}$ with $\mathrm{dd}_{2} \mathrm{O}$

- Adjust pH to 7.1 using $1 \mathrm{~N} \mathrm{NaOH}(\sim 2.56 \mathrm{~mL}$ )

- Make up to $200 \mathrm{~mL}$ using $\mathrm{dd}_{2} \mathrm{O}$

- Sterilize by filtration using a $0.22 \mu \mathrm{m}$ disposable filter

b. $70 \mathrm{mM} \mathrm{Na} 2 \mathrm{HPO} 4$

- Dissolve $5.01 \mathrm{~g} \mathrm{Na2HPO4.12H2O} \mathrm{(MW=368.14)}$

- Make up to $200 \mathrm{~mL}$ using ddH2O

- Sterilize by filtration using a $0.22 \mu \mathrm{m}$ disposable filter 
c. Mix $500 \mathrm{~mL}$ of $2 \times$ Hebs solution with $10 \mathrm{~mL}$ of $70 \mathrm{mM}$ $\mathrm{Na}_{2} \mathrm{HPO}_{4}$ solution. (Can be stored at room temperature for up to 6 months)

ii. $\quad 2.5 \mathrm{M} \mathrm{CaCl}_{2}$

a. Dissolve $73.5 \mathrm{~g} \mathrm{CaCl}_{2} .2 \mathrm{H}_{2} \mathrm{O}$ and make up to $200 \mathrm{~mL}$ using $\mathrm{ddH}_{2} \mathrm{O}$. Store at $-20^{\circ} \mathrm{C}$ (will not freeze)

iii. Plasmid DNA (Transfer vectors and packaging vectors)

Adapted from (Addgene, n.d.)

II. Transfection procedure

i. Make DNA mixture according to AddGene's protocol for 15 $\mathrm{mL}$ tubes (when using $15 \mathrm{~cm}$ plates) and $1.5 \mathrm{~mL}$ tubes (when using $10 \mathrm{~cm}$ plates):

N.B For more efficient transfection, use $1.5 x-2 x$ amount of $\mathrm{CaCl} 2$

\begin{tabular}{|l|l|l|l|}
\hline ID & & & \\
\hline $15-\mathrm{cm}$ dish & & $10-\mathrm{cm}$ dish & \\
\hline $\mathrm{H}_{2} \mathrm{O}$ & $\mu \mathrm{l}$ & $\mathrm{H}_{2} \mathrm{O}$ & $\mu \mathrm{l}$ \\
\hline $\begin{array}{l}\text { Transfer vector } \\
(60 \mu \mathrm{g})\end{array}$ & $\mu \mathrm{l}$ & $\begin{array}{l}\text { Transfer vector } \\
(20 \mu \mathrm{g})\end{array}$ & $\mu \mathrm{l}$ \\
\hline psPAX2 $(45 \mu \mathrm{g})$ & $\mu \mathrm{l}$ & psPAX2 $(15 \mu \mathrm{g})$ & $\mu \mathrm{l}$ \\
\hline $\begin{array}{l}\text { pMD2.G envelop } \\
\text { plasmid }(18 \mu \mathrm{g})\end{array}$ & $\mu \mathrm{l}$ & pMD2.G $(6 \mu \mathrm{g})$ & $\mu \mathrm{l}$ \\
\hline $2.5 \mathrm{M} \mathrm{CaCl}$ & $150 \mu \mathrm{l}$ & $2.5 \mathrm{M} \mathrm{CaCl}_{2}$ & $50 \mu \mathrm{l}$ \\
\hline Total Volume & $1.5 \mathrm{ml}$ & Total volume & $0.5 \mathrm{ml}$ \\
\hline
\end{tabular}

ii. For a $15 \mathrm{~cm}$ plates, Add DNA mixture dropwise into a $15 \mathrm{~mL}$ tube containing $1.5 \mathrm{~mL} 2 x \mathrm{HBS}$, while gently vortexing the tube 
For $10 \mathrm{~cm}$ plates, Add DNA mixture dropwise into a $1.5 \mathrm{~mL}$ tube containing $0.5 \mathrm{~mL} 2 x \mathrm{HBS}$

iii. Incubate a room temperature for 10-15 minutes

iv. Add $1 \mathrm{~mL}$ (for $10 \mathrm{~cm}$ plates) or $3 \mathrm{~mL}$ (for $15 \mathrm{~cm}$ plates) of transfection mixture to each plate

v. Evenly distribute the transfection mixture over plate by gentle rocking up-down and left-right. Do not swirl.

vi. Incubate plates at $37^{\circ} \mathrm{C}, 5 \% \mathrm{CO}_{2}$ for 6 hours

vii. After 6 hours, remove medium containing DNA precipitate and replace with $32 \mathrm{~mL}$ (for $15 \mathrm{~cm}$ plates) or $12 \mathrm{~mL}$ (for $10 \mathrm{~cm}$ plates) of fresh medium (DMEM $+10 \%$ FCS).

Adapted from (Addgene, n.d.)

III. Transfection validation - Transgene expression assay

i. Transfected HEK293T/17 cells will be examined under fluorescent microscopes for the presence of green fluorescent protein encoded in the transfer vectors.

\section{Lentivirus Harvest}

I. Supernatant harvest \#1

i. Collect supernatant from each dish and pool. Replace media and incubate dishes at $10 \% \mathrm{CO}_{2}, 37^{\circ} \mathrm{C}$ overnight. Supernatant can contain active lentiviral particles so should be sealed again (in a ziplock bag) and stored at $4{ }^{\circ} \mathrm{C}$. 
Adapted from (Tiscornia, Singer, \& Verma, 2006)

II. Supernatant harvest \#2

i. Collect supernatant as previously outlined and pool with harvest \#1 supernatant. Cell debris can be filtered out by running supernatant through a $0.45 \mu \mathrm{m}$ filter. Viral titer will be low thus should be concentrated, however this can be used for direct transduction.

ii. Supernatant can be stored at $4{ }^{\circ} \mathrm{C}$ for $3 \mathrm{~d},-20^{\circ} \mathrm{C}$ for periods $<1$ month or $-80{ }^{\circ} \mathrm{C}$ for periods $>1$ month. It is advised not to freeze/thaw more than 3 times. Depending on the needs of the experiment, this step may be adequate concentration of viral particles, however further steps explain concentration.

Adapted from (Tiscornia, Singer, \& Verma, 2006)

III. Concentration of viral preparation

i. Preparation is ultracentrifuged to concentrate viral particles into a pellet. It is suggested to use conical tubes and swinging bucket rotors where available to aid in locating the pellet. Centrifuge the supernatant at $70,000 \mathrm{~g}$ for 2 hours at 20 ${ }^{\circ} \mathrm{C}$. To concentrate the whole $360 \mathrm{~mL}$, we will need to do consecutive spins, therefore after spin 1 we discard supernatant without affecting the pellet, and add the second half of supernatant and re spin.

ii. Discard supernatant and invert tube on paper towel to dry, siphoning off any remaining drops with an aspirator.

iii. Resuspend pellet in $100 \mu \mathrm{L} 1 \times$ HBSS, avoiding frothing. Tubes are then to be rinsed with $100 \mu \mathrm{L} 1 \mathrm{x}$ HBSS. Both volumes are then 
pooled, yielding a total volume of $200 \mu \mathrm{L}$. Transfer the viral preparation to a microcentrifuge tube and vortex for 15-30 minutes at low speed.

iv. Spin suspension using tabletop microcentrifuge to clear and transfer to a new microfuge tube, then take $20 \mu \mathrm{L}$ aliquots and store. This is in vitro grade quality.

Adapted from (Tiscornia, Singer, \& Verma, 2006)

IV. Purifying virus using sucrose cushion

i. The sucrose cushion is created layering $200 \mu \mathrm{L}$ of the viral supernatant on top of $1.5 \mathrm{~mL}$ of $20 \%$ sucrose. Addition of $1 x$ HBSS can be used to balance before centrifugation (may need around $3.5 \mathrm{~mL}$ ). Centrifuge tubes for 2 hours at $20^{\circ} \mathrm{C}$.

Adapted from (Tiscornia, Singer, \& Verma, 2006)

\section{Titration of lentiviral vectors}

i. Using the viral suspension make a 10 -fold serial dilution (from undiluted to $10^{-6}$ ) in $1 \times$ PBS, aiming for $50 \mu \mathrm{L}$ volume for each dilution.

ii. In each well of a treated 24-well plate seed $10^{5}$ HEK293 cells in a final volume of $500 \mu \mathrm{L}$ DMEM, then proceed quickly to next step.

iii. Add $20 \mu \mathrm{L}$ of each viral dilution to wells and mix gently. Incubate cells at $37^{\circ} \mathrm{C}$, eGFP should start to become visible after 24 hours from infection. 
iv. Culture cells for $48 \mathrm{~h}$, washing cells twice with $1 \mathrm{x}$ PBS to eliminate any leftover virus. Resuspend cells in $500 \mu \mathrm{L}$ DMEM (vigorous pipetting up and down).

v. Using FACS, determine the number of cells that are labelled with eGFP

vi. Calculate biological titer ( $\mathrm{BT}=\mathrm{TU} / \mathrm{mL}$, transducing units) $\mathrm{TU} /$ $\mathrm{uL}=(\mathrm{P} \times \mathrm{N} / 100 \times \mathrm{V}) \times 1 / \mathrm{DF}$ Where $\mathrm{P}=\%$ eGFP+ cells, $\mathrm{N}=$ number of cells at time of transduction $=10^{5}, \mathrm{~V}=$ volume of dilution added to each well $=20 \mu \mathrm{L}$, and $\mathrm{DF}=$ dilution factor $(1=$ undiluted, $1 / 10=$ $10^{-1}, 1 / 100=10^{-2}$ etc.)

Adapted from (Tiscornia, Singer, \& Verma, 2006)

\section{Ovary Aspiration}

i. Take collected ovaries and Strain by hand over sink, spray with ethanol to reduce risk of contamination.

ii. Place ovaries in Wide-mouthed thermos and pour warm (37 $\left.{ }^{\circ} \mathrm{C}\right)$ saline over them, using enough to cover them. Then rinse them by agitating with hand.

iii. Strain ovaries again and replace the warm saline. If there is still blood present in saline, rinse and strain again.

iv. Place empty saline bottles next to incubator and partially full bottles back inside incubator.

v. Take aspiration media from incubator and pour approximately $2 \mathrm{~mL}$ in $15 \mathrm{~mL}$ conical tubes $\left(37^{\circ} \mathrm{C}\right)$ for each cow ovary. Replace the lids on tubes and place in warmer $\left(30-35^{\circ} \mathrm{C}\right)$. Return aspiration media to incubator. 
vi. Select a bung with aspiration needle and a blunt needle (18 gauge).

vii. Place aspiration needle bung into the top of an aspiration tube. Place the blunt needle in the second hole of the bung. The end of the blunt needle should be higher than the end of the aspiration needle (i.e. closer to the bung), this is important as it reduces the risk of oocytes going up the aspiration line.

viii. Turn on aspiration pump and fix foot pedal in "on" position. Ensure boost inject light is on. Connect the tube to the pump by removing the needle and cover from one of the aspiration lines, and connecting the line to the blunt needle.

ix. Take an Ovary and remove excess saline using a paper towel. Firmly hold the ovary (using washed gloves) and select clear, yellow follicles ( $3 \mathrm{~mm}-10 \mathrm{~mm}$ diameter). Insert the aspiration needle into one of the selected follicles and ensure the pressure on the aspiration pump is $40-50 \mathrm{~mm} \mathrm{Hg}$. Also check that follicular fluid flows through the tube.

$x$. Move the needle inside the follicle and try to be thorough in extracting all the follicular fluid to increase the chance of aspirating the oocyte. Higher yield may be obtained if the needle is "pushed in continuous lines in all planes under the surface of the ovary".

xi. Repeat process on other selected follicles.

xii. If blood is aspirated, tubes must be changed immediately.

xiii. Change aspiration tubes when $3 / 4$ full.

Adapted from (AgResearch) 
I. IVM Plate preparation

i. Make up media afternoon prior to use

ii. On day of use, add cysteamine to media (refer to label for quantity) and swirl

iii. Using a sterile tip and electronic pipettor put $40 \mu \mathrm{L}$ droplets of IVM media in $10 \mathrm{~cm}$ dishes respective to the number of oocytes you have. Usually 10 droplets are used per dish, in the following fashion:

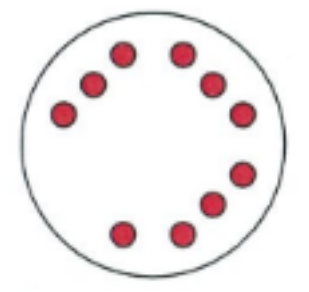

iv. Place dishes in $38.5{ }^{\circ} \mathrm{C}, 5 \% \mathrm{CO}_{2}$ incubator for 2 hours to equilibrate

Adapted from (AgResearch, 2010)

II. Oocyte transfer to IVM drops

i. Place aspiration tubes in rack and put on a warm box. Allow contents to settle during dish preparation

ii. Place appropriate number of $90 \mathrm{~mm}$ dishes (1 dish per 2-3 aspiration tubes) on a warm box. Add enough aspiration medium to cover the base of the dish (few $\mathrm{mL}$ )

iii. Take two $35 \mathrm{~mm}$ dishes and put them on a warm box. Add a few $\mathrm{mL}$ of $\mathrm{H} 199+10 \% \mathrm{FCS}$ to each dish. 
iv. Draw up sediment of an aspiration tube (approx. $1 \mathrm{~mL}$ ) using a $2 \mathrm{~mL}$ syringe attached to tubing and a sterile pasture pipette. Expel into $35 \mathrm{~mm}$ dish and allow to settle.

v. Place grid template on warm stage of microscope and then place petri dish on top. Using the grid template, search for oocytes 1 square at a time.

N.B if the medium still appears cloudy, it can be replaced with fresh media as long as care is taken not to disturb the oocytes

vi. Using a 50-200 $\mu \mathrm{L}$ pipette and sterile tips, pick up oocytes and place them in a $35 \mathrm{~mm}$ dish with $\mathrm{H} 199+10 \% \mathrm{FCS}$

vii. From the selected oocytes, assign each to a grade associated with the provided 6-step grading system:

Grade 1: tight cumulus, many layers surrounding oocyte

Grade 2: less compact cumulus, fewer layers surrounding oocyte

Grade 3: Corona only, may have exposed zona pellucida

Grade 4: naked oocyte with intact cytoplasm

Grade 5: expanded/mature oocyte

Grade 6: degenerate (lysed, atretic etc.)

viii. Transfer each oocyte into a new $35 \mathrm{~mm}$ dish containing B199+10\%FCS

ix. Immediately start transferring oocytes to pre-prepared IVM plates. Transfer $10 \mu$ l containing 10 oocytes into each drop

x. Incubate plates at $38.5{ }^{\circ} \mathrm{C}, 5 \% \mathrm{CO}_{2}$ for $22-26$ hours

Adapted from (AgResearch, 2010) 


\section{In Vitro oocyte Fertilisation}

I. IVF plate preparation

i. Using a pipette and sterile tips, place $30 \mu \mathrm{l}$ drops of IVF +PPHH medium in each plate - 1 drop per 5 oocytes, 10 drops per plate.

Adapted from (AgResearch, 2014)

\section{Sperm preparation}

i. Percoll gradient is prepared by adding $1 \mathrm{~mL} 45 \%$ percoll solution to a $15 \mathrm{~mL}$ falcon tube, then underlaying this with $1 \mathrm{~mL}$ 90\%percoll solution. (1 gradient facilitates 2 semen straws, 120 oocytes per straw at 1.5 million sperm $/ \mathrm{mL}$ ).

ii. Remove sperm straws from liquid nitrogen and thaw in air for 10 seconds, then in $35^{\circ} \mathrm{C}$ waterbath for 30 seconds.

iii. Dry straw in laminar flow hood and wipe ends with $70 \%$ ethanol - be careful not to risk contamination by touching ends.

iv. Cut off the end of the straw using sterile scissors and place in a sterile tube. Cut off other end and let contents of straw release into tube.

N.B semen can be fully expelled using a reversed yellow tip on a $1 \mathrm{~mL}$ pipette on the end of the straw.

v. Aspirate thawed semen and gently layer on top of percoll gradient.

vi. Check post thaw sperm motility under compound microscope using warmed glass slide and coverslip - motility needs to be $>50 \%$.

vii. Centrifuge percoll gradient tube at $700 \mathrm{~g}$ for $20 \mathrm{~min}$.

viii. At this time, refer to step iii. For oocyte preparation. 
x. Immediately after the centrifuge stops, remove sample and carefully remove supernatant from the tube.

xi. Gently aspirate sperm pellet from the bottom of the tube by adding a small quantity of HSOF $\left(20^{\circ} \mathrm{C}\right)$.

xii. Add sperm slowly to the tube containing $1 \mathrm{~mL}$ HSOF, mix gently and centrifuge at $200 \mathrm{~g}$ for 10 minute.

xiii. Immediately after the centrifuge stops, remove sample and carefully remove supernatant from the tube.

xiv. Resuspend sperm pellet in $200 \mu \mathrm{IVF}+\mathrm{PPHH}$ medium $\left(38.5^{\circ} \mathrm{C}\right.$, $\left.5 \% \mathrm{CO}_{2}\right)$. Add slowly and mix.

$x v$. Take a $10 \mu \mathrm{l}$ aliquot of sperm suspension and add to $190 \mathrm{ul} \mathrm{ddH}_{2} \mathrm{O}$ - this is a 1:20 dilution.

xvi. Measure remaining volume of sperm using pastuer pipette on $1 \mathrm{~mL}$ syringe.

xvii. Place sperm preparation in dark place on your person while determining sperm concentration.

xviii. Calculate final sperm concentration of $1.5 \times 10^{6}$ cells $/ \mathrm{mL}$ when added at 1:4 (volume of sperm:volume of eggs in drop)

Adapted from (AgResearch, 2014)

III. Oocyte preparation

i. Remove oocytes from IVM drops using $200 \mu$ pipette and place in a $35 \mathrm{~mm}$ dish containing HSOF.

ii. Pipette oocyte complexes up and down 2-3 times to loosen cumulus cells. Be gentle so as not to strip the oocytes completely.

iii. Wash oocytes again by transferring them to a new $35 \mathrm{~mm}$ dish containing HSOF. 
iv. Transfer oocytes to a third $35 \mathrm{~mm}$ dish containing IVF+PPHH medium $\left(38.5^{\circ} \mathrm{C}\right)$.

v. Transfer $10 \mu \mathrm{IIVF}+\mathrm{PPHH}$ containing 5 oocytes into each drop on pre-prepared IVF plates.

vi. Return plates to incubator at $38.5^{\circ} \mathrm{C}, \mathrm{CO}_{2}$.

Adapted from (AgResearch, 2014)

IV. Oocyte fertilisation

i. Add $10 \mu \mathrm{l}$ of diluted sperm preparation to each $40 \mu \mathrm{l}$ droplet on IVF plates

ii. Check IVF drops for sperm presence and motility

Adapted from (AgResearch, 2014)

\section{In Vitro Culture}

I. IVC Plate preparation

i. Using a pipette and sterile tips, place $20 \mu \mathrm{l}$ drops of ESOF

medium in each plate. Generally, 5 droplets are placed around edges of dish and a $40 \mu$ wash drop is placed in the center

ii. Overlay droplets using $3 \mathrm{~mL}$ Sigma mineral oil

iii. Place IVC dishes in a pre-equilibrated modulated incubation chamber (i.e. flying saucer) for 2 hours after gassing with $5 \%$ $\mathrm{CO}_{2}, 7 \% \mathrm{O}_{2}, 88 \% \mathrm{~N}_{2}$ gas

Adapted from (AgResearch, 2010) 
II. Oocyte culture

i. Transfer Oocytes from IVF droplets to $35 \mathrm{~mm}$ dish containing HSOF using a $200 \mu$ pipette.

ii. Pipette complexes up and down to remove most of the cumulus cells around the oocyte.

iii. Transfer oocytes to second $35 \mathrm{~mm}$ wash dish (containing HSOF).

iv. Use an unopette on the end of a $1 \mathrm{~mL}$ syringe and repeatedly suck up and down to strip cells off embryos.

v. Pick up embryos using a pulled glass Pasteur pipette and place them in the wash drop on the IVC plate. Do this step quickly and return the IVC plate to the flying saucer.

vi. When all plates are in flying saucer, seal and re-gas with $5 \% \mathrm{CO}_{2}$, $7 \% \mathrm{O}_{2}, 88 \% \mathrm{~N}_{2}$ gas. Gas flow should be vigorous (15-20 L gas/min) for 5 minutes, then return to normal.

vii. Transfer embryos to fresh late-SOF (LSOF) medium drops on day

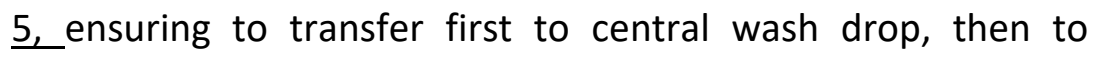
subsequent drop. Return plates to flying saucer and repeat step vi.

viii. Score embryo development on day 7

Adapted from (AgResearch, 2010) 


\section{References}

(n.d.).

Addgene. (n.d.). pMD2.G. Retrieved from Addgene: The Nonprofit Plasmid Repository: https://www.addgene.org/12259/

Addgene. (n.d.). Protocol for Lentivial Vector (LV) Production (2nd Generation Packaging). Retrieved from Addgene: https://www.addgene.org/static/data/plasmids/72/72256/72256attachment_MkjFMdoTMyEJ.pdf

Addgene. (n.d.). psPAX2. Retrieved from Addgene: The Nonprofit Plasmid Repository: https://www.addgene.org/12260/

Addgene The Nonprofit Plasmid Repository. (n.d.). Lentiviral Guide. Retrieved from Addgene The Nonprofit Plasmid Repository: https://www.addgene.org/viralvectors/lentivirus/lenti-guide/\#glossary

Addgene: The nonprofit plasmid repository. (n.d.). Addgene: The nonprofit plasmid repository. Retrieved from https://www.addgene.org/plasmid-protocols/bacterialplates/: https://www.addgene.org/plasmid-protocols/bacterial-plates/

Addgene: The nonprofit plasmid repository. (n.d.). Agarose Gel Electrophoresis. Retrieved from Addgene: The nonprofit plasmid repository: https://www.addgene.org/plasmidprotocols/gel-electrophoresis/

Addgene: The nonprofit plasmid repository. (n.d.). Inoculating a Liquid Bacterial Culture. Retrieved from Addgene: The nonprofit plasmid repository: https://www.addgene.org/plasmid-protocols/inoculate-bacterial-culture/

AgResearch. (2010). Procedure for in-vitro culture of abattoir derived bovine oocytes. Retrieved from AgResearch: http://www.agresearch.co.nz/

AgResearch. (2010). Title Procedure for in-vitro maturation of abattoir derived sheep oocytes. Retrieved from AgResearch: http://www.agresearch.co.nz/

AgResearch. (2014). Title Procedure for in-vitro fertilisation of abattoir derived bovine oocytes. Retrieved from AgResearch: http://www.agresearch.co.nz/

AgResearch. (n.d.). Title Procedure for aspirating abattoir-derived ovaries. Retrieved from AgResearch: http://www.agresearch.co.nz/

American Type Tissue Culture. (2016). 293T/17 [HEK 293T/17] (ATCC ${ }^{\circledR}$ CRL-11268 ${ }^{\text {TM}}$ ). Retrieved from ATCC: The Essential of Life Science Research Globally Delivered: https://www.atcc.org/Products/All/CRL-11268.aspx\#culturemethod

Amitai, G., \& Sorek, R. (2016). CRISPR-CAS adaptation: insights into the mechanism of action. Nature Reviews Microbiology, 67. 
Anders, C., Niewoehner, O., Duerst, A., \& Jinek, M. (2014). Structural Basis of PAMDependent Target DNA Recognition by the Cas9 Endonuclease. Nature, 569-73.

Anderson, R., Haskell, R., Xia, H., Roessler, B., \& Davidson, B. (2000). A simple method for the rapid generation of recombinant adenovirus vectors. Gene Therapy, 1034-38.

AnnRan, F., Hsu, P., Lin, C., Gootenberg, J., Konermann, S., Trevino, A., . . Zhang, F. (2013). Double Nicking by RNA-Guided CRISPR Cas9 for Enhanced Genome Editing Specificity. Cell, 1380-89.

Applied Biological Materials (abm) Inc. (n.d.). Knock-out of reporter GFP in Human Embryonic Kidney Cells Using CRISPR-Cas9 System. Retrieved from Applied Biological Materials (abm) Inc.: file:///C:/Users/Jevbot/Downloads/CRISPRCas9\%20Testing\%20Report\%20V2\%20(2).pdf

Augusto de Castro e Paula, L., Moises Franco, C., \& Hansen, P. (2011). Removal of Zona Pellucida with Pronase in Cattle. Florida: Dept. of Animal Sciences, University of Florida .

Bazer, F., Spencer, T., Johnson, G., Burghardt, R., \& Wu, G. (2009). Comparative aspects of implantation. Reproduction, 195-209.

Beef + Lamb New Zealand. (2018, October Thursday). NZ red meat exports top \$6.7 billion in 2017-18. Retrieved from Beef + Lamb New Zealand: https://beeflambnz.com/newsviews/nz-red-meat-exports-top-67-billion-2017-18

Berkley University of California. (n.d.). MiCodes: Contruction. Retrieved from Berkley University of California: http://2012.igem.org/Team:Berkeley/Project/Construction

Bouard, D., Alazard-Dany, N., \& Cosset, F. (2009). Viral vectors: from virology to transgene expression. British Journal of Pharmacology, 153-65.

Briner, A., \& Barrangou, R. (2016). Guide RNAs: A Glimpse at the Sequences that Drive CRISPR-Cas Systems. In J. Doudna, \& P. Mali, CRISPR-Cas: A Laboratory Manual (pp. 17-23). Cold Spring Habour: Cold Spring Habour Laboratory Press.

Campeau, P., Chapdelaine, P., Seigneurin-Venin, S., Massie, B., \& Tremblay, J. (2001). Transfection of large plasmids in primary human. Gene Therapy, 1387-94.

Crispo, M., Mulet, A., Tesson, L., Barrera, N., Cuadro, F., dos Santos-Neto, P., . . Menchaca, A. (2015). Efficient Generation of Myostatin Knock-Out Sheep Using CRISPR/Cas9 Technology and Microinjection into Zygotes. PLoS One, e0136690.

Davis, H., Morgan, J., \& Yarmush, M. (2002). Polybrene increases retrovirus gene transfer efficiency by enhancing receptor-independent virus adsorption on the target cell membranes. Biophysical Chemistry, 159-72.

Davis, H., Rosinski, M., Morgan, J., \& Yarmush, M. (2004). Charged Polymers Modulate Retrovirus Transduction via Membrane Charge Neutralization and Virus Aggregation. Biophysical Journal, 1234-42. 
Denning, W., Das, S., Guo, S., Xu, J., Kappes, J., \& Hel, Z. (2013). Optimization of the transductional efficiency of lentiviral vectors: effect of sera and polycations. Molecular Biotechnology, 308-14.

Doench, J., Fusi, N., Sullender, M., Hegde, M., Vaimberg, E., Donovan, K., . . Root, D. (2016). Optimized sgRNA design to maximize activity and minimize off-target effects of CRISPR-Cas9. Nature Biotechnology, doi: 10.1038/nbt.3437. 10.1038/nbt.3437. Retrieved from Addgene the nonprofit plasmid repository: https://www.addgene.org/80036/

DuBridge, R., Tang, P., Hsia, H., Leong, P., Miller, J., \& Calos, M. (1987). Analysis of mutation in human cells by using an Epstein-Barr virus shuttle system. Molecular and Cell Biology, 379-87.

Falabella, M., Sun, L., Barr, J., Pena, A., Kershaw, E., Gingras, S., . . Kaufman, B. (2017). Single-Step qPCR and dPCR Detection of Diverse CRISPR-Cas9 Gene Editing Events in Vivo. G3: Genes, Genomes, Genetics, 3533-3542.

Fonfara, I., Le Rhun, A., Chylinski, K., Makarova, K., Lécrivain, A., Bzdrenga, J., . . Charpentier, E. (2013). Phylogeny of Cas9 Determines Functional Exchangeability of Dual-RNA and Cas9 Among Orthologous Type II CRISPR-Cas Systems. Nucleic Acids Research, doi: 10.1093/nar/gkt1074.

Gao, Y., Wu, H., Wang, Y., Liu, X., Chen, L., Li, Q., . . Zhang, Y. (2017). Single Cas9 nickase induced generation of NRAMP1 knockin cattle with reduced off-target effects. Genome Biology, https://doi.org/10.1186/s13059-016-1144-4.

Gasiunas, G., Barrangou, R., Horvath, P., \& Siksnys, V. (2012). Cas9-crRNA Ribonucleoprotein Complex Mediates Specific DNA Cleavage for Adapive Immunity in Bacteria. Proceedings of the National Academy of Sciences, E2579-E2586.

Gilbert, L., Horlbeck, M., Adamson, B., Villalta, J., Chen, Y., Whitehead, E., . . Weissman, J. (2014). Genome-Scale CRISPR-Mediated Control of Gene Repression and Activation. Cell, 647-661.

Gilbert, S. (2013). Devlopmental Biology. In S. Gilbert, Devlopmental Biology (p. 123). Sinauer Associates Inc.

Gupta, S., Bansal, P., Ganguly, A., Bhandari, B., \& Chakrabarti, K. (2009). Human zona pellucida glycoproteins: functional relevance during fertilization. Journal of Reproductive Immunology, 50-55.

Hashimoto, M., \& Takemoto, T. (2015). Electroporation enables the efficient mRNA delivery into the mouse zygotes and facilitates CRISPR/Cas9-based genome editing. Scientific Reports, doi:10.1038/srep11315.

He, X., Tan, C., Wang, F., Wang, Y., Zhou, R., Cui, D., . . Feng, B. (2016). Knock-in of large reporter genes in human cells via CRISPR/Cas9-induced homology-dependent and 
independent DNA repair. Nucleic Acids Research, DOI:

https://doi.org/10.1093/nar/gkw064.

Hofmann, A., Kessler, B., Ewerling, S., Weppert, M., Vogg, B., Ludwig, H., . . Pfeifer, A. (2003). Efficient transgenesis in farm animals by lentiviral vectors. EMBO Reports, 1054-60.

Hsu, P., Lander, E., \& Zhang, F. (2015). Development and Applications of CRISPR-Cas9 for Genome Engineering. Cell, 1262-78.

Ikawa, M., Tanaka, N., Kao, W., \& Verma, I. (2003). Generation of transgenic mice using lentiviral vectors: a novel preclinical assessment of lentiviral vectors for gene therapy. Molecular Therapy, 666-73.

Jinek, M., Chylinski, K., Fonfara, I., Hauer, M., Doudna, J., \& Charpentier, E. (2012). A programmable dual-RNA-guided DNA endonuclease in adaptive bacterial immunity. Science, doi: 10.1126/science.1225829.

Jinek, M., Jiang, F., Taylor, D., Sternberg, S., Kaya, E., Ma, E., . . JA, D. (2014). Structures of Cas9 endonucleases reveal RNA-mediated conformational activation. Science, doi: 10.1126/science.1247997.

Kumar, M., Keller, B., Makalou, N., \& Sutton, R. (2001). Systematic determination of the packaging limit of lentiviral vectors. Human Gene Therapy, 1893-905.

Labun, K., Montague, T., Gagnon, J., Thyme, S., \& Valen, E. (2016). CHOPCHOP v2: a web tool for the next generation of CRISPR genome engineering. Nucleic Acids Research, doi:10.1093/nar/gkw398.

Lois, C., Hong, E., Pease, S., Brown, E., \& Baltimore, D. (2002). Germline Transmission and Tissue-Specific Expression of Transgenes Delivered by Lentiviral Vectors. Science, 86872.

McComb, S., Aguade-Gorgorio, J., Harder, L., Marovca, B., Cario, G., Eckert, C., . . . Bornhauser, B. (2016). Activation of concurrent apoptosis and necroptosis by SMAC mimetics for the treatment of refractory and relapsed ALL. Science Translational Medicine, doi: 10.1126/scitranslmed.aad2986. Retrieved from Addgene the nonprofit plasmid repository: https://www.addgene.org/75161/

McLeskey Kiefer, S., \& Saling, P. (2002). Proteolytic Processing of Human Zona Pellucida Proteins. Biology of Reproduction, 407-14.

Miao, K., Guo, M., An, L., Xu, X., Wu, H., Wang, D., .. . Tian, J. (2011). A new method to efficiently produce transgenic embryos and mice from low-titer lentiviral vectors. Transgenic Research, 357-63.

Mizuno, N., Mizutani, E., Sato, H., Kasai, M., Ogawa, A., Suchy, F., . . Nakauchi, H. (2018). Intra-embryo Gene Cassette Knockin by CRISPR/Cas9-Mediated Genome Editing with Adeno-Associated Viral Vector. iScience, 286-97. 
Moore, J., \& Haber, J. (1996). Cell cycle and genetic requirements of two pathways of nonhomologous end-joining repair of double-strand breaks in Saccharomyces cerevisiae. Molecular and Cell Biology, 2164-73.

Nishimasu, H., Ran, F., Hsu, P., Konermann, S., Shehata, S., Dohmae, N., . . Nureki, O. (2014). Cyrstal Structure of Cas9 in Complex with Guide RNA and Target DNA. Cell, 935-49.

Parrish, J. (2014). Bovine In vitro fertilization: In vitro oocyte maturation and sperm capacitation with heparin. Theriogenology, doi: 10.1016/j.theriogenology.2013.08.005.

Petters, R. (1992). Embryo development in vitro to the blastocyst stage in cattle, pigs and sheep. Animal Reproduction Science, 415-21.

Qiagen. (2012, April). (EN) - QIAGEN Plasmid Purification Handbook - April 2012. Retrieved from Qiagen: https://www.qiagen.com/de/resources/resourcedetail?id=462055950440-459e-9d93-50eb02e5707e\&lang=en

Qiu, P., Shandilya, H., D'Alessio, J., O'Connor, K., Durocher, J., \& Gerard, G. (2004). Mutation detection using Surveyor nuclease. BioTechniques, 702-07.

Ren, X., Chen, X., Wang, Z., \& Wang, D. (2017). Is transcription in sperm stationary or dynamic? The Journal of Reproduction and Development, 439-43.

Rubinson, D., Dillon, C., Kwiatkowski, A., Sievers, C., Yang, L., Kopinja, J., . . Parijs, L. (2003). A lentivirus-based system to functionally silence genes in primary mammalian cells, stem cells and transgenic mice by RNA interference. Nature Genetics, 401-06.

Sato, M., Koriyama, M., Watanabe, S., Ohtsuka, M., Sakurai, T., Inada, E., . . Miyoshi, K. (2015). Direct Injection of CRISPR/Cas9-Related mRNA into Cytoplasm of Parthenogenetically Activated Porcine Oocytes Causes Frequent Mosaicism for Indel Mutations. International Journal of Molecular Sciences, 17838-56.

Sato, M., Ohtsuka, M., Watanabe, S., \& Gurumurthy, C. (2016). Nucleic acids delivery methods for genome editing in zygotes and embryos: the old, the new, and the oldnew. Biology Direct, doi: 10.1186/s13062-016-0115-8.

Schmidt, F., \& Grimm, D. (2015). CRISPR Genome Engineering and Viral Gene Delivery: A Case of Mutual Attraction. Biotechnology Journal, doi: 10.1002/biot.201400529.

Shan, Q., Wang, Y., Li, J., \& Gao, C. (2014). Genome editing in rice and wheat using the CRISPR/Cas system. Nature Protocols, 2395-410.

Sternberg, S., Redding, S., Jinek, M., Greene, E., \& Doudna, J. (2014). DNA Interrogation by the CRISPR RNA-Guided Endonuclease Cas9. Nature, doi:10.1038/nature13011.

The Cell Cuture Dish. (2016, May 4). The CRISPR/Cas9 System and its Applications. Retrieved from The Cell Culture Dish: http://cellculturedish.com/2016/05/crispr-cas9-systemapplications/ 
Thermo Fisher Scientific inc. (2013). Fast and accurate nucleic acid measurements. Retrieved from Thermo Scientific Nanodrop Products:

http://www.nanodrop.com/nucleicacid.aspx

Tiscornia, G., Singer, O., \& Verma, I. (2006). Production and Purification of Lentiviral Vectors. Nature Protocols, 241-45.

Vajta, G., Peura, T., Holm, P., Páldi, A., Greve, T., Trounson, A., \& Callesen, H. (2000). New method for culture of zona-included or zona-free embryos: the Well of the Well (WOW) system. Molecular Reproduction and Development, 256-64.

Vejnar, C., Moreno-Mateos, M., Cifuentes, D., Bazzini, A., \& Giraldez, A. (2016). Optimized CRISPR-Cas9 Systems for Genome Editing in Zebrafish. Cold Spring Habour Protocols, 10.1101/pdb.prot086850.

Wang T., e. a. (2016). Protocol 2: Viral Packaging nd Cell Culture for CRISPR-Based Screens. Cold Spring Harbor Protools.

Wang, H., Yang, H., Shivalila, C., Dawlaty, M., Cheng, A., Zhang, F., \& Jaenisch, R. (2013). OneStep Generation of Mice Carrying Mutations in Multiple Genes by CRISPR/CasMediated Genome Engineering. Cell, 910-18.

Whitworth, K., Lee, K., Benne, J., Beaton, B., Spate, L., Murphy, S., . . Prather, R. (2014). Use of the CRISPR/Cas9 System to Produce Genetically Engineered Pigs from In VitroDerived Oocytes and Embryos. Biology of Reproduction, doi: http://dx.doi.org/10.1095/biolreprod.114.121723.

Wu, X., Scott, D., Kriz, A., Chiu, A., Hsu, P., Dadon, D., . . Sharp, P. (2014). Genome-wide binding of the CRISPR endonuclease Cas9 in mammalian cells. Nature Biotechnology, 670-76.

Zhang, X., Tee, L., Wang, X., Huang, Q., \& Yang, S. (2015). Off-target Effects in CRISPR/Cas9mediated Genome Engineering. Molecular Therapy - Nucleic Acids, doi: 10.1038/mtna.2015.37.

Zhang, Y., Xi, Q., Ding, J., Cai, W., Meng, F., Zhou, J., . . . Wu, Z. (2012). Production of Transgenic Pigs Mediated by Pseudotyped Lentivirus and Sperm. PLoS One, 7(4): e35335.

Zuo, E., Cai, Y., Li, K., Wei, Y., Wang, B., Sun, Y., ... Yang, H. (2017). One-step generation of complete gene knockout mice and monkeys by CRISPR/Cas9-mediated gene editing with multiple sgRNAs. Cell Research, 933-45. 